\title{
Abhandlung
}

Nourida Ateshi-Gadirova*

\section{Jahre deutsche und europäische Archäologie im Kaukasus. Eine kritische Analyse und Bestandsaufnahme vergangener und aktueller Forschungen}

DOI 10.1515/pz-2017-0009

Zusammenfassung: Der vorliegende programmatische Artikel wirft einen kritischen Blick auf 185 Jahre deutscher Forschung in Südkaukasien.

Dabei werden Lücken und in Frage zu stellende Interpretationen aufgezeigt, die sich teilweise bis heute negativ auf die wissenschaftliche Beurteilung der späten Bronze- und frühen Eisenzeit im Südkaukasus auswirken. Der Artikel vergleicht erstmals Originaldokumente und -funde mit den Publikationen deutscher, russischer und kaukasischer Archäologen aus diesen 185 Jahren. Eine der Hauptaufgaben bestand darin, die gegenwärtigen Aufbewahrungsorte der im 19. Jahrhundert in Südkaukasien ausgegrabenen Fundstücke ausfindig zu machen und die entsprechenden Grabungsdokumentationen und Ausgrabungsberichte aufzufinden, um sie mit den bis heute erschienenen Publikationen in verschiedenen Sprachen zu vergleichen. Dabei wurde festgestellt, dass die Archäologie und die Geschichtsschreibung der späten Bronze- und frühen Eisenzeit im Südkaukasus ganz unterschiedlich sind.

Die in verschiedenen Sprachen geschriebenen Werke zur Archäologie des Südkaukasus wurden einer neuen Bewertung unterzogen. Bei den Interpretationen insbesondere zur Historiografie der Denkmale der zentralsüdkaukasischen Kultur, ihrer Chronologie, Datierung und territorialen Zuordnungen, wurden historische, archäologische, anthropologische und ethnologische Fehler aufgezeigt. Die nicht objektiven, im Lichte der modernen Wissenschaft zweifelhaften Definitionen werden in diesem Artikel benannt und der kaukasischen, russischen und in-

\footnotetext{
*Corresponding author: Dr. Nourida Ateshi-Gadirova, Khazar Universität, Baku, Aserbaidschan, Departement Geschichte und Archäologie. Deutschland: Institut für Kaukasusforschungen, Pinnauweg 1, 14165 Berlin. E-Mail: Nateshi@khazar.org; ateshi@nourida.com
}

ternationalen Wissenschaft als Probleme aufgezeigt und klare Vorschläge und Lösungsansätze dargelegt.

In diesem Zusammenhang wurden insbesondere die große Kaukasussammlung und ihr Schicksal untersucht, die sich bis zum Zweiten Weltkrieg im Museum für Vorund Frühgeschichte in Berlin (MVF) befunden hatte. Auch aktuelle Probleme der archäologischen Erforschung Südkaukasiens werden klar dargestellt.

Die Arbeit zeigt, dass ein Großteil der in den deutschen Museen in den dortigen Kaukasus-Sammlungen vorhandenen Funde aus der späten Bronze- und frühen Eisenzeit nach dem Zweiten Weltkrieg in die UdSSR gebracht wurde und viele davon heute über russische Museen in Moskau und St. Petersburg verteilt sind. Sie sind bis jetzt der internationalen Forschung nicht frei zugänglich und müssen in internationaler Kooperation untersucht und neu bewertet werden. Auch die bis jetzt publizierten deutschen Abhandlungen zur Archäologie Südkaukasiens enthalten nach dem heutigen Stand der Forschung unrichtige Angaben.

Damalige Gelehrte und Ausgräber wie Rudolf Virchow, Waldemar Belck, Friedrich Bayern Carl Friedrich LehmannHaupt und und Emil Rösler haben zweifelhafte historische, geografische, ethnologische und anthropologische Schlüsse gezogen, die bis heute in verschiedener Weise tradiert werden. Nach dem Zerfall der Sowjetunion begann eine national geprägte Neuinterpretation der Geschichte der Nachfolgestaaten, die sich auch auf die Übersetzung deutschsprachiger Publikationen im neuen nationalen Sinn auswirkte. Der von W. Nagel und E. Strommenger herausgegebene Katalog über „Kalakent“ dient als Beispiel und zeigt dabei exemplarisch immer noch bestehende Diskrepanzen in der Kaukasusforschung.

Auch die Funde aus der Redkin-Lager Sammlung sind ein Beispiel für die Zersplitterung des kaukasischen Erbes; sie verteilen sich auf Museen in Aserbaidschan, Georgien, Deutschland, Frankreich und Russland und konnten bis heute nicht komplett erforscht werden. 
Schlüsselworte: Spätbronze- und Früheisenzeit in Südkaukasien; Kaukasus-Forschung; Zentralsüdkaukasische Kultur; Chodžali-Gedebey-Kultur; Gürtelbleche; Kaukasus-Sammlung; Kalakent

Résumé: Cet article contient un examen critique de 185 années de recherches allemandes dans le Caucase du Sud et montre des lacunes et des interprétations contestables, certaines avec un effet négatif sur l'évaluation scientifique de la fin de l'âge du bronze et du début de l'âge du fer qui se poursuit encore aujourd'hui.

Dans ce contexte, l'examen de la grande collection d'artefacts provenant du Caucase conservée au Musée de Préhistoire et de Protohistoire de Berlin jusqu'à la Seconde Guerre Mondiale et son destin ultérieur sont une partie importante de cet article.

En outre, il met en évidence certains problèmes actuels qui affectent la recherche archéologique dans le Caucase du Sud.

Dans cet article, les publications des archéologues allemands, russes et caucasiens parues durant les 185 dernières années sont comparées pour la première fois à la documentation originale et aux trouvailles.

L'une des tâches principales fut d'identifier où les artefacts, qui ont été découverts au $19^{\text {ème }}$ siècle dans le Caucase du Sud, sont conservés de nos jours, mais aussi de trouver la localisation actuelle des rapports de fouilles et de la documentation concernée.

Ainsi ils peuvent être comparés aux publications qui sont parues depuis en plusieurs langues.

Il semble évident que l'archéologie et l'historiographie concernant la fin de l'âge du Bronze et le début de l'âge du Fer dans le Caucase du Sud varient considérablement.

Les travaux écrits dans différentes langues sur l'archéologie du Caucase du Sud ont été soumis à une évaluation.

Des erreurs historiques, archéologiques, anthropologiques et ethnologiques sont été identifiés concernant particulièrement l'interprétation de l'historiographie concernant les monuments de la culture du Caucase central et méridional, leur chronologie, leur datation et leurs attributions territoriales.

Les définitions subjectives et, selon les normes de la science contemporaine, souvent douteuses, sont nommées dans cet article et fortement soulignées en tant qu'un problème de la recherche scientifique du Caucase, de la Russie et internationale, en même temps que des propositions claires et des solutions possibles sont proposées.

Ce travail montre qu'une grande partie des artefacts appartenant à l'âge du Bronze Récent et au début de l'âge du Fer, qui étaient conservées dans les collections caucasiennes des musées allemands, a été emmenée en URSS après la Seconde Guerre Mondiale. Aujourd'hui beaucoup de ces collections sont dispersées dans les musées russes de Moscou et de Saint Pétersbourg, mais aussi dans les musées des pays caucasiens. Encore aujourd'hui, ces trouvailles ne sont pas accessibles aux chercheurs internationaux, et ils ont besoin d'être réexaminés et réévalués dans le cadre d'une coopération internationale.

En outre, certains travaux allemands sur l'archéologie du Caucase du Sud publiés jusqu'à ce jour contiennent certaines informations dont les résultats des recherches récentes ont révélé qu'elles sont inexactes.

Des archéologues et des érudits tels que Rudolf Virchow, Waldemar Belck, Friedrich Bayern et Emil Roesler ont tiré des conclusions contestables concernant l'histoire, la géographie,

Après la chute de l'URSS, l'histoire des états post-soviétiques fut réinterprétée d'une manière nationaliste, ce qui eut un impact sur certaines publications allemandes qui furent traduites de façon incorrecte, c'est ainsi le cas du catalogue de l'exposition sur Kalakent rédigé par W. Nagel et E. Strommenger, qui illustre les contradictions qui existent encore aujourd'hui dans la recherche sur le Caucase.

Mots-clefs: âge du bronze récent et début de l'âge du fer dans le Caucase du Sud; recherches sur le Caucase du Sud; Culture du Caucase central et méridional; Culture de Khodjali-Gedebey; Ceinture en bronze; Collections caucasiennes; Kalakent

Abstract: This article contains a critical review of 185 years of German research in the southern Caucasus and shows gaps and questionable interpretations, some with a negative effect on the scientific evaluation of the late Bronze and early Iron Ages continuing even today.

In this context the examination of the large collection of artefacts from the Caucasus treasured at the Museum of Prehistory and Early History in Berlin until World War II and its subsequent fate is an important part of this article. Furthermore it highlights some current problems affecting archaeological research on the southern Caucasus. In this article the publications of German, Russian and Caucasian archaeologists published over the last 185 years are compared for the first time with the original documentation and finds. One of the main tasks was to establish where the artefacts are located today which had been excavated in the $19^{\text {th }}$ century in the southern Caucasus as well as finding out current location of the relevant excavation reports and documentations. So they can be com- 
pared with the publications that have since been released in several languages. It became apparent the archeology and the historiography on the late Bronze and early Iron Age in the South Caucasus differs immensely.

The works written in different languages on the archeology of the South Caucasus were submitted to evaluation.

Historical, archaeological, anthropological and ethnological errors were identified particularly concerning the interpretation of the historiography on the monuments of the central south Caucasian Culture, their chronology, dating and territorial allocations.

The unobjective and according to the standards of contemporary science often dubious definitions are named in this article and high lightened as a problem to the Caucasian, Russian and international science as well as clear proposals and solutions had been set out.

The research shows that a large part of the artefacts belonging to late Bronze and early Iron Ages treasured in the Caucasus collections of German museums were transferred to the USSR after World War II. Today many of them are dispersed in Russian museums in Moscow and Saint Petersburg as well as in museums in the Caucasian states. Even today they are not accessible to international scientific researchers, and they need to be re-examined and re-evaluated in international co-operation. Furthermore, some German publications on the archaeology of the southern Caucasus released to date contain some information that current research results show to be inaccurate. Archaeologists and scholars like Rudolf Virchow, Waldemar Belck, Friedrich Bayern and Emil Roesler have drawn some questionable conclusions concerning historic, geographic, ethnologic and anthropologic issues which continue to prevail even today. After the fall of the Soviet Union the history of the post-Soviet states was reinterpreted in a nationalistic way, which had an impact on German publications which were incorrectly translate, e.g. the catalogue of the Kalakent exhibition by W. Nagel and E.Strommenger which shows the ongoing discrepancies in research on the Caucasus.

Keywords: late Bronze and early Iron Age in the South Caucasus; research in the South Caucasus; central-southern Caucasian culture; Chodžali-Gedebey culture; bronze belts; Caucasus collections; Kalakent

\section{Zur Geschichte der deutschen und europäischen Forschung im Kaukasus}

Die Geschichte der europäischen Archäologie im Kaukasus lässt sich bis in das frühe 19. Jahrhundert zurückverfolgen ${ }^{1}$. 1829 bereiste der damals 28-jährige deutsche Philosoph und Orientalist Friedrich Eduard Schulz (17991829), Professor in Gießen und Göttingen, den Kaukasus. Er war von Carl Ritter, dem Begründer der modernen historischen Geografie auf dieses Forschungsgebiet und die dort zu erwartenden Erträge hingewiesen worden. Schulz unternahm in den Jahren 1827-1829 mit organisatorischer und finanzieller Unterstützung französischer Institutionen eine Reihe von Reisen, die ihn in die Türkei, nach Iran sowie deren armenische Gebiete führten².

1828 begann er Forschungen in Van, darin unterstützt von der französischen Gelehrtengesellschaft „Société asiatique“, in deren Mittelpunkt das Studium der Regionen und Kulturen Asiens stand ${ }^{3}$. Zu seinen größten Erfolgen zählt auf diesen Reisen die Entdeckung der bedeutenden Keilinschriften auf der Stele von Kel-i-Schin (heute: Kelišin $)^{4}$, einem Hochgebirgspass im äußersten Westen von Iran, der heute die Grenze zum Irak bildet.

Schulz wurde jedoch in den von ihm bereisten Ländern nicht ausschließlich als Wissenschaftler wahrgenommen. So sah das damalige Oberhaupt von Baškale (Provinz Van, armenischer Teil des damaligen Osmanischen Reiches, heute Türkei), Nurullah Bey, in Schulz einen ausländischen Spion und befahl schließlich dessen Ermordung. 1829 wurde der junge Gelehrte in der Nähe von Hakkari (Provinzhauptstadt im äußersten Südosten der Türkei, kurdischer Name „Colemerg“, in türkischer Schreibung „Çölemerik“) bei einem Raubüberfall eines kurdischen Stammesoberhauptes getötet ${ }^{5}$.

Im gleichen Jahr entsandte das russische Zarenreich den in Moskau beheimateten Forscher A. Janovskij nach Aserbaidschan, um vor Ort nach archäologischen Spuren des von den römischen und griechischen Historiografen Plinius („Naturalis Historia“) und Strabon („Geographica“) beschriebenen „kaukasischen Albania“ zu suchen. Seine Ergebnisse veröffentlichte Janovskij 1846 in der Schrift „Altes kaukasisches Albania“6.

\footnotetext{
1 Avšarova/Pirquliyeva 2010, 28

2 Lehmann-Haupt, 1910, 6.

3 Ebd.

4 Anadolu uyqarlıkları 1982, 140-144.

5 Ebd.

6 Janovskij 1846.
} 
Spätestens ab dem 18. Jahrhundert lässt sich in der europäischen Öffentlichkeit ein gesteigertes Interesse an jenen alten Kulturen bemerken, die in antiken Schriften verzeichnet werden. Dies betrifft alle Anrainer des Mittelmeeres, wie dies schlaglichtartig die militärische und wissenschaftliche Unternehmung Napoleon Bonapartes in Ägypten in den Jahren 1798-1801 belegt, aber auch Regionen wie den Kaukasus ${ }^{7}$. Etwa ab den 1830er Jahren drängten immer mehr an der Geschichte des Kaukasus interessierte Forscher in das Gebiet, darunter Franzosen, Schweizer, Deutsche oder Österreicher. In jener Phase entstanden erste Privatsammlungen diverser Fundstücke, die z. T. auch an europäische Museen verkauft wurden. Obgleich diese Artefakte eher tumultarisch ergraben wurden, bildeten sie doch die Grundlage einer Archäologie des Kaukasus.

Im letzten Drittel des 19. Jahrhunderts kam es nicht mehr automatisch zur Verlagerung von Fundstücken nach Europa. So gründete 1867 der Danziger Biologe und Geograf Gustav Radde (1831-1914) in Tiflis (Tbilisi) das kaukasische Museum und die kaukasische Bibliothek, deren erster Direktor er wurde (Abb. 1). Hier entstand darüber hinaus auch ein wissenschaftliches Zentrum zur Erforschung der Geschichte und Kultur kaukasischer Volksgruppen. Aus beiden Einrichtungen ging schließlich das heutige Staatliche Historische Museum Georgiens in Tbilisi hervor.

1871 kam es in Tbilisi zur Gründung des Kaukasischen Archäologischen Komitees ${ }^{8}$, dessen Aufgabe die wissenschaftliche Organisation, Bewertung und Kontrolle archäologischer Ausgrabungen sein sollte. Den sich damit manifestierenden kulturellen wie administrativen Anspruch konnte diese Institution jedoch in der Realität nicht erfüllen.

Seit ihrer Gründung 1859 führte die in St. Petersburg ansässige „Kaiserliche Archäologische Kommission (ИАК), “ in allen russischen Gebieten, so auch im Kaukasus, Ausgrabungen durch.

Mit der archäologischen Arbeit in Nordossetien betraut war der offizielle „Beauftragte der Kaiserlichen Archäologischen Kommission in St. Petersburg“, Vasilij Dolbežev, geheimer Staatsrat und Oberlehrer am Gymnasium in Vladikavkaz ein nach Ansicht Rudolf Virchows „sehr schneidiger und intelligenter Mann“. Sowohl Dolbežev, wie auch das örtliche ossetische Clanoberhaupt Chaboš Kanukov, der das tumultuarische Graben in Koban kontrollierte, pflegten ihre Funde mit Vorliebe an zahlungskräftige Ausländer zu verkaufen: Dolbežev hatte ferner die Erlaubnis,

7 Göyüşov/Martinov 1990, 114.

8 Ebd. 9.

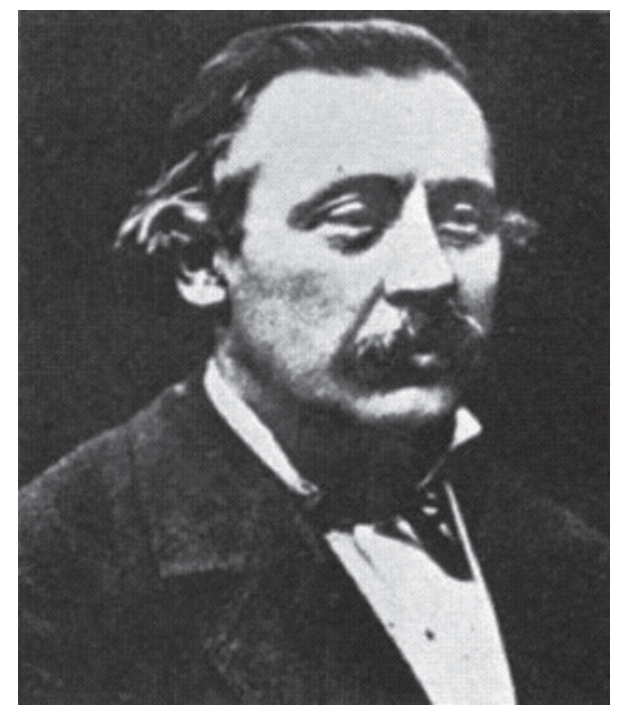

Abb. 1: Der Danziger Biologe und Geograf Gustav Radde (1831-1914)

mit Duplikaten und Triplikaten nach Gutdünken zu verfahren ${ }^{9}$, hatte also auch aus diesem Grund Interesse an einem ständigen Fundzuwachs.

Der größte Teil der aus der späten Bronze und frühen Eisenzeit datierenden Funde, die der Chodžali-GedebeyKultur (Zentralsüdkaukasische Kultur) entstammen, wurde in russische Museen verbracht, vor allem nach Moskau und St. Petersburg.

\section{Kaukasische Funde in europäischen und russischen Museen}

In den europäischen Zentren und Hauptstädten entstanden spätestens im 19. Jahrhundert große Museen, die sich der Sammlung nationaler wie internationaler Altertümer verschrieben hatten. Dabei gelangen den Museen zum Teil spektakuläre Erwerbungen aus den Regionen der antiken Hochkulturen, die noch bis in heutige Tage das Bild jener Institutionen prägen. Bedient wurden unterschiedliche regionale Sammlungsschwerpunkte, wie etwa Griechenland, die Levante, Nordafrika oder der vorderasiatische Raum. Bei übereinstimmenden Schwerpunktsetzungen kam es zwischen den Institutionen zu Wettläufen um die fundträchtigsten Plätze, die häufig von den Kolonialmächten wie dem britischen Königreich oder Frankreich für sich entschieden wurden. So hatten bereits um die Mitte des 19. Jahrhunderts vor allem in den Hauptstädten

9 Motzenbäcker 1996, 23. 
des Assyrerreiches umfangreiche französische und englische Ausgrabungen stattgefunden, deren Denkmälerfülle dem staunenden Publikum 1847 im Louvre und 1848 im Britischen Museum vorgestellt wurden. Die Ressourcen für die Ausstattung der Museen waren trotz eindrucksvoller Erwerbungen dementsprechend eingeschränkt, so dass auch andere Sammlungsregionen erschlossen wurden, u.a. solche, die im Blickpunkt damals aktueller wissenschaftlicher Strömungen standen. Dies betraf jedoch nicht nur die Museen des Deutschen Kaiserreiches nach seiner Gründung, sondern auch die Institutionen der anderen Großmächte, so dass auch Funde des Kaukasus in das jeweilige Sammlungsportefeuille wanderten.

Die von Rudolf Virchow gesammelten kaukasischen Funde gelangten nach Berlin, die Kollektionen weiterer Sammler wie Ernest Chantré (1843-1924) oder Jacques de Morgan kamen nach Frankreich (in die Museen von Saint-Germain-en-Laye und Lyon), das Naturhistorische Museum Wien wurde von Franz Heger bedacht. Dass es dabei zur Übernahme von schlecht oder nicht dokumentierten Ausgrabungsfunden kam, führte zwangsläufig zu fehlerhaften Zuweisungen wie auch zweifelhaften Interpretationen, die z.T. bis heute fortbestehen und der Korrektur harren, sofern dies möglich ist.

Die Sammlungspolitik der russischen Seite erfolgte spiegelbildlich zu jener der anderen Großmächte. Im Zarenreich versuchte man dem Abfluss diverser Artefakte durch die Gründung von Kommissionen und Gesellschaften zu kontrollieren und die Verbringung damit in eigene Bahnen zu lenken.

1846 wurde in St. Petersburg die „Russische Archäologische Gesellschaft“" gegründet, im Jahre 1864 wurde die „Moskauer Archäologische Gesellschaft“ gegründet und am 2. Februar 1859 die „Kaiserlichen Moskauer Archäologischen Gesellschaft“ ins Leben gerufen. Diese sollte die Verbringung von kaukasischen Artefakten nach Europa soweit wie möglich kontrollieren, was jedoch nur bedingt gelang.

In Georgien wurde 1871 das „Kaukasische ArchäologieKomitee“ gegründet, zu dessen Aufgaben die Aufsicht über die archäologischen Funde aus dem Kaukasus gehörte; sie sollte auch einen Beitrag zu einer wissenschaftlicheren Behandlung dieser Funde leisten. Bedauerlicherweise konnte das Komitee diese Aufgabe nicht in vollem Umfang erfüllen, da zahlreiche Kulturgüter nach Deutschland, Frankreich und Österreich sowie in russische Museen verbracht wurden. Ungeachtet dessen konnte dieses Komitee erreichen, dass einige der archäologischen Ausgrabungen im Kaukasus in einem einigermaßen geordneten und damals richtig empfundenen wissenschaftlichen Rahmen durchgeführt wurden.
Vom 8. bis zum 21. September 1881 tagte der „5. Allrussische Archäologische Kongress“ in Tbilisi mit dem Hauptthema „Kaukasien“, womit die gründliche archäologische Erforschung Kaukasiens zu einem wichtigen Ziel erklärt wurde.

Lange Jahre nach Beginn erster Forschungen in der Region nahm nun das Interesse von Seiten russischer und ausländischer Gelehrten enorm zu. So führte der Geograf A. A. Ivanovski ab 1896 im Auftrag der Archäologischen Gesellschaft Moskau eine Reihe von Ausgrabungen in Nord- und Süd-Aserbaidschan durch. Die Funde aus etwa 72 Steinkistengräbern wurden an das Historische Museum in Moskau übersandt und später als „Materialien zur Archäologie Kaukasiens “ in Sammelwerken veröffentlicht ${ }^{10}$, deren Niveau in wissenschaftlicher Hinsicht jedoch bedauerlich niedrig blieb ${ }^{11}$.

Im gleichen Jahr führte A. J. Joakimov, Inspektor einer Volksschule in Elisavetpol, einige Grabungen durch. Die Funde wie auch weitere zufällig durch Anwohner in der Gegend entdeckte Artefakte wurden ebenso an das Staatliche Historische Museum in Moskau verschickt ${ }^{12}$.

Undokumentierte und unkontrollierte Grabungen, die eher als Schachtungen anzusprechen sind, erfolgten in West-Aserbaidschan durch den deutschstämmigen Bergbauingenieur B. Schultz sowie den Apotheker B. Rosendorf und dessen Bruder. Für wertvoll erachtete Funde jener Expeditionen wurden nach Europa verschickt, die übrigen Stücke zerstört ${ }^{13}$.

\section{Kaukasische Funde in französischen Museen}

Für die Sammlungsgeschichte kaukasischer Altertümer in französischem Besitz ist der adlige Frédéric Du Bois de Montpéreux von Bedeutung, dessen Reisen ihn ab 1834 von Šuša in Berg-Karabach nach Tbilisi führten. Auf dem Weg dorthin verweilte er kurzfristig in Helenendorf (heute Göygöl) und führte vor Ort Ausgrabungen durch, die einen reichen Artefaktbestand erbrachten. De Montpéreux barg bronzene Gegenstände sowie schwarzgrundige Keramiken ${ }^{14}$. In der heutigen aserbaidschanischen Exklave Nachičevan grub de Montpéreux 30 Kurgane aus und übersandte die aus ihnen geborgenen Grabbeigaben

\footnotetext{
10 Ivanovskiy 1911.

11 Safarov 1989, 8.

12 Ebd. 8-9.

13 Ebd. 9.

14 Safarov 1989, 6.
} 


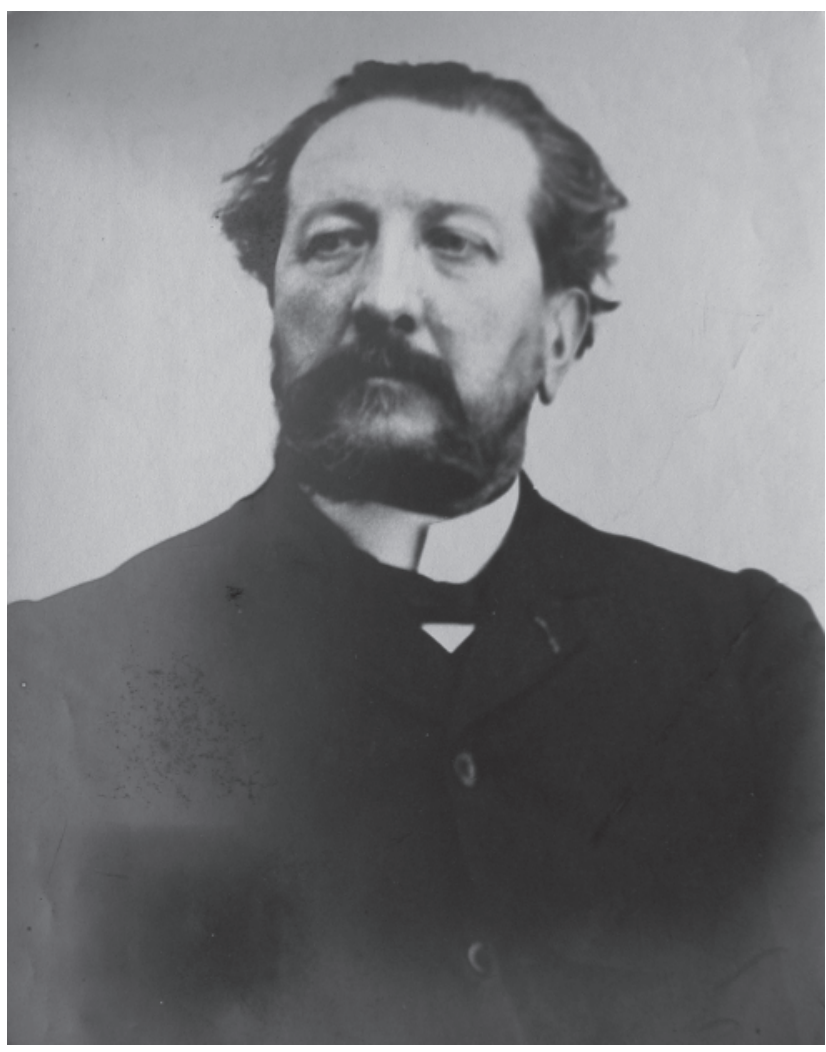

Abb. 2: Ernest Chantré (1843-1924)

nach Frankreich ${ }^{15}$. Seine Untersuchungen veröffentlichte er bereits 1839 in der Schrift „Voyage autour du Caucase, chez les Tcherkesses et les Abkhases, en Colchide, en Arménie et en Crimée“"16.

Eine weitere wichtige Persönlichkeit jener Zeit war Ernest Chantré (1843-1924; Abb. 2). Chantré - Archäologe, Paläontologe, Anthropologe und Geologe - hielt an der Faculté des Sciences in Lyon eine Professur und führte dort ab 1881 die Lehren der Anthropologie und 1892 der Ethnologie ein, zusätzlich unterrichtete er Geografie. Seit 1877 war er am Museum für Naturkunde in Lyon Vizedirektor unter Louis Lortet. Seine Forschungsreisen, die er im Auftrag des Museums unternahm, führten ihn nach Armenien, auf die Krim, in den Kaukasus, ferner nach Anatolien, Tunesien, Algerien und Ägypten. 1893/94 führte er als erster ausländischer Forscher in Boğazköy, der hethitischen Hauptstadt Hattuša, Ausgrabungen durch. Aufgrund des zur damaligen Zeit heiklen Verdachtes einer Parteiname für die Armenier sowie und in Folge einer grassierenden Cholera-Epidemie, mussten die Grabungen jedoch abgebrochen werden.

15 Bünyadov 1960, 8.

16 Montpéreux 1839.
Eine weitere illustre Persönlichkeit war der Franzose Jacques de Morgan (1857-1924; Abb. 3), der einige Jahre lang archäologische Grabungen in Iran, in Armenien und in Aserbaidschan durchführte und die Ergebnisse wie auch Karten seiner Grabungsstellen zum Teil publizierte $^{17}$ (Abb. 4). 1890 untersuchte er im Talischin-Gebirge (Aserbaidschan) mehrere Höhlen und Dolmen und öffnete mehr als 230 Gräber. Die hier entnommenen Fundstücke datieren in das Ende der Bronzezeit und den Anfang der Eisenzeit. Die wertvollsten Artefakte gingen u.a. an das Museum von Saint Germain bei Paris ${ }^{18}$. Aus heutiger Sicht müssen jene französischen Grabungen eines de Morgan aber auch solche deutscher Forscher wie W. Belck, auf den später noch einzugehen ist, sehr kritisch betrachtet werden, wurden doch kaum jemals Standards eingehalten oder angestrebt, die zur wissenschaftlichen Deutung archäologischer Güter zwingend notwendig sind ${ }^{19}$. Für de Morgan stand denn auch eher die Gewinnung umfangreicher Objekte im Mittelpunkt seiner Tätigkeiten - $16 \mathrm{~kg}$ so aufgedeckter Bronzen sind von einer seiner Grabungen überliefert - als das Sammeln umfangreicher Kenntnisse vergangener Kulturen: „Meine Leute, die für mich Beute sammeln, haben einige Ausgrabungen durchgeführt" ${ }^{\text {"20 }}$.

Jacques de Morgan bezeichnete jene sich heute in Frankreich befindlichen Fundstücke aus Aserbaidschan als „Persische und armenische Kulturgüter“. Bis heute sind die Objekte dort unter dieser Bezeichnung eingeordnet $^{21}$, was ihrer tatsächlichen kulturellen und historischen Einordnung erheblich im Wege steht. Allerdings mag sich dies künftig ändern, wurde doch 2011 ein Vertrag zwischen Frankreich und Aserbaidschan über die Zusammenarbeit im Bereich Wissenschaft und Forschung geschlossen ${ }^{22}$, der dazu beitragen dürfte, die Sammlungsgeschichte auf ein neues Fundament zu stellen ${ }^{23}$.

Die angesprochenen Grabungen dienten wie beschrieben der Gewinnung von Artefakten, nicht jedoch von ver-

\section{7 de Morgan 1889.}

18 Bünyadov 1960, 9.

19 Machmudov 2008, 10-12.

20 Ebd. 215.

21 Müseyibli 2014.

22 Zweites Projekt zwischen der Akademie der Wissenschaften von Aserbaidschan/Nachetschevan und GNRS France.

23 Einbezogen werden dürften dann auch jene Objekte, die de Morgan bei Ausgabungen in Armenien fand. Dazu zählen einige Dutzend metallene Gürtelfragmente aus einer Schlucht des Flusses Debed, aus dem Gräberfeld von Karmir berd (acht Exemplare - Esayan 1962, 1; 204-205), aus Bestattungen nahe des Dorfes Bdzni (drei Exemplare - ebd.), aus Stepanavan, Chrtanos, Airivank, Astchi Blur, dem Becken des Sevan-Sees (Nor Bayazet), aus Sanain (eine Schlucht des Fluses Debed) sowie dem Dorf Vaagni (Kreuz Kirovakan). 


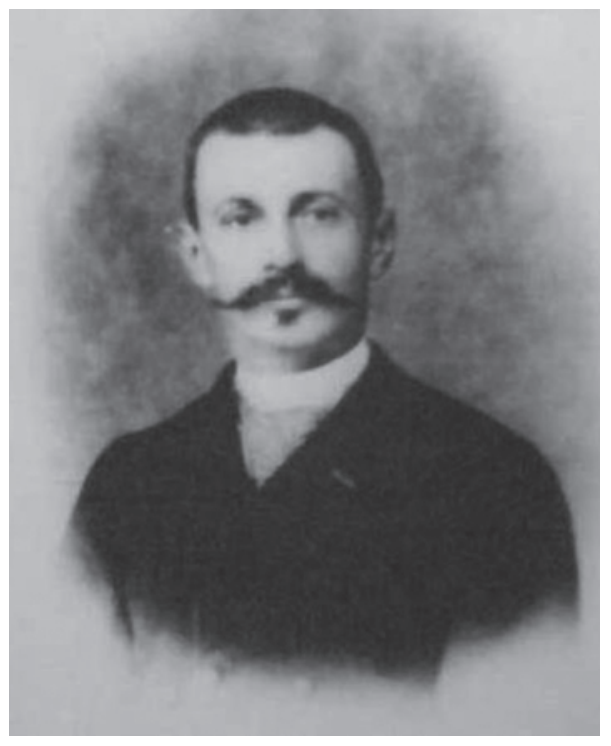

Abb. 3: Jacques de Morgan (1857-1924)

wertbarem Wissen ${ }^{24}$. Daher verwundert es nicht, dass die jeweiligen Grabungsbefunde heute nicht mehr rekonstruiert werden können, handelt es sich doch um die schlichte Aufdeckung und Aufsammlung archäologischer Funde. Da in der Regel kein Interesse an den Befunden bestand, wurden diese zumeist nicht dokumentiert und fanden somit auch keinen Eingang in Grabungsberichte, sofern solche überhaupt angefertigt wurden.

Ein weiterer 1896 im Auftrag der Kaiserlichen Archäologischen Kommission“ (ИАК) in Nachičevan (Gizilveng) tätiger Ausgräber war N. F. Fjodorov. Er barg zahlreiche bronze- wie eisenzeitliche Artefakte, die ihrer Verlagerung ebenso wenig wie die sonstigen undokumentiert geborgenen Funde entgingen und sich heute im staatlichen Museum in Moskau befinden ${ }^{25}$.

Zwar war seinerzeit intendiert, die in Kaukasien getätigten Funde vollständig in das in Tbilisi (Georgien) gegründete „Museum Caucasicum“ (Kaukasisches Museum) $\mathrm{zu}$ verbringen, gerade für exzeptionelle Funde erfolgte dies jedoch nicht, wurden jene doch auf zahlreiche Sammlungen und Museen verteilt.

Dies illustriert auch die Geschichte der seinerzeit berechtigt als sensationell angesprochenen Funde aus einem im heutigen Armenien gelegenen Nekropole im „RedkinLager“. Der hier bestatteten, mit den Insignien der Macht und des Krieges ausgestatteten Frau waren zahlreiche Objekte beigegeben worden. Diese wie auch umfangreiche Inventare weiterer Kurgane und Gräber finden sich heute

24 Bünyadov 1960, 7-8.

25 Ebd. 10. international verstreut in diversen Sammlungen wieder und sind somit ein typisches Beispiel für die Zersplitterung des kaukasischen Erbes.

Dieser Problematik war man sich von offizieller Seite bereits in jener Zeit bewusst. Mit der Eröffnung einer Filiale der Moskauer Archäologischen Gesellschaft ${ }^{26}$ 1901versuchte man, den Export prähistorischer Funde und anderer heimischer Kulturgüter aus Kaukasien nach Europa zu beenden. Diese sollten in der Region verbleiben und im Archiv der Kaukasus-Abteilung gesammelt werden. Grabungen sollten nach dieser Gründung von nun an nur mit Genehmigung und damit auch Kontrolle der kaukasischen Abteilung stattfinden.

So unternahm 1905 der Offizier der Reserve B. A. Skinder in Elisavetpol (heute Gence, Aserbaidschan) genehmigte Ausgrabungen, bei denen sieben Kurgane in der Nähe von Tschovdar sowie zwei Steinkistengräber geöffnet wurden. Im Jahr 1906 veröffentlichte Skinder monografisch einen „Opit archeologiceskij razvedki“ - einen „Erfahrungsbericht der archäologischen Forschung “227.

Dass auch jene institutionellen Entwicklungen und die so theoretisch vorhandene Kontrolle nicht alle Probleme zu beseitigen halfen, zeigen die 1908 vom Bergbauingenieur Ferdinand Lass in Daškesen im Dorf Gušču erfolgten Ausgrabungen, bei der sieben Steinkistengräber geöffnet wurden; von den Funden gelangte nur ein kleiner Teil in das Volkskundemuseum Helenendorf. Über den Verbleib der weiteren Funde ist nichts bekannt ${ }^{28}$.

Ähnlich verhält es sich mit den Funden einer Siedlungsgrabung, die 1904 der armenische Ethnologe E. Lalayan in Nachičevan (Gizilveng) am Ufer des Araxes unternahm. Geborgen wurden Kulturgüter aus dem Neolithikum sowie der Bronze- und Eisenzeit, von denen nur ein nicht exakt zu beziffernder Prozentsatz in das kaukasische Museum in Tbilisi gelangte ${ }^{29}$.

Andere europäische Forscher ignorierten offenbar die neuen Strukturen oder nahmen diese nicht wahr und führten weiterhin Untersuchungen durch, was dann auch $\mathrm{zu}$ Fundteilungen führte. Ein wenig rühmliches Kapitel schrieben in diesem Kontext die Lehrer O. Wenzel und D. Bermann. Sie öffneten bei Helenendorf einige Kurgane und verschickten die besten Stücke nach Deutschland, vermeintlich „wertlose“ Objekte hingegen fielen der Zerstörung anheim ${ }^{30}$.

\footnotetext{
26 Göyüšov/Martinov 1990, 22.

27 Safarov 1989, 9-10.

28 Ebd. 10.

29 Bünyadov 1960, 11.

30 Скиндер 1906.
} 


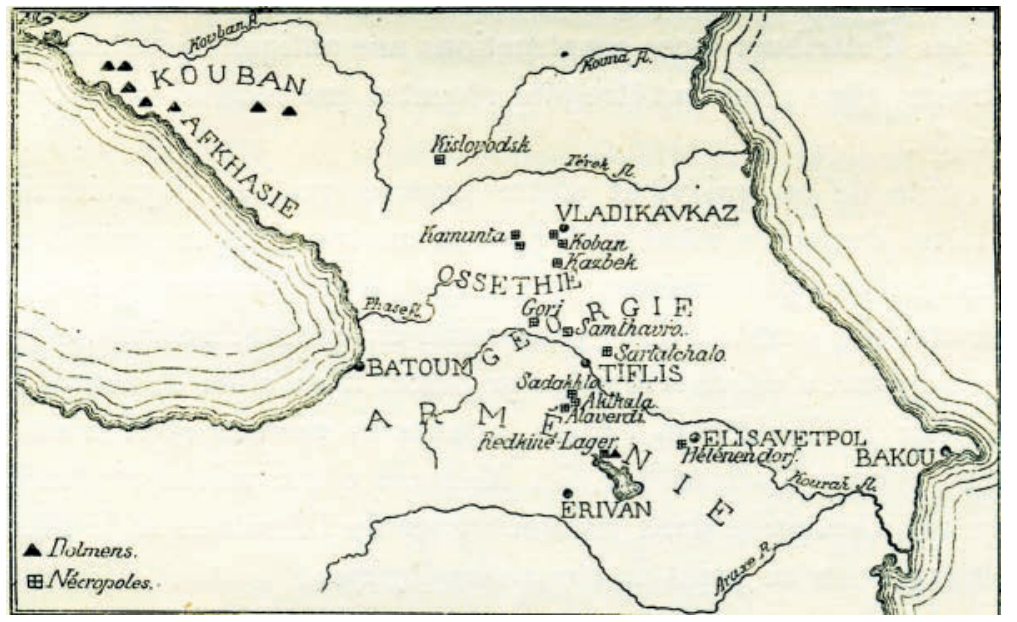

Abb. 4: Kartierung des Kaukasus und archäologischer Fundstellen (de Morgan 1889)
Besser erging es Artefakten, die V. Ter-Gukasov in den Jahren 1908-1920 in der Nähe von Gence ergraben bzw. anderweitig gesammelt hat. Ter-Gukasov übergab diese dem neu gegründeten Aserbaidschanischen Historischen Museum, ferner bemühte er sich um die systematische Katalogisierung unterschiedlicher Funde. So erfasste er jene 1913 in der Örtlichkeit Gušču entdeckten bronzezeitlichen Funde aus Steinkistengräbern wie auch von den Einwohnern gesammelte Bronzeobjekte bzw. Keramiken und übergab sie dem Georgischen Nationalmuseum als Schenkung ${ }^{31}$.

Die institutionalisierte Ausgrabungstätigkeit kam während der Kriegs- und Bürgerkriegsjahre zwischen 1914 bis 1922 zum Erliegen, unkontrollierte Grabungen fanden jedoch weiterhin statt, so dass zahlreiche weitere kaukasische Kulturgüter in die Museen der Großmächte gelangten und noch heute die Sammlungen etwa französischer und österreichischer Museen bereichern.

Im folgenden Kapitel soll insbesondere die Forschungsgeschichte der zweiten Hälfte des 19. Jahrhunderts bis zum Ausbruch des ersten Weltkrieges dargestellt werden. Verbunden ist diese Geschichte $\mathrm{u}$. a. mit den Gebrüdern Siemens.

\section{Die Gebrüder Siemens und ihre Bedeutung für die Archäologie Kaukasiens}

Nur wenig bekannt ist, dass der Auf- und Ausbau der Telegraphie im Russischen Reich und damit auch in dessen kaukasischen Provinzen wichtige Impulse für die Ent-

31 Ebd. wicklung der kaukasischen Archäologie vermittelte. Verbunden sind diese infrastrukturellen Maßnahmen mit den Gebrüdern Siemens.

Im Kontext ebenso von Bedeutung sind außerdem Angehörige der Familie Nobel. 1843 reisten die Söhne von Immanuel Nobel - Alfred, Ludwig und Robert - von Schweden nach Russland. Sie begannen mit der finanziell einträglichen Produktion von Waffen, die seitens der zaristischen Armee im Krimkrieg (1853-1856) eingesetzt wurden. Robert Nobel kam 1873 nach Lenkeran in das südliche Aserbaidschan, um aus dem in der Region wachsenden Eisenholzbaum Gewehrkolben fertigen zu lassen. Von Lenkeran aus reiste er nach Baku, und gelangte dort angesichts sprudelnder Ölquellen zur Überzeugung, dass es lohnenswert sei, der Familie Nobel ein weiteres Betätigungsfeld zu eröffnen.

So gründeten die Gebrüder Nobel 1875 die „Ölproduktionsgesellschaft der Brüder Nobel“ und schlossen mit den Gebrüdern Siemens einen Vertrag, wonach diese das gesamte an den Bohrstellen als Nebenprodukt anfallende Kupfer und Pyrit (Schwefelkies) übernehmen durften.

Aufgrund jenes Vertrages gelangten für einen langen Zeitraum die alleinigen Abbaurechte nahezu aller bei Gedebey in Aserbaidschan befindlichen Kupferminen in den Besitz der Gebrüder Siemens.

Bereits 1847 hatte die Firma Siemens \& Halske eine Tochterfirma in Russland gegründet, die sich dem Aufbau eines Telegrafennetzes widmete. Um das für die Telegrafenleitungen benötigte Kupfer selbst abbauen und in einer Fabrik verarbeiten zu können, erwarben sie 1864 im bereits angesprochenen Gedebey eine Kupfermine. Den Grundstein der Fabrik legte Ernst Werner Siemens (Abb. 5), den Aufbau gab er in die Hände seines Bruders Walter.

Bereits im August 1865 erfolgte die Inbetriebnahme des Werks (Abb. 6). Walter Siemens konnte die weitere wirtschaftliche Expansion der Firma jedoch nicht mehr 


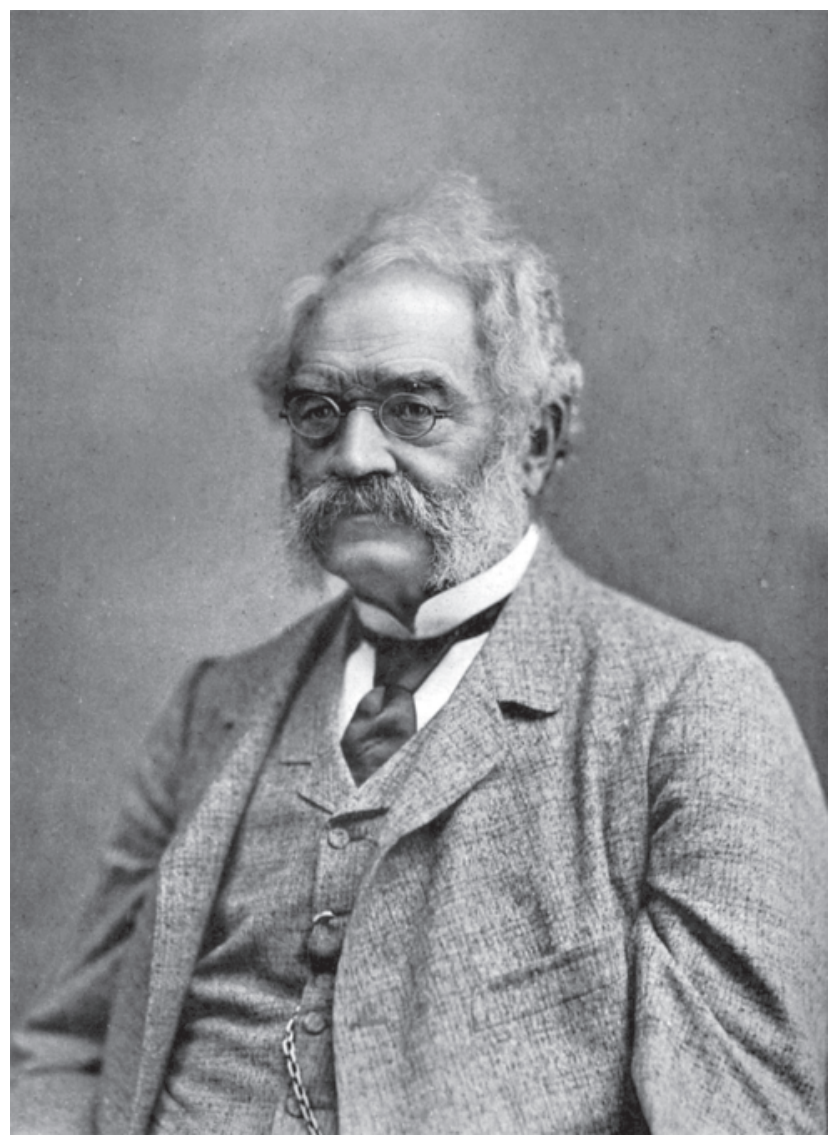

Abb. 5: Werner von Siemens (1816-1892)

(Foto: G. Brogi, Wikimedia C. C. 2.0)

mitgestalten, da er im November 1868 bei einem Reitausflug in Gedebey vom Pferd stürzte und bald aufgrund seiner schweren Verletzungen verstarb. Wie auch sein Bruder Otto wurde Walter Siemens auf dem katholischen Friedhof von Tbilisi bestattet. Walters Brüder Werner und Carl übernahmen nach dessen Tod die Leitung der Fabrik.

Schon während des Aufbaus der Fabrik stießen die Bauarbeiter auf zahlreiche Befunde und Funde, zu denen Steinkistengräber, Skelette, Waffen und Schmuckstücke aus Bronze zählten. Die archäologischen Fundstücke wurden nach Berlin verschickt und gelangten so zu Rudolf Virchow (1821-1902), der mit der Familie Siemens eng befreundet war.

Rudolf Virchow, von seiner Ausbildung her Mediziner und Anthropologe, war vielfältig interessiert, insbesondere was die heimische, aber auch die außereuropäische Archäologie betrifft. So war er Mitbegründer der noch immer existierenden „Berliner Gesellschaft für Anthropologie, Ethnologie und Urgeschichte“ (i. F.: BGAEU). Zum Kreis der Mitglieder und Förderer der BGAEU zählte unter anderem Werner Siemens. Virchow war zu jenem Zeitpunkt, als er mit den kaukasischen Artefakten in Kontakt kam, zeitlich anderweitig gebunden, so dass er die Funde an eine Vertrauensperson weiterschickte. Dabei handelte es sich um den bereits angesprochenen Waldemar Belck, der sich ebenso in Gedebey angesiedelt hatte. Belcks' Ausgrabungen müssen in der Rückschau als überwiegend finanziell motiviert angesehen werden. Archäologische Schichten wurden von ihm unbeachtet zerstört, die Kohärenz der Funde und Befunde zerrissen. Belck ergrub über die Jahre auf tumultarischem Weg eine Sammlung erheblichen Umfangs, die größtenteils an Rudolf Virchow nach Berlin ging. Virchow erhielt aber auch aus anderen Quellen Funde aus dieser Region, etwa im Rahmen der Unternehmungen der Gebrüder Siemens. So war bei den Siemens beispielsweise 1883 in Šamchor (heute Šemkir) ein Ingenieur namens Koch angestellt, der diesen etwa 40 Artefakte aus Feuerstein schenkte ${ }^{32}$. Weitere Feuersteine kamen noch hinzu und gelangten als Schenkung erneut an Rudolf Virchow, der sich aus anthropologischen, kulturhistorischen und auch archäologischen Gesichtspunkten für Kaukasien interessierte ${ }^{33}$.

1884 stieß der Lehrer Kirchhof, ebenso bei Siemens in Gedebey angestellt, bei Bauarbeiten im Hof der Fabrik auf einige Steinkistengräber. Kirchof hatte sich während seiner Dienstjahre eine Privatsammlung zugelegt, die er Waldemar Belck, dem Vertrauten Virchows, bei dessen erstmaliger Visite in Gedebey zeigte: „Er gestattete mir, die besten Exemplare seiner Sammlung für Hrn. Virchow, der, wie ich hier schon bemerken will, überall wo ich hinkam, sowohl in russisch, wie in türkisch Armenien, vom Renomee sehr gut gekannt war, auszuwählen“34.

\section{Rudolf Virchows Einfluss auf die Geschichtsschreibung des Kaukasus im Kontext seiner Zeit}

Um Virchows Einfluss auf die kaukasische Archäologie einordnen zu können, ist ein kritischer Blick auf seine Zeit und den damaligen Stand der Wissenschaft im vorherrschenden kulturellen Umfeld erforderlich.

Rudolf Virchow (1821-1902) war nicht nur von wissenschaftlicher Bedeutung, er agierte mit Unterbrechungen auch immer wieder im politischen Umfeld. Virchows Einstieg in die Politik ${ }^{35}$ erfolgte in der Strömung einer liberalen Nationalbewegung, reichte von der gescheiter-

32 Belck 1893, 67.

33 Safarov 1989, 7.

34 Belck 1893, 67.

35 Goschler 2002, 54. 


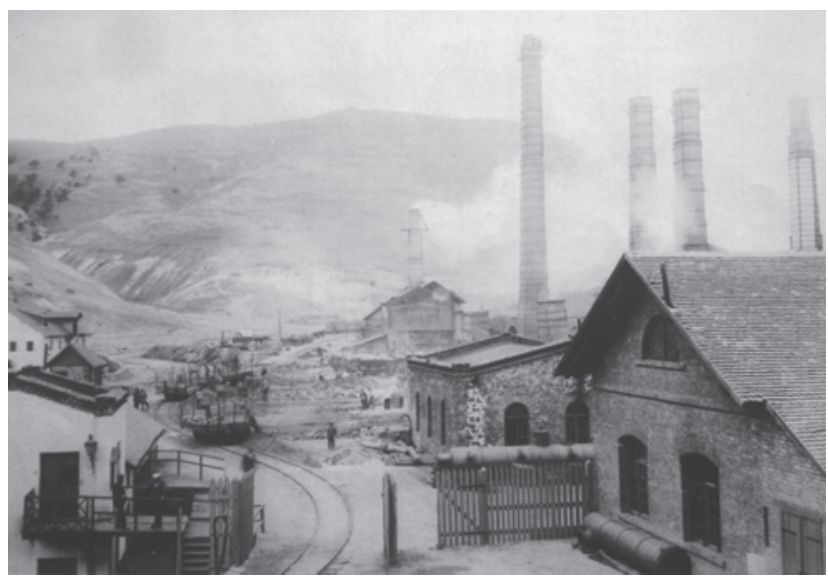

Abb. 6: Kupferhütte in Gedebey (Aserbaidschan. Foto: Siemens, Historical Institute, Corporate Archives, München)

ten Märzrevolution 1848 bis zur Gründung des Deutschen Reiches 1871 und noch darüber hinaus. In Berlin engagierte sich Virchow verstärkt ab 1856 inmitten einer allgemeinen Aufbruchsstimmung. Seit 1859 gehörte er der Berliner Stadtverordnetenversammlung an, ab 1862 auch dem Preußischen Abgeordnetenhaus. In beiden Häusern blieb er bis zu seinem Tode im Jahr $1902^{36}$. Für einen Zeitraum von dreizehn Jahren (1880-1893) war Virchow sogar Abgeordneter des Deutschen Reichstages. Alles in allem zeigt sich so, dass Virchow sowohl an den Schaltstellen der Macht als auch der Kultur saß und damit eine der einflussreichsten Personen seiner Zeit war.

So rege wie auf dem politischen Felde blieb er auch in Wissenschaft und Lehre. Virchow übernahm das Ordinariat für Pathologie der Charité und war dort zudem Prosektor, ihm oblag also u. a. das Sezieren menschlicher Leichen.

Doch damit nicht genug. Im September 1869 veröffentlichte die Sektion für Anthropologie und Ethnologie der Versammlung deutscher Naturforscher und Ärzte einen Aufruf zu Gründung einer deutschen Gesellschaft für Anthropologie und Ethnologie und Urgeschichte sowie der entsprechenden Lokalvereine. Initiator dieser Bewegung war wiederum Rudolf Virchow ${ }^{37}$. Noch vor der Konstituierung einer gesamtdeutschen Dachorganisation gründete er mit fast dreißig Vertretern der Berliner Gelehrtenwelt den Berliner „Lokalverein für Anthropologie und Ethnologie" und Urgeschichte. Am 17. November 1869, dem Tag der konstituierenden Sitzung der „Berliner Anthropologischen Gesellschaft“, konnte der Verein bereits 120 Mitglieder verzeichnen. Virchow wurde zum Vorsitzenden

36 Saherwala et al. 2002, 31.

37 Ebd. $34 \mathrm{f}$. gewählt und blieb bis zu seinem Tod führendes Mitglied dieser Vereinigung ${ }^{38}$. Politischer Einfluss wie große Bedeutung für das wissenschaftliche Leben bündelte sich somit in der Person Rudolf Virchows.

Das Interesse am Kaukasus gründete sich bei Virchow auf der Auseinandersetzung mit zwei wissenschaftlichen Theorien: einer anthropologischen und einer archäologischen, deren Wahrheitsgehalt zu überprüfen es sich Virchow zur Aufgabe gemacht hatte. Auf der anthropologischen Seite sind die Theorien von Johann Friedrich Blumenbach (1752-1840) zu nennen, für den der Kaukasus als Ursprungsgebiet der „weißen Rasse“ galt ${ }^{39}$, in archäologischer Hinsicht wurde dem Kaukasus - der griechischen Überlieferung folgend - das Primat der Entwicklung der Metallurgie zuerkannt. Virchow folgte der rassischen Zuweisung Blumenbachs und Virchows Helfer als Nichtanthropologen und -archäologen folgten wiederum Virchows Vorstellungen.

In dem vorliegenden Kontext liegt der Fokus auf den Auswirkungen dieser anthropologischen Zuweisungen.

In diesem Rahmen ist auch Rudolf Virchows Teilnahme am 5. Allrussischen Archäologischen Kongress in Tbilisi 1881 zu sehen. Virchow hatte sich bereits vor Beginn des Kongresses am 20. September 1881 im Nordkaukasus aufgehalten, genauer gesagt war er vom 16.-18. September in Nordkaukasien, im Fiagdon-Tal, in Tagaurien und Ossetien, wo er auf dem Gräberfeld von Koban am Berg Kazbek Gräber öffnen ließ ${ }^{40}$.

Nach diesen Unternehmungen trat Virchow eine ausgedehnte Reise durch den Kaukasus an und gelangte dabei auch nach Aserbaidschan und Armenien. Zurück in Deutschland hielt er über seine Reisen eine Reihe öffentlicher, viel beachteter Vorträge und verfasste mehrere archäologische Beiträge. Dies war für ihn eine gängige Vorgehensweise, und aus den Publikationen der Verhandlungen der BGAEU liegen eine Reihe solcher Berichte vor, in denen Reisen zu fernen wie nahen Gräberfeldern - etwa im Berlin-Brandenburger Raum - die Suche nach Urnengräbern und deren Ausgrabung und Entleerung vor Ort geschildert werden ${ }^{41}$.

Über seine kaukasische Reise berichtete Virchow am 17. Dezember 1881 vor der Gesellschaft für Anthropologie, Ethnologie und Urgeschichte: „... In diesem Lande der Osseten, und gerade an einer der alten Übergangsstellen, ist im Augenblick die beste Fundgelegenheit vorhanden, und Sie begreifen, welches Interesse ich daran hatte,

\section{Ebd.}

39 Virchow/Dolbežev 1882, $107 \mathrm{ff}$.

40 Andree 1976; 2008; Virchow 1883.

41 Virchow 1888, 581. 
vielleicht unsere Vettern, zu besuchen und bei der Gelegenheit wenn möglich noch irgendwelche alten Stammeserinnerungen mit ihnen auszutauschen. (...) Ich war schon vorher auf diese Verhältnisse vorbereitet, indem ein sehr intelligenter und schneidiger Mann, der vorhin schon erwähnte Oberlehrer Dolbežev in Wladikawkas, sich ganz spontan vor Jahr und Tag an mich gewendet hatte, um mir Mitteilung zu machen über Gräberfunde im Lande der Osseten. Er hatte mir auch einige Proben geschickt, von denen ich jedoch aus einer, wie sich nachher herausstellte, unnötigen Vorsicht nichts veröffentlicht hatte. Ich hatte geglaubt, auf ein ganz intaktes Gebiet zu stoßen; es ergab sich aber, dass nicht bloß verschiedene russische Sammler, sondern auch Hr. Bayern und Hr. Chantré mir zuvorgekommen waren und ich auf eine stark ausgebeutete Stelle kam. Nichtsdestoweniger ist das Feld noch hinreichend ergiebig gewesen, so dass ich in der Lage bin, von den wesentlichsten Sachen Vorlagen machen zu können“42.

Auch eine weitere Schilderung ist für den hiesigen Kontext aufschlussreich. Virchow scheint eine überaus angenehme Zeit während seines Aufenthalts in Koban verbracht zu haben, ließ ihn doch der erbliche Stammesfürst (Aldar) der tagaurischen Osseten - Chaboš Kanukoff eine „liebenswürdigste Gastfreundschaft“ ${ }^{\star 43}$ angedeihen. In seinem 1881 veröffentlichten Bericht in der Zeitschrift für Ethnologie weist Virchow entschuldigend darauf hin, dass sich Kanukoff für die Möglichkeit der Ausgrabung belohnen ließ, die Gelegenheit schien ihm (Virchow) jedoch zu günstig, um sie verstreichen zu lassen. Tatsächlich war Kanukoff das Oberhaupt der örtlichen Ausgräber, die sich ihre Tätigkeiten von reichen Moskowitern oder zahlungskräftigen Ausländern bezahlen ließen ${ }^{44}$.

An dieser Stelle zeigt sich ein Facettenreichtum, der sich in Virchows Persönlichkeit bündelt ${ }^{45}$. Virchow konnte erfolgreich auf vielen Ebenen agieren, sowohl als Forscher wie als Politiker, aber auch als Sammler in Konkurrenz mit anderen Europäern.

Die von ihm initiierten Laiengrabungen im Kaukasien müssen in diesem Rahmen gesehen werden, nicht außer

42 Ebd. 417.

43 Ebd. 418.

44 Motzenbäcker 1996, 23 mit weiterführender Literatur.

45 Veit 2006, 48: „Diese Leistungen sind, jedenfalls unter den forschungsgeschichtlich interessierten Fachvertretern, seit langem bekannt (Narr 1979) und begründen Virchows Ruf, als Doyen der entstehenden Zunft prähistorisch orientierter Archäologen’ ... „Permanent forderte er dabei zur Erschließung neuer Quellen auf, warnte aber gleichzeitig auch vor voreiligen Schlussfolgerungen.“ ebd. 49; „Oft wird auch verkannt, dass Virchow in viel größeren Zusammenhängen dachte als die anderen zeitgenössischen Fachvertreter.“ Ebd. acht gelassen werden dürfen jedoch auch die Virchow umtreibenden wissenschaftlichen Fragestellungen seiner Zeit. So unterstützte etwa die von Virchow ins Leben gerufene „Berliner Gesellschaft für Anthropologie, Ethnologie, und Urgeschichte“ wie auch die „Rudolf-Virchow-Stiftung“ von 1888 bis 1891 den Ausgräber Waldemar Belck, von dessen Grabungen man sich Antworten auf die in jener Zeit von Philologen, Archäologen und Anthropologen viel diskutierte Frage nach der Urheimat der Indoeuropäer erhoffte (s. o. „Heimat des weißen Mannes“), und die in jenen kaukasischen Gebieten vermutet wurde ${ }^{46}$.

Im Rahmen dieser Fragestellung nahm Rudolf Virchow anthropologische Untersuchungen an aus Südkaukasien stammenden Skeletten vor und kam zum Schluss, dass es sich der Schädelform jener menschlichen Überreste zufolge bei diesen um „Kaukasier“ gehandelt habe, die er als „Rasse“ definierte. Als im Kaukasus eng verwandte Ethnie sah er die Armenier an, so dass von nun an per ,wissenschaftlicher Vorwegeinordnung“ alle anthropologisch als „kaukasisch“ identifizierbaren Skelette als „Armenier“ eingestuft und die jenen vor- und frühgeschichtlichen Kulturen zuweisbaren Funde und Befunde übereinstimmend als „armenisch“ bezeichnet wurden. Nach seiner Ansicht begann die von „Armeniern“ besiedelte Region „... in der Kuraebene bei der Eisenbahnstation Dsegam (Zeyem), [sie] zieht in südlicher Richtung weit auf das armenische Hochplateau bis in die Mitte des Kupferbergwerkes Gedebey, gehörig der Firma Geb. Siemens in Berlin, und wird im Osten vom Gebirgsfluße Schamchor begrenzt“. Diese Ansprachen finden sich in unterschiedlichen Schriften bis in jüngste Zeit wieder ${ }^{47}$.

In jener indifferenten und undifferenzierten Ansprache wurzeln noch heute zahlreiche fehlerhafte Fortschreibungen in der wissenschaftlichen Interpretation. Dieser Querschluss - Kaukasier $=$ Armenier und kaukasische Funde $=$ armenische Funde - wird bedauerlicherweise in der Regel nicht thematisiert, wobei anzunehmen ist, dass auch nicht allen sich mit diesen Regionen beschäftigenden Forschern die entsprechenden Hintergründe bekannt sind.

An dieser Stelle muss aber auf die wissenschaftliche Bedeutung und außerordentliche Wichtigkeit der Auseinandersetzung mit jenen historisch bedingten Kategorisierungen und Deutungen hingewiesen werden. Durch die kritisch-wissenschaftliche Analyse können einerseits die damaligen Beweggründe für jene Zuschreibungen verstanden werden; andererseits ist diese Analyse notwendig, um die in den folgenden mehr als 100 Jahren erfolgte

46 Kohlmeyer/Saherwala 1983, 15.

47 Ebd. $64 \mathrm{f}$. 


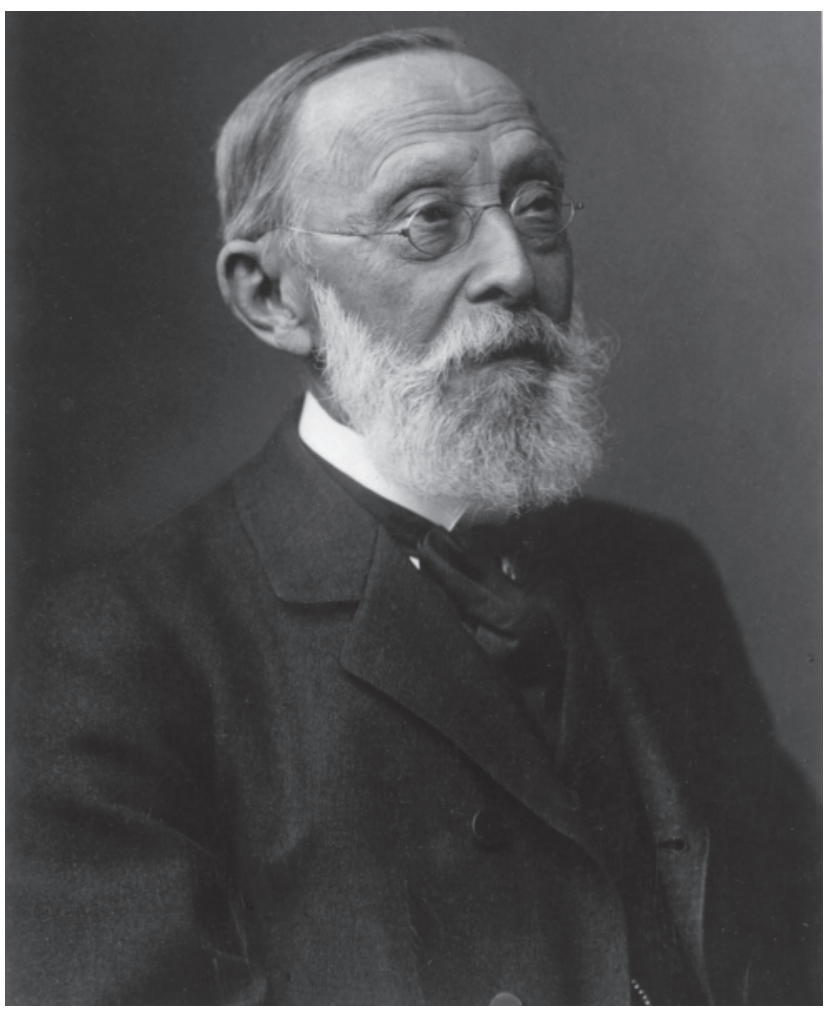

Abb. 7: Rudolf Virchow (1821-1902) (Foto: Veit 2006, Abb. 1)

Geschichtsschreibung Kaukasiens gerade auch im Lichte heutiger Forschungsergebnisse auf eine neue Basis stellen zu können.

Die von Rudolf Virchow (Abb. 7) gesammelten Fundstücke aus dem Kaukasus wurden bis zu seinem Tod am 5. September 1902 im Pathologischen Institut der Charité aufbewahrt, die bronzenen Fundstücke gelangten anschließend in die damalige Prähistorische Abteilung des Königlichen Museums für Völkerkunde in Berlin ${ }^{48}$.

\section{Zum Einfluss Rudolf Virchows auf die deutsche Geschichtsschreibung des Kaukasus}

Recherchen in der „Zeitschrift für Ethnologie“ (Abb. 8) sowie in den „Verhandlungen der Berliner Gesellschaft für Anthropologie, Ethnologie und Urgeschichte“ zum Thema Kaukasus für den Zeitraum von 1871 bis 1902 bringen so zahlreiche Beiträge Rudolf Virchows zu Tage, dass man sich angesichts der einzubeziehenden vielen weiteren $\mathrm{Pu}$ -

48 Motzenbäcker 1996, 7. blikationen und Vorträge zu den Themen Anthropologie und Archäologie Kaukasiens über dessen enorme Arbeitsleistung nur wundern kann.

Diese Fülle an Aktivitäten und Publikationen lässt sich unter Berücksichtigung der damaligen Infrastruktur nur mit der Inanspruchnahme einer Schar von Zulieferern erklären, die ihn mit Material und Informationen aus der Region versorgten. Nur so war es möglich, dass Virchow zur prähistorischen Archäologie 1.103 Schriften veröffentlichte, was noch zu ergänzen ist durch 246 Arbeiten zur prähistorischen Anthropologie. Die sich bereits aus der Quantität seiner Arbeit ergebende wissenschaftliche Präsenz brachte ihm in jener Zeit die Reputation einer internationalen Autorität, womit die von ihm geprägte Sicht auf die Geschichte des Kaukasus nachhaltig Verbreitung gefunden hat, was bis heute eine Langzeitwirkung hinsichtlich der wissenschaftlichen Deutung kaukasischer Funde entfaltet ${ }^{49}$.

Durch die Finanzierung auswärtiger, im Kaukasus agierender Personen unterschiedlicher Profession ermöglichte er die Durchführung von Grabungen mit der Maßgabe, die ihm anschließend hierbei entdeckten Artefakte zu übersenden. Virchow trug so im Laufe der Jahre eine beachtliche Anzahl von Fundstücken aus dem Kaukasus zusammen, die den Grundstock der Berliner Kaukasus-Sammlung bildet.

Auf der Basis seiner Überzeugung, dass ein umfassendes Bild der Entwicklung des Menschen nur durch die Einheit geistes- und naturwissenschaftlicher Forschungen gewonnen werden könne, beschäftigte sich Virchow etwa ab 1865 mit jenen Fragen der prähistorischen Archäologie. Dies fällt zusammen mit dem Bau der Kupferfabriken der Gebrüder Siemens in Aserbaidschan. Funde, die er als Geschenk von den Gebrüdern Siemens erhielt, dürften für sein verstärktes Interesse nicht von unwesentlicher Bedeutung gewesen sein. Sein Engagement für die Einführung wissenschaftlicher Methoden und die Schaffung entsprechender Institutionen, Organisationen und Publikationsorgane machte ihn zum Mitbegründer der wissenschaftlichen Prähistorie in Deutschland, die er in eine fruchtbare Verbindung zur Anthropologie setzte ${ }^{50}$.

Virchow verstand unter Anthropologie die Wissenschaft vom Woher und Wohin der Menschheit. Seine holistische Denkweise erlaubte so eine „offene“ Definition, deren Kernaussage seither ebenso als akzeptiert angese-

49 Von Rudolf Virchow sind noch weitere anthropologische Fehleinschätzungen bekannt. Sein größter Irrtum betrifft die Überreste des ersten aufgefundenen Neandertalers, den dieser als sterbliche Überreste eines rachitischen Franzosen ansah.

50 Motzenbäcker 1996, 34-35. 

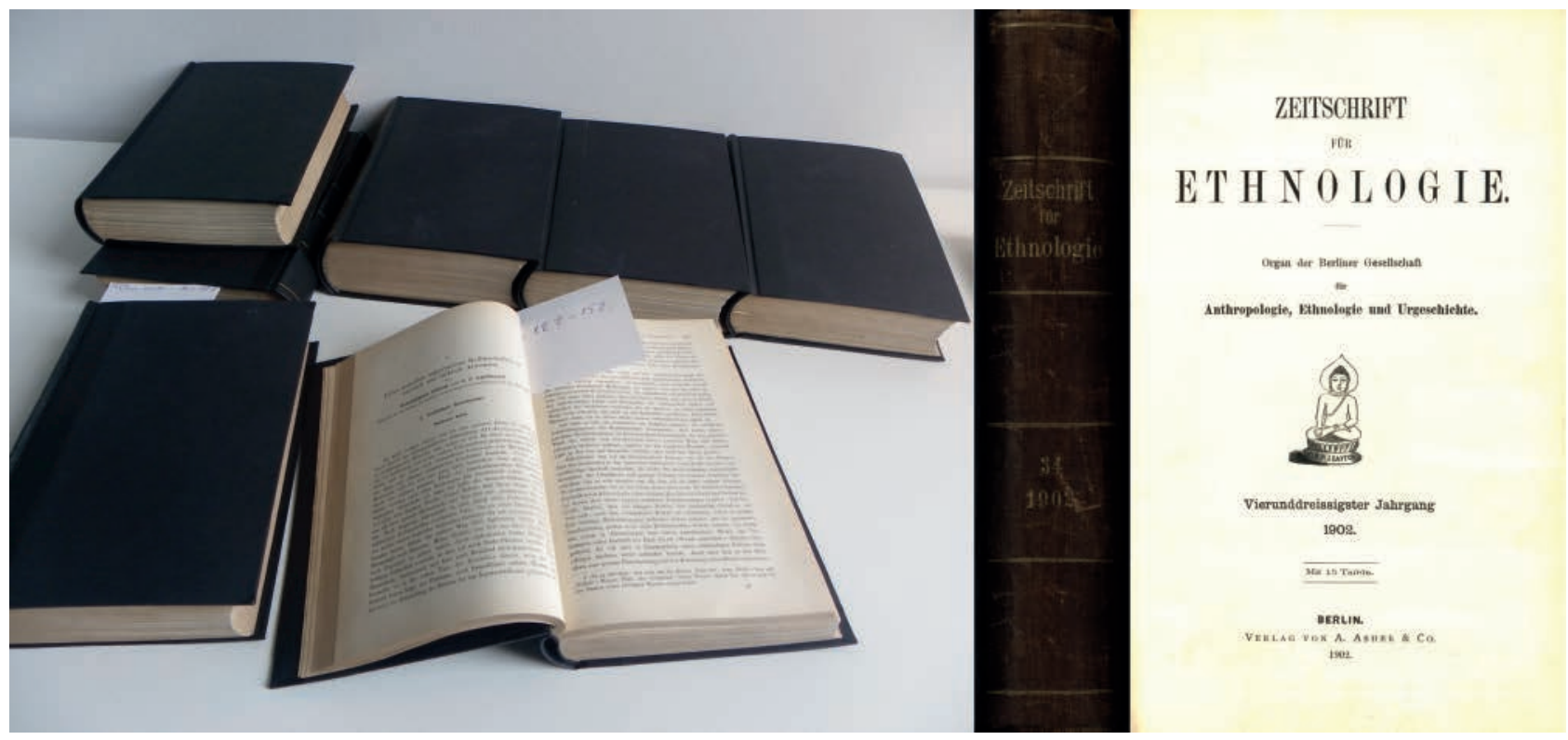

Abb. 8: Die Zeitschrift für Ethnologie (ZfE) (Bestand des Instituts für Prähistorische Archäologie, Foto: N. Ateshi-Gadirova)

hen wird, wie beispielweise seine Vorstellung, dass ein einzelner Beleg nicht genüge, um „das Tatsächliche zu finden“"51. Bei Zugrundelegung dieses Ansatzes war es für ihn folgerichtig, seine anthropologische Forschungstätigkeit vornehmlich auf Sammlungsgut zu gründen.

Zur Minderung des von ihm immer wieder beklagten Mangels daran nutzte er unermüdlich jede sich bietende Gelegenheit: Er sammelte selbst, kaufte an, animierte und instruierte Reisende (z. B. Schiffsärzte, Geografen, Privatsammler), schaltete Institutionen ein (Ministerien) und gründete Gesellschaften und Vereine (BGAEU) ${ }^{52}$.

Die von Philologen, Archäologen und Anthropologen in jener Zeit diskutierte Frage zur „Urheimat der Indoeuropäer" konnte Virchow aus den ihm übersandten Artefakten jedoch nicht klären, was aus heutiger Sicht sowohl hinsichtlich der Fragestellung, dem „Lösungsansatz“ als auch der mangelnden archäologischen Ausbildung seiner Ausgräber nicht verwundern mag. Die Ziele Virchows wie der Ausgräber waren außerdem - unabhängig von der Unmöglichkeit der Identifikation einer „Urheimat“ auf Basis archäologischer Funde - zu unterschiedlich. Hatte Virchow sowohl den Wissenszuwachs wie auch die Ausstattung der nationalstaatlichen Museen im Blick, so ging es den Ausgräbern vor Ort durch die Übersendung immer neuer Funde um weitere Aufträge. Aufgrund dieser Vorgehensweise ging vielfach die Möglichkeit verloren, Erkenntnisse zu gewinnen, die sich bei regulären Ausgrabungen

51 Ebd. 37.

52 Ebd. etwa aus stratigrafischen Beobachtungen, der Lage und Verteilung der Fundstücke und anderen Merkmalen mehr ergeben. Dies gilt jedoch für zahlreiche Grabungen auf nationaler wie internationaler Ebene unterschiedlicher Staaten.

Virchow war nur einer unter zahlreichen weiteren ausländischen Sammlern, der Aufträge für Ausgrabungen erteilte oder bei örtlichen Sammlern Exponate aus dem Kaukasus erstand. Die hierbei ergrabenen Funde wurden zum Grundstock der damals im Entstehen begriffenen Sammlungen europäischer Nationalstaaten, etwa den bereits benannten Museen von Saint-Germain-en-Laye und Lyon oder dem Naturhistorischen Museum Wien.

Der Bau des Königlichen Museums für Völkerkunde als Ort der Repräsentation auch seiner Sammlungen war nur dem zähen Ringen Virchows und der Berliner Gesellschaft zu verdanken. Bald nach seiner Eröffnung im Jahre 1886 kam neben der ethnologischen und der prähistorischen Sammlung der Königlichen Museen die anthropologische Sammlung der BGAEU zur Aufstellung. 1888 bezog auch die Geschäftsstelle der Gesellschaft ihre neuen Räume in diesem Gebäude ${ }^{53}$.

Eine Reihe von Autoren und Biografen Virchows haben seine Hinwendung zur kommunalen Politik als „Resignation“ und „Enttäuschung“ interpretiert, die aus der Bismarck'schen Einigung Deutschlands resultierte ${ }^{54}$. Aus der Perspektive eines Strebens nach Einfluss und
53 Ebd. 34-35.

54 Bringschulte 2002, $82 \mathrm{f}$. 
zur Eröffnung finanzieller Quellen stellt sich dies jedoch anders dar. Virchow war geschickt darin, finanzielle Mittel $\mathrm{zu}$ akquirieren und weiter zu verteilen. Es wundert daher nicht, dass er als Vorsitzender der Budget-Kommission im Preußischen Abgeordnetenhaus über Jahrzehnte hinweg für die Königlichen Museen von großer Bedeutung war. Er nutzte seine politischen, wissenschaftlichen und finanziellen Möglichkeiten zur Einflussnahme, um in Berlin eine umfangreiche Kaukasus-Sammlung entstehen zu lassen, die gerade auch mit Blick auf die europäische Konkurrenz von Bedeutung sein sollte. Zu dieser Konkurrenz zählte neben Jacques de Morgan, der das identische Ziel für Frankreich verfolgte, auch die ИАК, deren Bestreben es war, den russischen Museen exquisite Funde zu sichern.

Diese scheinbare Omnipräsenz Virchows auf naturwissenschaftlich-geisteswissenschaftlichem Terrain unter Ignorierung kunstgeschichtlicher Bereiche wurde jedoch auch unter Zeitgenossen offenbar nicht kritiklos betrachtet. Eine solche Kritik findet sich etwa in den Memoiren Wilhelm von Bodes, der, bevor er Generaldirektor der Königlichen Museen wurde, als Abteilungsleiter selbst von Virchows Engagement profitierte. Lediglich an einer einzigen Stelle ist von Virchow die Rede, darin aber deutlich in der Aussage. Im Preußischen Abgeordneten Haus, schreibt Bode, ,... gab es für uns niemanden, der Kunstinteresse besaß. Mommsen und Virchow waren ihren Kollegen im Abgeordnetenhause auch in der Kunst maßgebend, und diese betrachteten sie ausschließlich von wissenschaftlichen Standpunkt. Die Zustände in der Verwaltung der Museen wurden von ihnen in die Diskussion gezogen, die sich von der Kammer auch in der Presse (Curtius contra Mommsen) übertrug, aber sie trafen nicht den Kern, sondern hielten sich in starren Theorien, die von falschen Gesichtspunkten ausgingen und daher mehr schadeten als nutzten. Eine Republik selbstständiger Direktoren, der einzelnen Abteilungen, deren Konsortium den Generaldirektor ersetzen sollte, und die völlige Lostrennung der Museen vom Hof unter Beseitigung des Protektors, schien ihnen die wünschenswerte Lösung “55.

In Berlin ging mit dem Tod von Rudolf Virchow 1902, dem Ableben von Philipp Wilhelm Adolf Bastian 1905 (Arzt, Ethnologe und Gründungsdirektor des Berliner Museums für Völkerkunde) und dem des Prähistorikers Albert Voß (erster Direktor der 1886 gegründeten Prähistorischen Abteilung des Königlichen Museums für Völkerkunde) im Jahr darauf die Dominanz einer naturwissenschaftlich orientierten, durch die einflussreiche Berliner Gesellschaft für Anthropologie, Ethnologie und Urge-

55 Michel 2002, $108 \mathrm{f}$. schichte gestützte und von der Troika Virchow-BastianVoß dirigierte evolutionistische Vorgeschichtsforschung ihrem Ende entgegen ${ }^{56}$.

\section{Friedrich Bayern (1817-1886): „Der Begründer der kaukasischen Prähistorie“}

Einer der wichtigsten Zuträger Virchows war Friedrich Bayern, den dieser als „Gründer der kaukasischen Vorgeschichte“ bezeichnete (Abb. 9) ${ }^{57}$. Friedrich Bayern, geboren 1817 in Kronstadt in Siebenbürgen (heute Braşov, Rumänien), gestorben 1886, kam auch in den Genuss von Virchows großzügiger Finanzierung über dessen Stiftung. Er unternahm im Kaukasus Ausgrabungen, die zahlreiche Funde aufdeckten, wissenschaftliche Befunde jedoch zerstörten. Er grub an Orten wie Marienfeld (1869), Sartaşlı (1869), Mcxeta-Samtavro (1872), Kazbek (1879) und Redkin-Lager (1879) ${ }^{58}$. Bayern, seinerzeit auch Mitglied der BGAEU, war zeitweise Lehrer in Odessa, gründete in Tbilisi die Gesellschaften „Freunde der Archäologie des Kaukasus“ und „Gesellschaft der Altertumsforscher des Kaukasus“. Die Mehrzahl der von ihm geborgenen Funde befindet sich heute in Aserbaidschan (Baku), in Georgien (Tbilisi), einige lagern auch in Russland (Moskau und St. Petersburg), in Deutschland (Berlin) und in Frankreich (Paris). Bereits darauf hingewiesen wurde, dass das „Museum Caucasicum“ in Tbilisi in zaristischer Zeit als der zentrale Sammelort für archäologische Funde Gesamtkaukasiens gedacht war.

Ein Teil seiner Funde wurde nach Tbilisi, ein anderer nach Moskau und wiederum ein weiterer Teil nach Berlin zu Virchow geschickt. Ein weiterer und bis heute unerforschter Teil befindet sich im Museum Saint-Germainen-Laye in Paris. Nach dem Ende des Zweiten Weltkrieges schloss sich die Verbringung eines Großteils der Funde aus Berlin in die UdSSR an. Noch heute lagert die Mehrzahl jener Stücke unerforscht in russischen Museen, der überwiegende Teil im Staatlichen Historischen Museum Moskau, im Staatlichen Museum für Bildende Künste A. S. Puschkin in Moskau sowie in der Eremitage in St. Petersburg. Das Kaukasische Museum in Tbilisi überließ 1925 einen Teil dieser Exponate dem neu gegründeten Nationalen Museum für Aserbaidschanische Geschichte in Baku ${ }^{59}$.

56 Menghin 2004/2005.

57 Virchow 1895, 21.

58 Kohlmeyer/Saherwala 1983, 12.

59 Chalilli 2006, 238-239. 


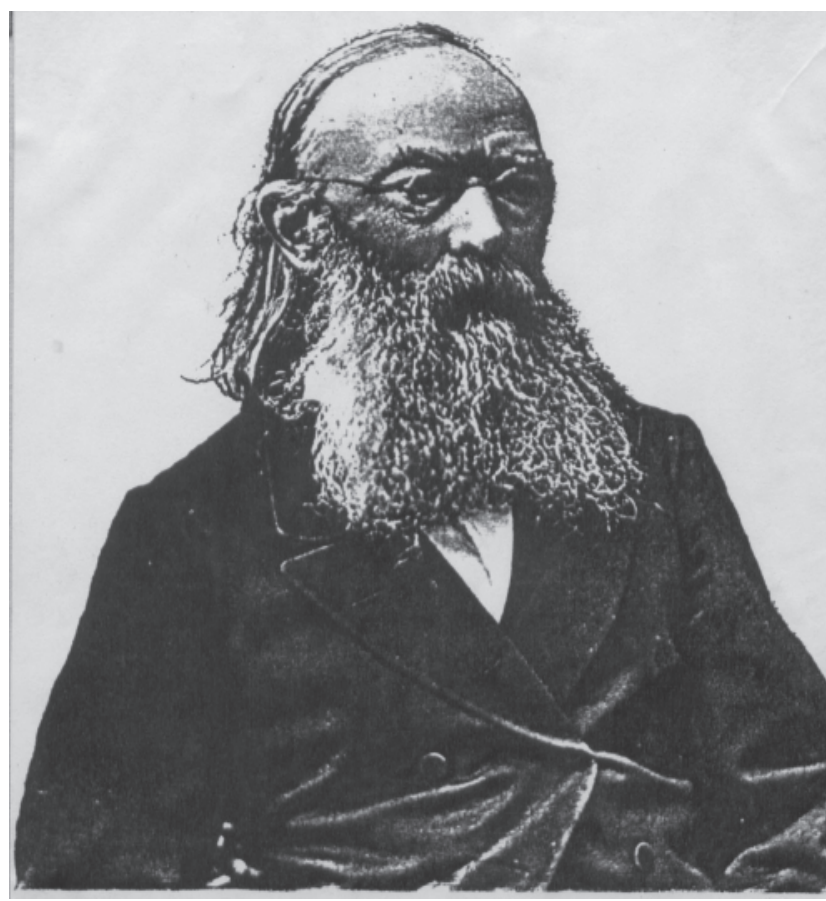

Abb. 9: Friedrich Bayern (1817-1886)

Ein kleiner Teil liegt bis heute im Museum für Vor- und Frühgeschichte Berlin.

\section{Die Funde des Redkin-Lagers - ein Beispiel für die Zersplitterung des kaukasischen Kulturerbes}

Die Sammlung „Redkin-Lager“ umfasst Funde aus dem eponymen Gräberfeld, das sich in einer Entfernung von 6,3 km von der im heutigen Armenien gelegenen Stadt Dilican am Oberlauf des Ağstafa-Flusses an dessem rechten Ufer befindet. Das Territorium der Nekropole gehörte ehemals zum Khanat Gence. 1868, zur Zeit des Zarenreiches, war Dilican Bestandteil des Gouvernements Elisavetpol.

Das Gräberfeld befindet sich dabei auf einer kleinen, über dem Meeresspiegel gelegenen Hochebene. Es wurde in gewissem Abstand zum Fluss angelegt und erstreckt sich über das gesamte Gebiet, das bis zu waldbedeckten niedrigen Bergketten reicht und das Tal mit den Hängen jenes Gebirges verbindet.

Die Bezeichnung „Redkin-Lager“ leitet sich vom Namen des Ingenieurs Redkin ab, der hier in den 1850er Jahren zum Bau einer Landstraße sein Lager aufschlug. Schon damals stießen die Straßenbauer bei der Funda- mentierung eines Hauses für die Ingenieure auf Spuren von Grabanlagen, denen anfänglich jedoch noch keine Bedeutung beigemessen wurde. Erst später stellte es sich heraus, dass die Landstraße sowie alle Zweckbauten das Gräberfeld direkt durchquerten. Daher ist anzunehmen, dass bei der Anlage der Landstraße eine große Zahl von Gräbern zerstört wurde. Auszugehen ist ferner davon, dass bereits vorher zahlreiche Gräber Plünderungen zum Opfer fielen.

„Erst zwanzig Jahre später - 1876 - mit der Ernennung des Ingenieurs und Obristen Weiß von Weißenhoff zum Leiter des Landstraßenbaus, wurde der Wissenschaft bekannt, dass sich an dieser Stelle eine prähistorische Grabstätte befand. Zusammen mit seinem Schwager öffnete Weiß von Weißenhoff einige Gräber und hat deren Inhalt zu Bayerns Museum gegeben“60. Im März 1879 ergruben Bayern und von Weißenhoff im Verlauf weniger Tage fünf Gräber aus dem Redkin-Lager. Die Funde verschickten sie an die Anthropologische Gesellschaft in Moskau ${ }^{61}$, die Bayern für seine Arbeit finanziell entlohnte ${ }^{62}$. Bayern setzte später und in seiner Dienstzeit die Grabungen fort, dies über einen Zeitraum von zwei Monaten und mit materieller Unterstützung durch von Weißenhoff. Hierbei gelangte er in den Besitz zahlreicher wertvoller Artefakte.

Noch im selben Jahr schickte Bayern prähistorische Fundstücke an das von ihm in Tbilisi aufgebaute Museum sowie nach Berlin. Eine weitere Nachricht besagt, dass ein Teil der Funde aus dem Gräberfeld Redkin-Lager im von 1874 bis 1878 bestehenden Museum der „Gesellschaft der Amateure der Kaukasusarchäologie“" verwahrt wurde ${ }^{63}$.

Später beschäftigten sich G. D. Filomonov sowie Graf und Gräfin Uvarova mit der Erforschung der Nekropole. Es liegen auch Berichte darüber vor, dass die Schwester F. Bayerns sich daran beteiligte und sogar ein weiteres außergewöhnliches Grab entdeckt habe ${ }^{64}$. In der Sowjetzeit befasste sich B. B. Pjotrovskij mit der Erforschung der Grabstätte, insbesondere solcher Funde, die er selbst 1942 geborgen und dokumentiert hatte ${ }^{65}$.

Die systematische Erkundung der Grabstätte und ihre wissenschaftliche Vorlage ist jedoch Friedrich Bayern zuzuschreiben, der diese in der Jahresschrift der Berliner Gesellschaft für Anthropologie, Ethnographie und Urgeschichte vorstellte ${ }^{66}$. Rudolf Virchow hat Bayerns Werk

60 Bayern 1885, 1.

61 Ebd. 49.

62 Uvarova 1900, 23; 48.

63 Pjotrovskij 1949, 6.

64 Uvarova, 1900, 48.

65 Arešjan 1974, 193.

66 Bayern 1885, 1-60. 
redigiert, das Vorwort verfasst und die Schrift nach dem Tode Bayerns in der Jahresschrift veröffentlicht. Obwohl sich Virchow von einigen Thesen Bayerns distanzierte, veröffentlichte er dessen bisweilen abstrusen Theorien. Bayern beteiligte sich nicht nur intensiv an der Erforschung der Grabstätte Redkin-Lager, sondern ergrub auch andere archäologische Denkmäler des Kaukasus.

Bestandteile der Sammlung Redkin-Lager befinden sich heute unter anderen im Berliner Museum für Vor- und Frühgeschichte (MVF), im Moskauer Staatlichen Historischen Museum und im georgischen Nationalmuseum, in der Eremitage in St. Petersburg, in Baku und in Museum Saint-Germain-en-Laye in Paris.

Aus den in Redkin-Lager entdeckten Objekten lassen sich im MVF nur noch sehr wenige Fundstücke identifizieren. Dazu zählen zwei gelochte Anhänger aus Bronze ${ }^{67}$, ein Bronzeanhänger mit Gitter ${ }^{68}$, ein rechteckiges Stück Bronze $^{69}$, sieben Kügelchen aus Antimon ${ }^{70}$ sowie ein bronzenes Röhrchen ${ }^{71}$.

Aufgrund der vom Museum zu den Objekten aus Redkin-Lager gemachten Angaben wird der übrige Fundstoff grundsätzlich als Kriegsverlust verbucht; es ist jedoch damit zu rechnen, dass ein Teil der Stücke sich in Museen in Russland befindet ${ }^{72}$. Es ist weiterhin anzunehmen, dass die während des Zweiten Weltkriegs im Martin-GropiusBau in Berlin aufbewahrten Exponate zerstört wurden, als das Gebäude während der alliierten Bombenangriffe zerstört wurde. $\mathrm{Zu}$ vermuten ist ferner, dass Keramiken der Sammlung Redkin-Lager sich momentan noch im Fundus des MVF befinden, evtl. bei jenen Funden, die aufgrund der Kriegsschäden nicht mehr direkt mittels Beschriftung oder beigelegter bzw. angeklebter Zettel einem Fundplatz zugewiesen werden konnten ${ }^{73}$. Dies betrifft eine Reihe von Objekten unterschiedlichster Fundstellen. Es besteht jedoch die nicht unbegründete Hoffnung, dass ein erheblicher Teil des Materials aus Redkin-Lager wieder identifiziert und so der Forschung zur Verfügung gestellt werden kann. Auch im Nationalen Historischen Museum Aserbaidschans wird ein Teil der Redkin-Lager-Sammlung verwahrt.

Die Sammlung Redkin-Lager war dem Museum im Jahre 1925 vom Kaukasus-Museum (Tbilisi) übertragen und

67 IIId 5377 und 5378.

68 IIId 5381.

69 IIId 5382.

70 IIId 5644-5650.

71 III 5850.

72 Auskunft des Museums für Vor- und Frühgeschichte Berlin durch M. Nawroth vom 27. 01. 2014.

73 Ebd. übergeben worden. Bei der Verbringung der Sammlung nach Aserbaidschan und ihrer Übergabe an das Staatliche Museum der Aserbaidschanischen SSR (heute das Nationale Historische Museum Aserbaidschan) erwarb Davud bey Sherifov, Direktor des Hauses in den Jahren 1923-1928, große Verdienste ${ }^{74}$. Dass der Redkin-Lager-Kollektion auch Fundstücke anderer Denkmäler zugeteilt wurden, hatte organisatorische Gründe, da jenes in der Zarenzeit an verschiedenen Orten im Kaukasus ausgegrabene archäologische Material in der Regel dem in Tbilisi befindlichen Kaukasischen Museum übergeben wurde.

Das gegenwärtig im Nationalen Historischen Museum Aserbaidschans aufbewahrte Material aus Redkin-Lager ist in zwei Inventarbüchern erfass $\mathrm{t}^{75}$. Aufgelistet sind hier im Wesentlichen Töpferwaren (Abb. 10; 11), verschiedene Schmuckstücke aus Bronze und anderen Materialien sowie Knochenfragmente. Einige der hier erfassten Tongefäße aus Redkin-Lager wurden dann jedoch 1944 dem Museum von Schamachı und 1958 weiter dem von Nucha (heute Scheki in Aserbaidschan) übergeben. Insgesamt wurden für die Fundstücke aus Redkin-Lager 351 Inventarnummern vergeben.

Nachdem Bayern zeitweilig in Odessa als Lehrer gearbeitet hatte, zog er nach Tbilisi, wo durch seine Bemühungen im Jahr 1873 die „Gesellschaft der Altertumsforscher des Kaukasus“ und anschließend die „Gesellschaft für Geschichte und Archäologie des Kaukasus" entstanden. Zugleich war Bayern Mitglied der von Rudolf Virchow in Berlin ins Leben gerufenen und mitbegründeten BGAEU sowie weiterer wissenschaftlicher Institutionen. Bayern barg selbst und erwarb von Einheimischen im Auftrag der genannten Gesellschaften unzählige archäologische Funde aus dem heutigen Armenien und Georgien, und verkaufte diese u.a. nach Russland oder Deutschland.

Da auf europäischer Seite das wissenschaftliche Interesse im späten 19. Jahrhundert eher darin lag, den Ursprung der Europäer - die nach damaliger Sicht der Dinge „indoeuropäischen Arier“ - in Armenien zu finden, wurde die Mehrzahl der Forschungen auf jenes Ziel fokussiert. Ferner wurden alle albanischen Kirchen und Schriften sowie die in die Spätbronze- und Früheisenzeit datierenden Gräber als „alt-armenisch“ bezeichnet und dementsprechend beschrieben. Diese Ausrichtung geht wie bereits beschrieben zu einem erheblichen Anteil auf Rudolf Virchow zurück, dessen wissenschaftliches Renommee dazu beitrug, die südkaukasischen Funde entsprechend zu klassifizieren. Jene Einordnung wurde allzu lange unkritisch übernom-

74 Chalilli 2006, 238.

75 Inventarbuch 1 und 2. 


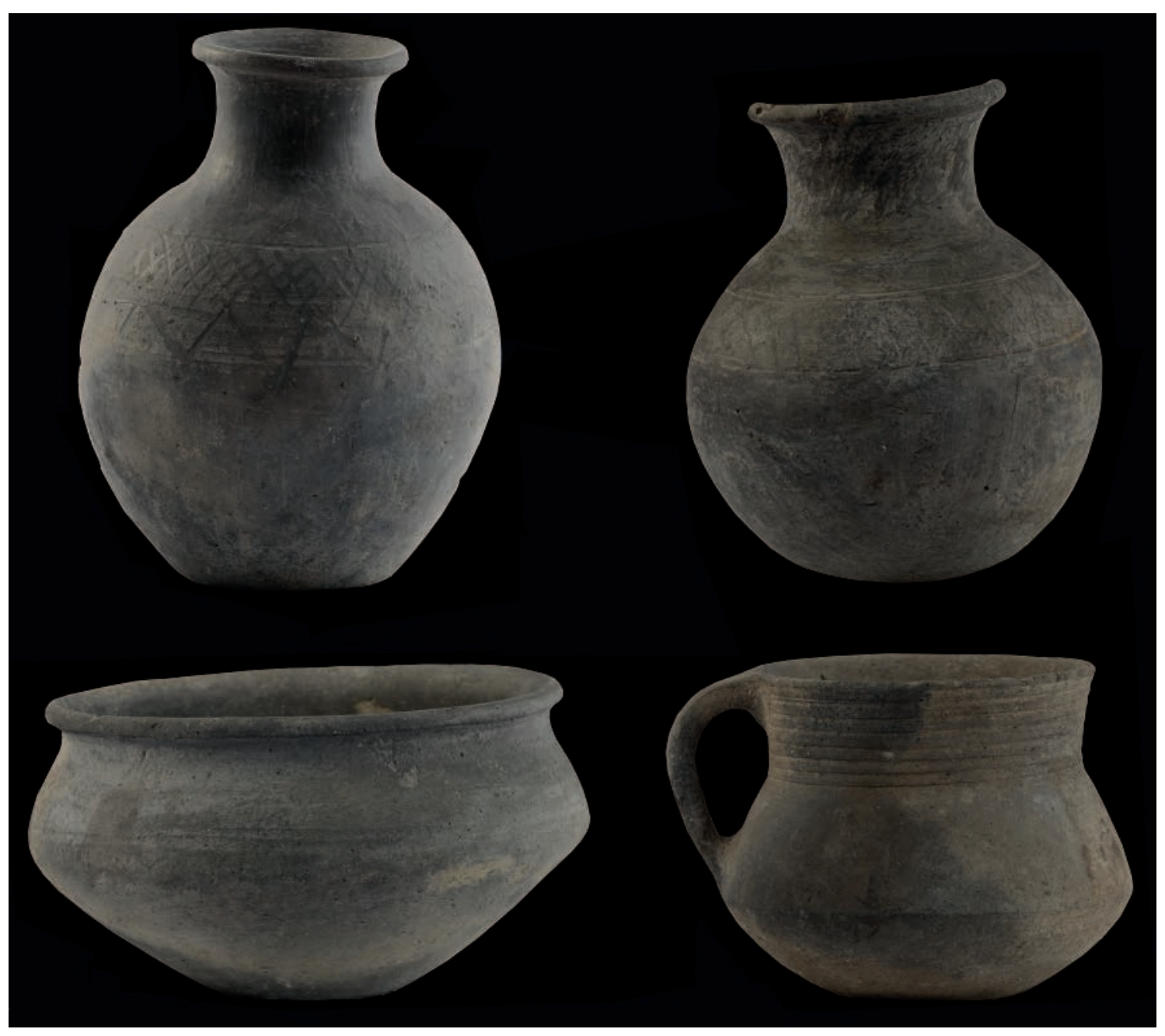

Abb. 10: Keramik aus der Sammlung Redkin-Lager, heute im Historischen Nationalmuseum von Aserbaidschan, Baku (Foto: N. Ateshi-Gadirova)

men, dies gleichermaßen von russischen, deutschen und kaukasischen Wissenschaftlern.

Die Folgen waren Verdrehungen, Irrtümer und Verfälschungen. Virchow hielt auf Grundlage der Funde Belcks' zahlreiche Vorträge und veröffentlichte auch umfangreiche Schriften in der Zeitschrift für Ethnologie. Er verfasste eine Monografie über Gürtelbleche „Über die kulturgeschichtliche Stellung des Kaukasus “76, welches damals in der Wissenschaftswelt als eine herausragende akademische Abhandlung “77 galt, Lehmann-Haupt schrieb „Armenien einst und jetzt ${ }^{\text {"78 }}$. Damit handelte er einen ziemlich langen Zeitraum in nur einem Werk auf Basis der hier geschilderten zweifelhaften Quellen ab. Dieses Werk weist in der Durchsicht zahlreiche kleinere, aber auch größere
Fehler auf, dies hinsichtlich historischer, anthropologischer und archäologischer Sachverhalte. So bezeichneten Virchow und auch Lehmann-Haupt entsprechend ihren Zuweisungen beispielsweise die Region Gedebey oftmals als „Hoch-Armenien“, die bronzezeitliche und vorarmenische Geschichte des Kaukasus sprachen die beide als „alte armenische Geschichte“ an. Diese im Stil und auf dem Hintergrundwissen seiner Zeit verfassten Irrtümer sind für die heutige Diskussion jedoch als solche zu kennzeichnen, $\mathrm{zu}$ berücksichtigen und in künftigen Untersuchungen zu korrigieren.

76 Virchow 1895.

77 Nagel/Strommenger 1985, 14.

78 Lehmann-Haupt. 1910. 


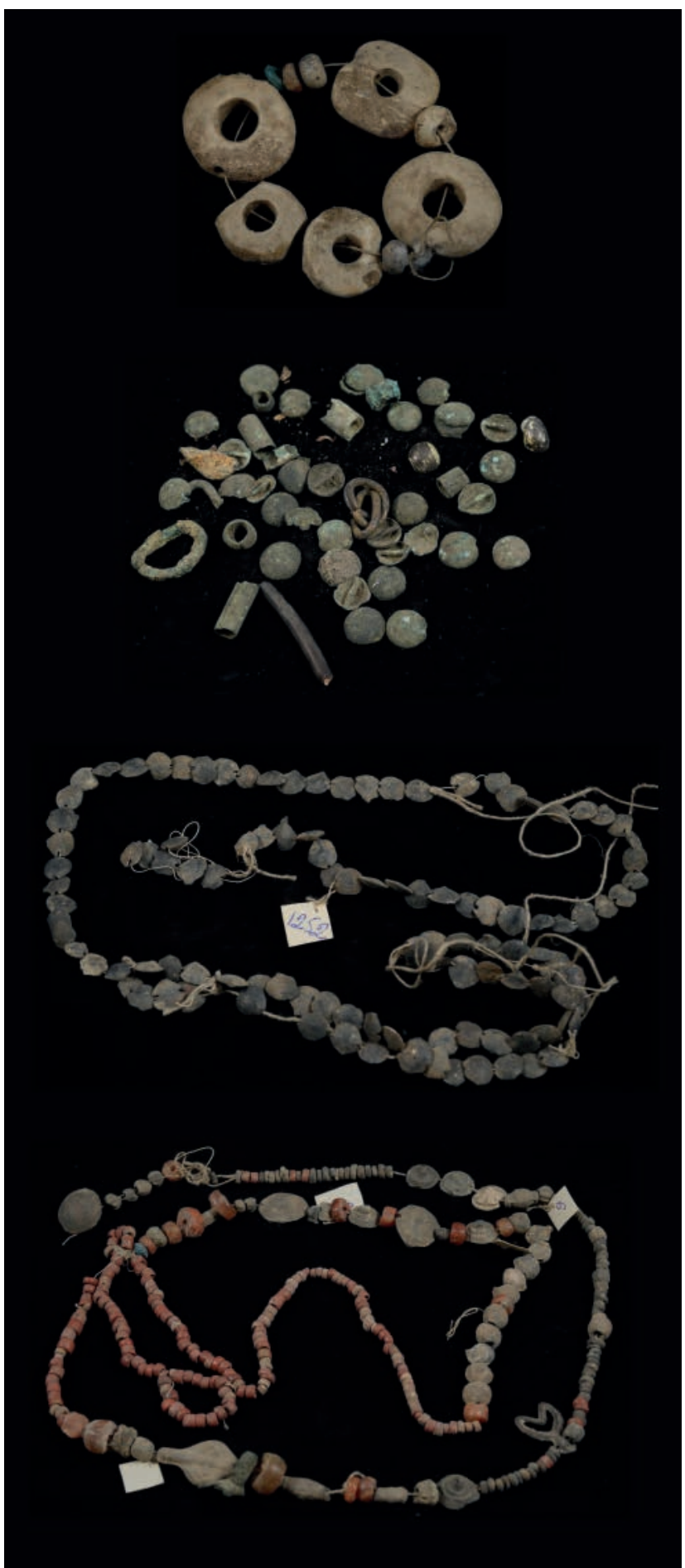

Abb. 11: Kettengehänge und andere Grabbeigaben aus der Sammlung Redkin-Lager, heute im Historischen Nationalmuseum von Aserbaidschan, Baku (Foto: N. Ateshi-Gadirova)

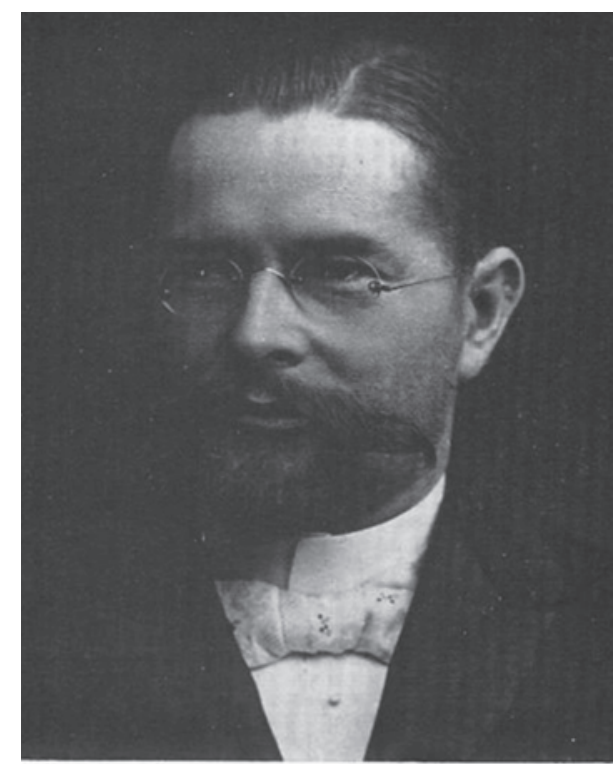

Abb. 12: Waldemer Belck (1862-1932)

\section{Der Ausgräber Waldemar Belck (1862-1932)}

Eine der wichtigsten Personen unter den für Virchow tätigen Ausgräbern war Waldemar Belck (Abb. 12). Albert Voß, erster Direktor der 1886 gegründeten Prähistorischen Abteilung des Königlichen Museums für Völkerkunde, vermerkte über Belck und seine Sammlung: „Das von Dr. Belck gesammelte Material zeichnet sich außerdem nicht allein durch Reichhaltigkeit der Formen und die Zahl der Gegenstände, sondern besonders dadurch aus, dass es von ihm größtenteils selbst ausgegraben ist, und genau von ihm verfasste Ausgrabungsberichte vorhanden sind.“

Waldemar Belck kam 1888 im Auftrag der Firma Siemens als Elektroingenieur nach Gedebey. Vor Ort eingetroffen, begann er alsbald mit der Aufdeckung archäologisch relevanter Fundstellen. Laut eigener Feststellung grub er dabei wöchentlich zwischen $\mathrm{zwei}^{79}$ und fünf Gräber aus ${ }^{80}$.

Belcks' Ausgrabungen waren - wie bei seinen „Ausgrabungskollegen“ auch - nicht selbstloser Natur, sondern wurden entlohnt. Als weitere (erfüllte) Gegenleistung verlangte er für seine umfangreiche Grabungs- und Sammeltätigkeit im Briefverkehr mit Rudolf Virchow, dass dieser

79 Belck an Virchow aus Kalakent, Brief vom 19. 08. 1888. Nagel/ Strommenger 1985, $19 \mathrm{ff}$

80 Belck an Virchow aus Kalakent, Brief vom 19. 04. 1889. Nagel/ Strommenger 1985, $37 \mathrm{ff}$. 
ihm den Status eines korrespondierenden Mitglieds der Gesellschaft für Ethnologie und Urgeschichte einräumen sollte ${ }^{81}$

Einigen Schriften und Briefen Virchows zufolge hatte dieser von der Art und Weise der Ausgrabungen Belcks' durchaus Kenntnis ${ }^{82}$. Ein Beleg hierfür ist ein Brief von Belck an Virchow vom 19. 08. 1888, den dieser in Kalakent verfasste: „Ich hoffe so viel Zeit erübrigen zu können, um wöchentlich zwei Gräber auszuräumen; aber dazu gehört Geld, zumal ich mir von den Eigentümern der Ländereien die Erlaubnis zum Graben erkaufen muss. Bitte schreiben Sie mir also bald, welche Summe mir die Anthropologische Gesellschaft für diesen Zweck zustellen kann; es wäre aber mir gerade nicht angenehm, wenn Geheimrat von Siemens erführe, dass ich mich nebenbei so intensiv mit Urgeschichte beschäftige, er liebt es eben nicht, wie ich gehört habe.“

Dabei hatte Virchow nicht nur die Vervollständigung der eigenen Sammlung im Auge, vielmehr half er auch anderen Museen, ihre Sammlungen weiter ausgestalten zu können, etwa dem Danziger Museum ${ }^{83}$, mit dem Belck brieflichen Kontakt aufnahm ${ }^{84}$.

Die Sammlung in Danzig war Virchow eine echte Herzensangelegenheit. So schrieb er Belck: „Bitte berücksichtigen Sie bei dieser Sammlung doch auch das Museum meiner Vaterstadt, wie Sie versprachen. Ich habe Herrn Dr. Conwentz bereits mitgeteilt, dass er von Ihnen demnächst eine kleine Kollektion kaukasischer Gräberfunde erwarten wird ..." ${ }^{85}$. An anderer Stelle kommt er erneut auf dieses Museum zu sprechen: „... ich bitte Sie für das Danziger Museum [Funde] zu reservieren ..." ${ }^{\text {86 }}$. Belck nahm solche Aufträge gerne an und meldete entsprechend Vollzug: „.... Ich nahm ein Grab in Angriff, so dass ich außerordentlich zufrieden mit meiner Ausbeute war ..." ${ }^{87}$. „... Ich habe übrigens nach Ihren Wünschen sämtliche Fundstücke an Sie abgesandt und überlasse es Ihnen, hiervon geeignete Stücke eventuell für das Museum zu Danzig auszusuchen ...“88.

81 Belck an Virchow aus Kalakent, Brief vom 11. 02. 1890. Nagel/ Strommenger 1985, $83 \mathrm{f}$.

82 Nagel/Strommenger 1985, 32.

83 Ebd.

84 Belck an Virchow aus Kalakent, Brief vom 19. 04. 1889. Nagel/ Strommenger 1985, $37 \mathrm{ff}$.

85 Belck an Virchow aus Kalakent, Brief vom 22. 02. 1890. Nagel/ Strommenger 1985, $83 \mathrm{ff}$.

86 Belck an Virchow aus Kalakent, Brief vom 21. 01. 1891. Nagel/ Strommenger 1985, $141 \mathrm{ff}$.

87 Belck an Virchow aus Kalakent, Brief vom 14. 08. 1889. Nagel/ Strommenger 1985, $41 \mathrm{ff}$.

88 Belck an Virchow aus Gedebey, Brief vom 08. 03. 1889. Nagel/ Strommenger 1985, $32 \mathrm{f}$.
Belck sprach in seinen Schreiben an Virchow die Vorgehensweise bei seinen Ausgrabungen auch einmal genauer an: ,... Bei Migrier, am unteren Araxes, habe ich zusammen mit einem freundlichen Armenier, den ich sehr für archäologische Ausgrabungen in Ihrem Interesse gewonnen habe, prähistorische Gräber (vom offenen Typus II) gefunden. Wir haben drei derselben mit meinen sechs Kosaken (trotz alle neuerlichen Verfügungen des Ministeriums, welche alle Ausgrabungen ohne Erlaubnis der archäologischen Kommission auf das Strengste untersagen) geöffnet, aber keine Beigaben gefunden ...“89.

Insgesamt dürfte Belck zwischen 1888 und 1891 etwa 350 Kurgane (bei manchen Angaben 370) und prähistorische Gräber geöffnet haben ${ }^{90}$. Geheimrat von Siemens erlangte mit gewisser Wahrscheinlichkeit auch Kenntnis von dieser Tätigkeit, vermerkte doch Belck in einem Brief an Virchow: „Ich benutze gerne die Gelegenheit, es dankbar anzuerkennen, dass mein damaliger Chef, unser verewigter Werner v. Siemens, diese Arbeiten nicht nur bereitwillig gestattete, sondern auch durch den Gedebeker (Gedebey) Generaldirektor Herm William Bolton, in liberalisierter Weise unterstützen ließ ${ }^{\text {“91. }}$. Über die teilweise diffusen Aktivitäten der Gebrüder Siemens im Kaukasus ist noch wenig bekannt, thematisiert wird dies an anderer Stelle ${ }^{92}$.

\section{Das Ende der Grabungen Waldemar Belcks}

Belck kehrte 1891 nach Deutschland zurück, nachdem die vom russischen Zaren entsandte „Kaiserliche Archäologische Kommission“ (ИАК) ihm persönlich weitere Grabungen endgültig untersagt hatte ${ }^{93}$.

Damit endeten jedoch nicht die von Virchow finanzierten Grabungen, es folgte nun von 1892-1903 Emil Rösler ${ }^{94}$, der Virchow damit bis zu seinem Tod 1902 diente. Aus den in St. Petersburg verwahrten Archivalien wird ersichtlich, dass Rösler bereits als korrespondierendes Mitglied ab 1892 für die ИАК arbeitete. Mit Belck hatte Virchow offensichtlich eine Absprache getroffen, wie sich aus Belcks' Briefen entnehmen lässt: „Ich habe während meines Aufenthaltes in Tbilisi übrigens die Überzeugung gewonnen, dass mir die Regierung hier sehr bald das Handwerk legen würde,

89 Belck an Virchow aus Kagisman, Brief vom 28. 06. 1891. Nagel/ Strommenger 1985, $153 \mathrm{ff}$.

90 Nagel/Strommenger 1985, 11.

91 Ebd. 14.

92 Ateshi 2015.

93 Belck an Virchow aus Kalakent, Brief vom 19. 11. 1890. Nagel/ Strommenger 1985, $124 \mathrm{ff}$.

94 Belck an Virchow aus Gießen, Brief vom 07. 09. 1893. Nagel/ Strommenger 1985, 157. 
sobald sie von meinen Ausgrabungen erfahren würde; es soll hier ein Gesetz geben, wonach man für solche Arbeiten die Erlaubnis der Behörden braucht ... Nun muss ich Ihnen zu meinem Bedauern auch noch mitteilen, dass der Geheimrat von Siemens mir von Tbilisi aus schrieb, er und sein Bruder wollten mögliche Differenzen mit den Behörden wegen Ausgrabungen (worunter doch eventuell nur ich zu leiden habe) aus dem Wege gehen, weshalb ich angewiesen sei, diese Arbeiten einstweilen ruhen zu lassen. Das war Anfang Oktober; ich habe aber doch in aller Stille bis zum 9. November weitergearbeitet ..."95. Belck öffnete in diesen 28 Tagen nach dem Verbot seiner Arbeitgeber weitere 45 Gräber $^{96}$.

Belck, dem nun offenbar eine finanzielle Quelle wegbrach, bat Virchow, für die „... Aufhebung dieses Verbotes Sorge zu tragen, was Ihnen ja nicht schwerfallen kann“97.

Damit überschätzte er aber offensichtlich Virchows Einfluss auf Siemens, und wohl auch seine eigene Stellung, denn Virchow konnte oder wollte diesen Wunsch nicht erfüllen. Belck war schließlich gezwungen, Gedebey $\mathrm{zu}$ verlassen. Vorher jedoch engagierte er in Šuša Emil Rösler.

Belck schrieb dazu: ,... Es ist erfreulich, dass Herr Rösler so fleißig weiterarbeitet; hoffentlich gelangt der größere Teil seiner Sammlung dieses Mal nach Berlin ..."98. Virchow bezeichnete Rösler in seinen Publikationen als Archäologen und präsentierte ihn der deutschen Wissenschaft auch als Anthropologen.

\section{Der Ausgräber Emil Rösler}

Als Waldemar Belck 1891 nach Deutschland zurückgekehrt war99, plante Virchow die Fortführung der von ihm finanzierten Ausgrabungen. Dabei kam ihm entgegen, dass sich 1892 der deutschstämmige Gymnasiallehrer Emil Rösler aus Helenendorf (heute Göygöl/Aserbaidschan), für eine Heilbehandlung in Deutschland aufhielt. Virchow nutzte die Gelegenheit für ein Treffen mit Rösler und sprach mit ihm seine Ausgrabungspläne für die nächsten Jahre $a b^{100}$. Bis 1895 grub Rösler dann für Virchow in den Gebieten Berg-Karabach und Gence. Dabei beeinflussten

95 Belck an Virchow aus Kalakent, Brief vom 19. 11. 1890. Nagel/ Strommenger 1985, $124 \mathrm{ff}$.

96 Ebd.

97 Ebd.

98 Belck an Virchow aus Gießen, Brief vom 07. 09. 1893. Nagel/

Strommenger 1985, 156.

99 Nagel/Strommenger 1985, 124.

100 Džafarov 2000, 6. ihn Virchows' und Belcks' Thesen über die kaukasischen Volksstämme, ihre Friedhöfe,und Kirchen Positiv anzumerken ist, dass sich die von Emil Rösler angefertigten Grabungsberichte wesentlich von anderen Publikationen unterscheiden, sie wurden in St. Petersburg ${ }^{101}$ und in der Zeitschrift für Ethnologie veröffentlicht ${ }^{102}$. Seine Thesen können in heutiger Zeit jedoch nicht mehr ungeprüft übernommen werden, sie sind unter den Aspekten moderner wissenschaftlicher Forschung erneut zu überprüfen und zu bewerten.

Die Kaiserliche Archäologische Kommission hatte von Röslers Grabungen bald Kenntnis erlangt und verbat 1894 auch ihm, für Virchow zu arbeiten. Dieses Verbot erfolgte auf Basis der gesetzlichen Bestimmungen des Zarenreichs, nach denen alle Fundstücke in Russland zu verbleiben hatten ${ }^{103}$. Im Gegensatz zu Belck hielt sich Rösler an diese Gesetzgebung und arbeitete von nun ab bis mindestens 1906 weiter nach den Weisungen der Kommission. In einem Brief berichtete E. Rösler Virchow über eine Genehmigung der Kaiserlichen Archäologischen Kommission für Ausgrabungen im Jahr 1894 in Berg-Karabach Šuša, Chodžali, Dovšanli und Arčadzor ${ }^{104}$. E. Röslers' Ausgrabungsberichte wurden meist als Berichte der ИАК archiviert ${ }^{105}$, ihr Inhalt aber findet sich in aserbaidschanischen Zitaten in verfälschter, veränderter oder gelegentlich gar ergänzter Form wieder ${ }^{106}$.

Zahlreiche Berichte Röslers wurden auch in den Verhandlungen der Zeitschrift für Ethnologie (ZfE) veröffentlicht ${ }^{107}$. Fast in jedem Jahr seiner Tätigkeit verfasste er solche mit einem teilweise erheblichen Umfang. Aufgrund der Fülle seiner Veröffentlichungen bietet es sich an, die Angaben und Ausführungen in der ZfE von 1872 bis 1909 genauer $\mathrm{zu}$ betrachten und die damaligen Darstellungen mit den Originalunterlagen sowie neueren Untersuchungen zu vergleichen.

101 Ebd. 7.

102 Rösler 1894, 213; 241.

103 Mahmudov 2008, 13.

104 Rösler 1896a, 77.

105 Archiv IIMK AN SSSR, Fond 1, Dela Archeologičeskij Komissi Nr. 130/1891; 54/1894, 60/1895, 36/1896, 48/1897; OAK za 1894-1897 gg.

106 So u. a. auch bei Džafarov 2000

107 Rösler 1892a; b; 1894; 1895a; b; 1896a; b; 1897; 1898; 1899; 1901;1902a; b; 1903; 1905. 


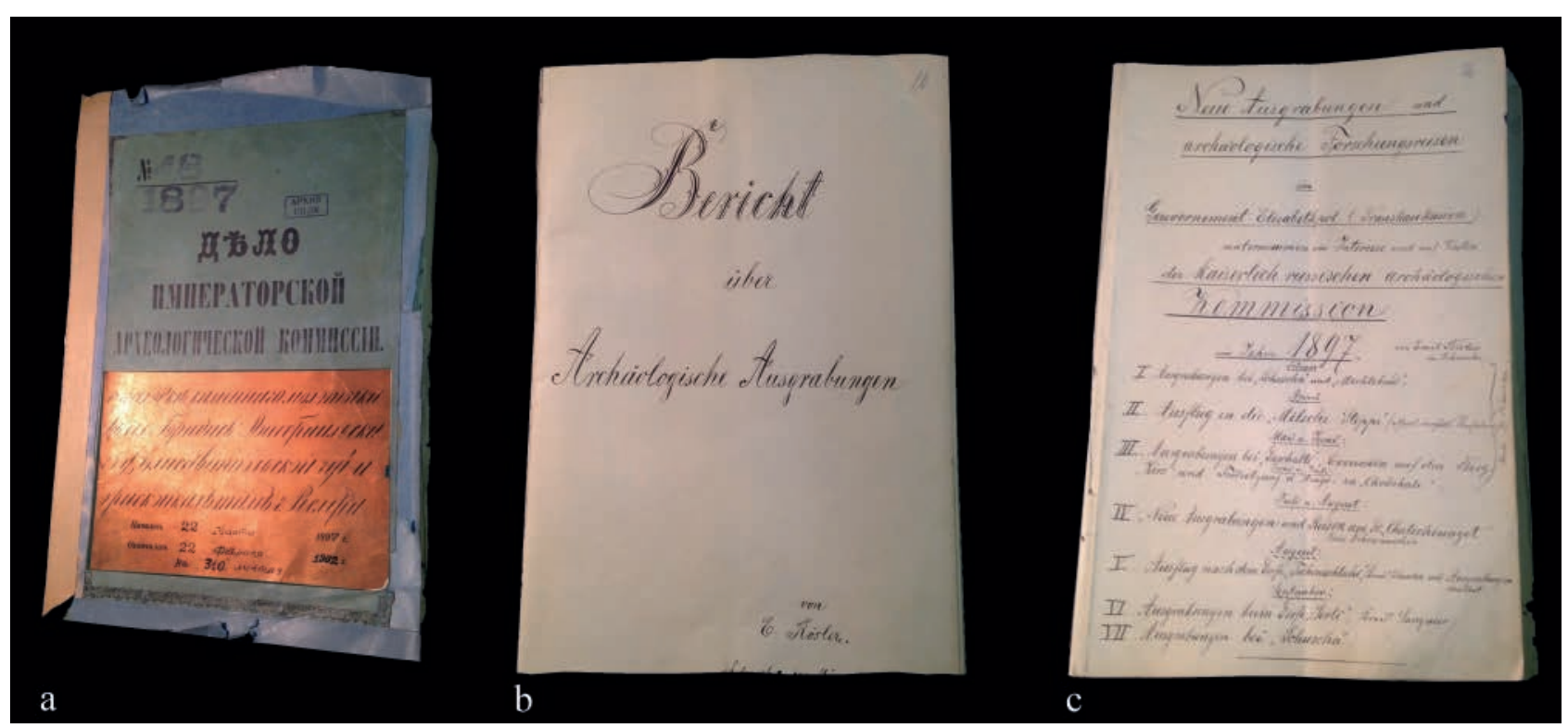

Abb. 13: Berichte von E. Rösler. A: Bericht für die „Kaiserliche Archäologische Kommission“; b-c: Ausgrabungsberichte (St. Petersburg, Archiv des RAN Institut Materialnogo Kultura/Russische Akademie der Wissenschaften, Institut für Materielle Kultur, Foto: N. Ateshi-Gadirova)

\section{Emil Röslers Grabungsberichte - die Originale im Lichte aktueller Forschungen}

Die Kaiserliche Archäologische Kommission in St. Petersburg im RAN Institut Materialnogo Kultura (Russische Akademie der Wissenschaften, Institut für Materielle Kultur) bewahrt heute die Originale der Ausgrabungsberichte Röslers auf (Abb. 13a-c).

Alle Berichte liegen sowohl in Russisch wie auch in Deutsch vor. Liest man diese in beiden Sprachen, so kann man feststellen, dass namhafte und renommierte Archäologen aus Deutschland, Russland oder dem Kaukasus diese Schriften studiert haben und sie auch zitieren, jedoch keiner von ihnen über die Jahre hinweg eine Notwendigkeit sah, die mehrsprachigen Berichte miteinander zu vergleichen.

Koryphäen wie E. Pochomov (1955), I. I. Iessen (1958), Ione (1954), K. Aliev (1958), I. Q. Narimanov (1953), T. Bünyadov (1954) oder H. Džafarov (1987) zogen die Texte zwar für ihre Forschungen als Quellen heran, ihre „Erkenntnisse" mündeten dann jedoch in nationalistisch geprägten Interpretationen, die in den Originaltexten Röslers keine Basis finden ${ }^{108}$.

108 Džafarov 2000. Es genügt nun aber nicht, das Versäumnis eines nicht durchgeführten Vergleichs der Quellen nur für die Zukunft anzumahnen. Vielmehr hat die Verfasserin aus diesem Grunde die

\section{Die Berliner Kaukasus-Sammlung}

Die Kaukasus-Sammlungen des Berliner Museums für Vor- und Frühgeschichte umfassten vor dem Zweiten Weltkrieg mindestens 6.563 inventarisierte Objekte und Objektgruppen. Hinzuzurechnen sind später noch mindestens weitere 500-2.000 Objekte, die bis 1939 nicht in den Inventarbüchern des Berliner Museums erfasst worden waren ${ }^{109}$.

2003 erfolgte die Aufnahme aller in den historischen handschriftlichen Sammlungskatalogen des MVF enthaltenen Objekte mit Herkunftsorten wie „Kaukasien“ in einer Datenbank. In den Folgejahren wurden die Datensätze ergänzt und ausgebaut. Der Zusatz „mindestens weitere 500-2.000 Objekte“ berücksichtigt den Umstand, dass sämtliche Originalbände des Sammlungskataloges „Südrussland“ seit 1945 nicht mehr zugänglich sind (Kriegsverlust) und die 1942 erfolgte Mikroverfilmung (auf die letztlich alle vorliegenden systematischen Objektdaten zurückgehen) leider vereinzelte Lücken aufweist ${ }^{110}$.

Originalberichte Röslers erstmalig mit den deutschen, russischen und aserbaidschanischen Publikationen abgeglichen. Die Veröffentlichung der einzigartigen Dokumente befindet sich in Vorbereitung. Die oben benannten Daten sind daber als der chronologisch fixierte Beleg unpublizierter archivalischer Quelle zu verstehen.

109 Auskunft des Museums für Vor- und Frühgeschichte Berlin durch H. Junker vom 02. 11. 2013.

110 Auskunft des Museums für Vor- und Frühgeschichte Berlin durch H. Junker vom 02. 11. 2013. 
Rudolf Virchow sammelte die ihm übersandten Funde zunächst wie beschrieben im Pathologischen Institut der Berliner Universität, wo sie bis zu seinem Tode am 05. 09. 1902 verblieben.

1903 wurden Belcks' und Korthaus' Sammlungen aus Gedebey zusammen mit anderen Sammlungen von Belck aus der Türkei und Armenien in die Abteilung für Vor- und Frühgeschichte des Berliner Ethnologischen Museums überführt. Hans-Hermann von Schweinitz übergab dem MVF etwa 180 Objekte. Beim Sortieren stellte sich heraus, dass 1901 einige Fundstücke bei einem Brand im Pathologischen Institut der Universität verloren gegangen waren. Trotz dieser Verluste können die Kaukasus-Sammlungen in Berlin vor dem Krieg als sehr groß und umfangreich angesprochen werden.

Albert Voss, erster Direktor der 1886 gegründeten Prähistorischen Abteilung des Museums für Völkerkunde, stellte fest: „Durch diese höchst belangreiche Schenkung würde das königliche Museum für Völkerkunde eine so vollständige Repräsentation Transkaukasiens erhalten, wie sie bis jetzt kein anderes europäisches Museum besitzt, die Museen in Petersburg und Moskau ausgeschlossen. Nur das kleine Museum in Tbilisi würde wie es selbstverständlich ist, reicher an derartigen Funden sein. Die Kaukasusfunde sind bisher im königlichen Museum für Völkerkunde nur äußerst dürftig vertreten und stehen denen in den Museen von Wien, Lyon und Paris ganz bedeutend nach. Allerdings wird die Lücke, welche sich hauptsächlich in der Sammlung Nordkaukasische Altertümer zeigt und welche in den genannten europäischen Museen namentlich in hervorragende Weise vertreten sind, nur zum Teil ergänzt, weil die Belcksche Sammlung die transkaukasischen Ländern umfasst. Das von Belck gesammelte Material zeichnet sich außerdem nicht allein durch Reichhaltigkeit der Formen und die Zahl der Gegenstände, sondern auch besonders dadurch aus, dass es von ihm größtenteils selbst ausgegraben ist, und genau von ihm verfasste Ausgrabungsberichte vorhanden sind“111.

Diese Feststellung zeigt, wie ernst die deutsche Wissenschaft die damaligen Grabungsberichte Belcks nahm, was bis heute zu diversen fachlichen Problemen geführt hat.

Die Sammlungsverzeichnisse des Berliner Museums für Vor- und Frühgeschichte für die Kaukasus-Sammlung gelangten 1945/1946 in die damalige Sowjetunion und befinden sich noch heute in Russland ${ }^{112}$. Da die Originale in Berlin fehlen, arbeitet man dort mit SW-Kopien jener

111 Nagel/Strommenger 1985, 11-12.

112 Auskunft des Museums für Vor- und Frühgeschichte Berlin durch H. Junker vom 02. 11. 2013.
Sammlungsverzeichnisse, die auf Basis einer 1942 erfolgten Mikroverfilmung angefertigt wurden. Die Verfilmung der Inventarbücher erfolgte 1942 jedoch unter Auslassung einzelner Seitenfolgen, und exakt jene Seiten fehlen heute in den rekonstruierten Berliner Inventarbüchern. Es ist davon auszugehen, dass auf diesen fehlenden Seiten weitere Objekte und Objektgruppen mit Kaukasus-Provenienz benannt und beschrieben wurden. Um wie viele Objekte es sich exakt gehandelt haben mag, muss so lange ungeklärt bleiben, bis eine Auswertung der originalen Sammlungsverzeichnisse der Berliner Kaukasus-Sammlung in Russland erfolgt sein wird.

Die meisten Objekte der Kaukasus-Sammlung des Berliner Museums für Vor- und Frühgeschichte wurden während des Zweiten Weltkrieges an geschützte Orte verlagert. Bereits 1941 wurden einige besonders wertvolle Goldfunde der Kaukasus-Sammlung in der Preußischen Staatsbank in Berlin und im sog. Flakturm am Berliner Zoo deponiert ${ }^{113} .1944$ und 1945 gelangten zahlreiche Objekte der Kaukasus-Sammlung in die Keller des Berliner Stadtschlosses und in die Salzbergwerke Grasleben bei Helmstedt sowie Schönebeck bei Magdeburg ${ }^{114}$. Die im Flakturm am Zoo (einem Hochbunker) und im Berliner Stadtschloss geborgenen Teile der Kaukasus-Sammlung gelangten nach Ende des Zweiten Weltkrieges in die Sowjetunion, jene in den Salzbergwerken Grasleben und Schönebeck befindlichen Sammlungsteile wurden vorübergehend im britischen Kunstgutdepot Schloss Celle verwahrt. Von dort gelangten jene Objekte zwischen 1956 und 1958 nach Berlin zurück ${ }^{115}$, während die in die Sowjetunion verbrachten Gegenstände aus der Berliner Kaukasus-Sammlung in Russland verblieben, in verschiedenen Museen von Moskau und St. Petersburg liegen und bis heute für individuelle wissenschaftliche Forschungen unzugänglich sind.

Schon als 1903 die Grabfunde Belcks' in die damalige Prähistorische Abteilung des Völkerkundemuseums überführt wurden, hatten sie Verluste erlitten ${ }^{116}$. Ein Brand im

113 Auskunft des Museums für Vor- und Frühgeschichte Berlin durch H. Junker vom 02. 11. 2013. Die im Flakturm am Zoo eingelagerten Edelmetall-Objekte kaukasischer Provenienz sind weitgehend identisch mit den im Inhaltsverzeichnis der sog. drei Goldkisten des Berliner Museums für Vor- und Frühgeschichte aufgeführten Gegenständen dieser Herkunft. Vergleiche dazu Goldmann/Reich 1996, 42. 114 Auskunft des Museums für Vor- und Frühgeschichte Berlin durch H. Junker vom 02. 11. 2013 und 23. 01. 2014. Zu den einzelnen Sicherungs- und Verlagerungsmaßnahmen vergleiche Goldmann/ Reich 1996, 11-19; 24-25.

115 Staatliche Museen zu Berlin, Preußischer Kulturbesitz, Dokumentation der Verluste, Band IV. MVF, 21-23.

116 Nagel/Strommenger 1985, 9. 
Pathologischen Institut der Universität im Jahre 1901 hatte wie beschrieben einen Teil zerstört ${ }^{117}$.

Weitere Grabfunde Belcks haben gewiss auch durch den Brand des Museums für Vor- und Frühgeschichte am 3. 02.1945 gelitten. Unter den ausgeglühten nummernlosen Metallobjekten und in hunderten von Kisten mit zerbrochenen, zum Teil durch Brandhitze versinterten Keramiken, die aus den Trümmern des Museums geborgen werden konnten, befinden sich mit hoher Wahrscheinlichkeit auch Objekte der Sammlung Belck ${ }^{118}$. Bisher konnten die im Museumsarchiv befindlichen Kisten nur teilweise zugeordnet und bearbeitet werden, für die Mehrzahl trifft dies nicht zu.

Bei künftigen Forschungsarbeiten in den russischen Museen (Eremitage St. Petersburg, Historisches Museum Moskau und im Staatlichen Museum für Bildende Künste A. S. Puschkin) müsste gemeinsam mit russischen Forschern nach Objekten mit den Inventarnummern des MVF gesucht werden. Im MVF befinden sich außerdem mehr als 50 Kisten Keramikschutt aus der Kriegszeit, deren Identifizierung bis heute nicht gelang. Anzunehmen ist, dass eine nicht unbeträchtliche Anzahl der ursprünglichen Objekte während des Zweiten Weltkrieges unrettbar verloren ging ${ }^{119}$.

1945 - nach dem Sieg über das „Dritte Reich“ wurden auf Anweisung des Komitees für Angelegenheiten der Künste beim Ministerrat der UdSSR unter den Inventarnummern 6 und 7, Fundus № $962^{120}$ zahlreiche Kisten abtransportiert, die mit Artefakten gefüllt waren und als Kriegsbeute in die UdSSR gebracht wurden. Diese sog. „Beutekunst“ gelangte in das Puschkin-Museum in Moskau, 1946 in die Orient-Abteilung der Eremitage in St. Petersburg sowie in andere Museen zur vorübergehenden Aufbewahrung ${ }^{121}$.

Gegenwärtig befinden sich von der Fundstelle Gedebey und seiner Umgebung nur noch ca. 158 Exponate im Berliner MVF ${ }^{122}$. Erfolg versprechend wäre es möglicherweise, auch in anderen Museen Deutschlands nach weiteren Spuren zu suchen.

117 Ebd.

118 Ebd. 10.

119 Nagel/Strommenger 1985.

120 Die Akten werden im Russischen Staatsarchiv für Literatur und Kunst (РГАЛИ) in Moskau aufbewahrt.

121 Die Verfasserin des Beitrags stieß am 04. 06. 2014 bei ihren Recherchen im Russischen Staatsarchiv für Literatur und Kunst (RSALK) in Moskau auf diese Fakten. Weitere Forschungen wurden ihr anschließend versagt.

122 Auskunft H. Junker vom 10. 02. 2014.

\section{Die Sammlung Frank Korthaus}

Ein Teil der Exponate im Berliner MVF stammt vom Sammler Frank Korthaus ${ }^{123}$. Dieser hielt sich gleichzeitig mit Waldemar Belck in Gedebey auf. Bei seiner Sammlung handelt es sich um eine Kollektion von etwa 130 Fundobjekten aus der späten Bronze- und frühen Eisenzeit, die aus der direkten Umgebung von Gedebey stammen. Korthaus erwarb diese über einen längeren Zeitraum und übergab sie schließlich Belck zur Bearbeitung und weiteren Verwertung ${ }^{124}$. Dies erschließt sich aus einem Bericht zur Herkunft der Sammlung, die Belck Rudolf Virchow in Gedebey übergeben hatte ${ }^{125}$. Auch diese Sammlung wurde von W. Belck erworben, der die Exponate nach Absprache mit Virchow aufgekauft hatte. Auf diesem Wege gelangten jene Stücke der Sammlung Korthaus zusammen mit Belcks Funden aus Gedebey nach Berlin.

\section{Die Sammlung Hans-Hermann Graf von Schweinitz}

Weitere Sammlungsbestandteile des MVF gehen auf HansHermann Graf von Schweinitz - Kavallerieoffizier und seit 1840 Mitglied der BGAEU - zurück. Dieser übergab dem MVF etwa 180 Objekte $^{126}$. Soweit es aus der Erwerbungsakte zu dieser Sammlung ersichtlich wird, war von Schweinitz nicht selbst Ausgräber der Artefakte ${ }^{127}$. HansHermann Graf von Schweinitz unternahm den archäologischen Versuch, 28 aus Dsegam stammende Gräber mit schlichten Handzeichnungen in eine chronologische Reihenfolge zu bringen. Dabei bezeichnete er im Stil dieser Jahre das gesamte Gebiet zwischen der Bahnstrecke von Dsegam (Zeyem N.A.) und der Kupferfabrik von Gedebey als ,armenische Hochplateau“.

Er vermerkte in seinem Bericht: „Die Ausgrabungen wurden ausgeführt auf dem Gute des Fürsten Schamchorski, im Gouverment Jelisawetpol [heute Gence] $40 \mathrm{Grad}$ n.br.,64 Grad östl. L.; das riesige Gut, es umfasst ein Areal von ca. $300 \mathrm{qkm}$, beginnt in der Kuraebene bei der Eisen-

123 Auskunft des Museums für Vor- und Frühgeschichte Berlin durch H. Junker vom 10. 02. 2014.

124 Nagel/Strommenger 1985, 11.

125 Ebd. 13.

126 Erwerbungsakte zur Sammlung des Grafen H.-H. von Schweinitz im Berliner Museum für Vor- und Frühgeschichte: SMB-PK/MVF, IA 14, Bd. 23, E 2051/13.

127 Auskunft des Museums für Vor- und Frühgeschichte Berlin durch H. Junker vom 02. 11. 2013. Informationen zur Sammlung Graf von Schweinitz siehe im Katalog: Kohlmeyer/Saherwala 1983, 64-67. 
bahn Station Dseqam [Zeyem], zieht in südliche Richtung weit auf das armenische Hochplateau bis in die Mitte des Kupferberges Kedabek [Gedebey], gehörig der Firma Geb. von Siemens in Berlin, und wird im Osten vom Gebiergsfluß [sic!] Schamchor begrenzt. Dank der südlichen Lage ist das Klima sehr milde, in der Ebene ist der Winter sehr kurz und im Gebirge liegt der Schnee auch nur 3 Monate und meist nur an den Nordabhängen. Grabstätten aus grauer Vorzeit gibt es auf dem ganzen Gebiet in sehr großer Zahl. Ausgegraben wurden sowohl in der Ebene, als auch im Gebirge im ganzen 28 Gräber“.

Bis heute wurden Aussagen wie diese in der Forschung immer wieder übernommen. Trotz der Fehlerhaftigkeit seiner Zuweisungen dürften von Schweinitz Aufzeichnungen und seine Fotosammlung für zukünftige Forschungen zur späten Bronze- und frühen Eisenzeit tatsächlich nützlich sein, eine kritische Überprüfung der in ihnen niedergelegten Fakten ist jedoch vorauszusetzen. Von Schweinitz beschrieb wie bereits seine Vorgänger Belck, Haupt, Bayern und Rösler, das gesamten Gebiets Gedebeys als „Armenisches Hochplateau”, oder auch Bestattungen als „vorgeschichtliche armenische Gräber“. Diese fehlerhaften Zuweisungen fanden Aufnahme in die Forschung und wurden bis in heutige Tage übernommen.

Grabungsberichte und Originalfotos von Schweinitz, die vor Ort im Gebiet des Zeyem (Aserbaidschan) gefertigt wurden, befinden sich glücklicherweise in den Erwerbungsakten des MVF in Berlin und können für zukünftige internationale Forschungen als objektive und wissenschaftlich verlässliche Quelle herabgezogen werden. Das Becken des Flußes Zeyem zählt als Ursprungsregion der in die späte Bronze- und frühe Eisenzeit datierenden Chodžali-Gedebey Kultur, von hier aus erfolgte ihre Verbreitung. Eine fehlerhafte Verortung bedeutender Fundplätze hat dementsprechend Auswirkungen auf die Forschung zu dieser und mit ihr in Kontakt stehender Kulturen. Es zeigt sich, dass der internationalen Forschung diese Problematik bislang nicht ausreichend bewusst war, so dass es dringend weiterer Untersuchungen gerade auch alter Quellen bedarf.

\section{Die Kaukasus-Forschung während der Sowjetzeit - zum Einfluss des Marxismus-Leninismus}

Nach der Oktoberrevolution am 07. 11. 1917 war es das Ziel der Bolschewiki, in den einzelnen nun entstandenen Sowjetrepubliken auf Basis der jeweiligen nationalen Tra- ditionen eine sozialistische Kultur zu entwickeln. Dabei wurden die archäologischen Denkmäler zum nationalen Erbe des gesamten Sowjetvolkes erklärt. Es entfalteten sich in den Folgejahren eine ganze Reihe von Aktivitäten sowohl auf administrativer Ebene als auch in wissenschaftlicher Hinsicht, um diesen Plan mit Leben zu erfüllen. 1920 wurde in Aserbaidschan das „Staatliche Historische Museum“ und 1923 das „Aserbaidschanische Archäologische Komitee“ gegründet. Ab 1926 kamen sowjetische Wissenschaftler nach Aserbaidschan, wie etwa I. I. Meššaninov (1926). J. A. Pachomov führte 1934 Ausgrabungen durch, und für die Jahre von 1938 bis 1940 ist J. I. Hummel anzuführen, der im Süden Aserbaidschans Grabungen vornahm. In den Kriegsjahren fanden keine weiteren wissenschaftlichen Unternehmungen statt.

Auf archäologischer Ebene setzte man sich mit der Untergliederung der archäologischen Kulturen auseinander. Heute sind die Kulturdenkmäler aus der Spätbronze- und Früheisenzeit im Südkaukasus in der archäologischen Literatur unter drei Namen bekannt: Zentralsüdkaukasische Kultur, Gence-Karabach Kultur und Chodžali-Gedebey Kultur ${ }^{128}$.

1929 unterteilte A. V. Schmidt die bronzezeitlichen Denkmäler des Kubangebietes in die drei Stufen Früh-, Mittel- und Spätkubanisch ${ }^{129}$. A. A. Iessen führte in den 1930er Jahren erstmals den Begriff „Nordkaukasische Kultur" für die bronzezeitlichen Fundgruppen aus dem Nordkaukasus ein und ordnete sie seiner „zweiten Etappe der Metallurgie“ $\mathrm{zu}^{130}$.

Ausgrabungen fanden an unterschiedlichen Orten statt. Im Umland von Helenendorf (heute Göygöl, Aserbaidschan) grub 1930 Jakob I. Hummel, in Nordossetien bis 1940 E. I. Krupnov ${ }^{131}$. Während der weiteren Sowjetzeit dann haben vor allem Russen im Kaukasus geforscht, aber auch Georgier, Armenier und Aserbaidschaner.

Für die Entwicklung und die weitere Geschichtsschreibung von Bedeutung waren B. B. Pjotrovskij, I. M. Dyakonov, H. F. Fyodorov, I. I. Meššaninov, A. A. Miller, A. A. Iessen, T. S. Passek, B. A. Latinin, A. B. Aršikovskij, E. I. Krupnov, S. M. Gazıyev, A. M. Apakidze, İ. M. Džafarzada, V. Bahšaliyev (2006), R. B. Göyüşov, A. I. Martinov (1991), R. M. Vahidov (1961), O. H. Habibullayev (1959), T. Bünyadov, H. Orucov, A. Janovskij (1846), Q. K. Nioradze, Q. N. Čubinišvili, V. V. Bjanijanin, B. A. Kuftin und andere mehr.

128 Göyüšov/Martinov 1990, 114.

129 Schmidt 1929, 9-21.

130 Iessen 1935.

131 Motzenbäcker 1996, 30. 
Diese russischen, georgischen, armenischen und aserbaidschanischen Forscher zitierten in ihren Werken regelmäßig J. de Morgan, E. Chantré, R. Virchow, W. Belck, F. Bayern und E. Rösler. Dabei wurden die Schriften der Vorgenannten als seriöse Quellen verwendet, ihre Thesen als glaubhaft bezeichnet, der Einfluss jener Ausgräber auf die folgenden Autoren ist dabei bisweilen deutlich sichtbar.

Dennoch gab es auch einen kritischen bzw. korrigierenden Umgang mit diesen Schriften. So zog etwa B. B. Pjotrovskij jene Werke häufig heran, er korrigierte jedoch beispielsweise fehlerhafte Ortsnamen und geografische Zuordnungen. Trotzdem müssen Pjotrovskijs Veröffentlichungen über die südkaukasische Geschichte, besonders hinsichtlich Urartu, überprüft und im Lichte der heutigen Erkenntnisse neu bewertet werden ${ }^{132}$.

\section{Die postsowjetische Zeit - Nationalismus und andere Probleme der aktuellen Forschung}

In den Nachfolgestaaten der Sowjetunion lassen sich in der gegenwärtigen Forschung oftmals starke Tendenzen einer Nationalisierung erkennen, was sich etwa auch auf die Geschichtsschreibung zur jeweiligen Vor- und Frühgeschichte auswirkt. Diese Tendenz setzte nach dem Zerfall der UdSSR ein und betrifft die unterschiedlichsten archäologischen Ebenen.

Vorauszuschicken ist, dass jene heute nationalistisch geprägten Wissenschaftler während der Sowjetzeit ausgebildet wurden und ihre akademischen Grade unter sowjetischer Herrschaft in Moskau, St. Petersburg oder Erewan erwarben. Eine der staatlichen Vorgaben jener Zeit war es, den Südkaukasus als homogenes Kulturgebiet anzusehen. Diese Vorgabe zieht sich dementsprechend wie ein roter Faden durch einzelne Arbeiten ${ }^{133}$. Nach dem Ende der Sowjetzeit machten sich einige Forscher daran, dieses durch die Homogenisierung entstandene vermeintliche archäologisch-soziokulturelle Vakuum zu füllen, indem sie in Darstellungen der späten Bronze- und frühen Eisenzeit fälschlicherweise einen türkischen Einfluss einfügten und sogar jene ganze für den Kaukasus dominierende Epoche als von Türken geprägt beschrieben.

Dieser Einfluss wirkt bis heute fort und äußert sich im Versuch der Türkisierung von Schul- wie Lehrbüchern und betrifft sogar Altlanten zur vorgeschichtlichen Zeit.

132 Pjotrovskij, 1949.

133 Siehe etwa die Untersuchungen H. Džafarovs.
Die Türkisierung erfolgt beispielsweise durch ethnische Zuweisungen. So spricht etwa der aserbaidschanische Archäologe Z. Hasanov die Skythen in seiner Dissertation „Car skifler“ (Kaiserliche Skythen) als Turkvolk $\mathrm{an}^{134}$, weist sie entsprechend einer wesentlich jünger definierten Sprachgruppe und Ethnie zu.

Seiner Ansicht nach sind die im 8. Jahrhundert vor Chr. nach Aserbaidschan kommenden und dort sesshaft werdenden Skythen und Kimmerer als Türken anzusehen, die damit auch als Urheber der sich in Aserbaidschan entwickelnden Chodžali-Gedebey-Kultur anzusehen wären. Hinsichtlich der Skythen handelt es sich nach allgemein anerkanntem Stand der Forschung um ein Konglomerat heterogener Reitervölker mit unterschiedlicher Herkunft, die jedoch alle eine reiternomadische Lebensweise pflegten. Sie hinterließen keine Schriftquellen, jegliches Wissen über sie beruht auf Bodenfunden bzw. den Fremdzuweisungen und Ansprachen der Historiographen anderer Völker, etwa dem griechischen Schriftsteller Herodot. Turkvölker werden in dieser Zeit allenfalls im chinesischen Kaiserreich als solche vermutet - was ebenso umstritten ist - nicht jedoch im Kaukasus.

Hasanovs Werk wurde auf Beschluss der Staatlichen Universität Baku mit Genehmigung der Aserbaidschanischen Akademie der Wissenschaften in verschiedene Sprachen übersetzt und findet eine weite Verbreitung.

Ein weiteres Beispiel hinsichtlich ethnisch nationaler Zuweisungen betrifft die Darstellungen mit Bögen bewaffneter Frauen, die auf neolithischen bzw. frühbronzezeitlichen Felszeichnungen in Gobustan entdeckt wurden. Der Forscher E. Farzali deutete sowohl diese Bewaffnung als auch die Trägerinnen um, indem er diese als aserbaidschanisch-türkische Musikerinnen ansprach, die die traditionelle orientalische Tar oder Ud mit einem Bogen spielten ${ }^{135}$.

Eine weitere Behauptung stammt von V. Aliev, der feststellte, dass „Turkvölker“ wie die Nachči und Gergez während der Bronze- und frühen Eisenzeit im Tal des mittleren Araz, in Berg-Karabach und in den nördlichen Regionen des Südkaukasus gelebt und dort die Gesellschaft, Wirtschaft und Kultur der alten, autochthonen aserbaidschanischen Völker des 3. bis 2. Jahrtausends vor Chr. geprägt hätten ${ }^{136}$.

In Dagestan versucht sich derweil der Historiker Jarali Jaraliyev in seinen Werken ${ }^{137}$ an einer Nationalisierung

134 Hasanov 2005.

135 Farzali 2008, 64-65.

136 Aliyev 2013, $76 \mathrm{f}$.

137 Jaraliyev/Osmanov 2003. 
der Geschichte des kaukasischen Albania, die er als Geschichte der Lezgier darstellt, einem der zahlreichen kaukasischen Völker der Gegenwart.

Problematisch ist in diesem Kontext die Annahme, ein breiter internationaler Kontakt könnte dazu beitragen, die hier aufscheinenden, von nationalistischen und nationalethnischen Vorstellungen geprägten Vorstellungen als Fehlentwicklungen zu kennzeichnen oder gar als unwissenschaftlich zu brandmarken. Dem steht jedoch die Struktur der heutigen Forschung entgegen. Nach der Sowjetzeit reisten unterschiedliche internationale Forschergruppen in die einzelnen Länder und nahmen an Tagungen teil oder besuchten einzelne Forschungsinstitutionen, andere wiederum kamen und kommen auf Einladung in die Kaukasusländer und verbleiben nur kurz vor Ort. Einige Ausgrabungsteams halten sich nur kurz - in der Regel zwischen drei und maximal fünf Jahren - im Land auf und führen Ausgrabungen durch. Diese Ausgräber benötigen die Hilfe orts- wie sprachkundiger Einwohner, da die jeweiligen Landessprachen von den Wissenschaftlern nicht oder nur bruchstückhaft beherrscht werden.

Entsprechende Teams verfügen oftmals über keinen Zugang zu regionalen Archiven, Bibliotheken oder ortsansässigen Forschern, und je nach Fragestellung werden nur kleinere Forschungsgebiete untersucht, kaum jedoch umfangreiche Perspektiven in den Blick genommen.

Entsprechend dieser gravierenden Hürden auf sprachlicher Seite - die wenigsten ausländischen Forscher sprechen oder lesen russisch odergar aserbaidschanisch - ist es eine zwangsläufige Folge, dass ein erheblicher Teil der einheimischen Literatur wie auch der sowjetischen bzw. prä-sowie postsowjetischen Geschichtsschreibung weder gelesen noch bewertet werden kann.

Wichtig ist dabei auch die Feststellung, dass die archäologische Geschichte des Kaukasus überwiegend in Russisch und Deutsch verfasst wurde, aber auch auf Georgisch, Armenisch und Aserbaidschanisch. Es ist daher nicht verwunderlich, wenn es beim Versuch der Erforschung der Archäologie eines dieser Länder ohne Kenntnis der örtlichen Sprachen bei der anschließenden Publikation der Ergebnisse in Artikeln, Monografien oder auch unter Abfassung umfangreicher Dissertationen zu mitunter gravierenden Fehlern kommt. Die Notwendigkeit des raschen Publizierens der Ergebnisse entsprechender Ausgrabungen, um andernorts neue Ausgrabungsgenehmigungen zu erhalten, führt in der Folge ebenso wenig zu qualitätvoller Forschung. Es lässt sich dementsprechend auch immer wieder erkennen, dass alte Publikationen in „gängigeren“ Sprachen Verwendung finden und die dort veröffentlichten, $z$. T. veralteten Behauptungen nicht hin- terfragt, sondern fortgeschrieben werden ${ }^{138}$. Ein weiteres Problem bei jenen Projekten stellt die Feststellung dar, dass abgesehen von den benannten Sprachproblemen häufig auch solche Archäologen tätig sind, deren eigentliche Spezialisierung in anderen Forschungsgebieten oder Perioden liegt.

Die geschilderten Probleme summieren sich bei der Erforschung des Kaukasus. Andere zeigen sich in der Nichtbeachtung des Verlustes einheimischer Kulturgüter, etwa bei der „Umnutzung “ und damit Zerstörung von Teilen eines UNESCO-Kulturerbes (Gobustan) (Abb. 14), um das gewonnene Baumaterial für den Hochhausbau $\mathrm{zu}$ verwenden ${ }^{139}$. Teilweise wurden auch Gräberfelder zerstört, um die Vorgeschichte, deren Kenntnis nicht im nationalistischen Sinne war, in Vergessenheit geraten zu lassen. Auf der einen Seite steht somit ein ausländisches Engagement im jeweiligen Land zur Erforschung unbekannter Fundstellen, auf der anderen Seite aber das Ignorieren vorhandener Literatur, sonstiger Quellen und auch der Zerstörung bereits ergrabener Kulturgüter.

Erschwerend kommt bei der Erforschung der späten Bronze- und frühen Eisenzeit des Kaukasus hinzu, dass die archäologischen Publikationen meist in deutscher, französischer und russischer Sprache verfasst wurden. Mit der Unabhängigkeit der ehemaligen Unionsrepubliken nach dem Zerfall der Sowjetunion gewannen die jeweiligen Landessprachen an Bedeutung, so dass archäologische Forschungsergebnisse von nun an für eine internationale Forschungsgemeinschaft in noch fremderen, d.h. unzugänglicheren Idiomen verfasst werden, und diese teilweise von einer nationalen Sichtweise durchzogen sind, wie sie etwa im mitteleuropäischen Raum inzwischen unüblich sind. Ein Vergleich verschiedensprachiger Darstellungen steht dabei aus, eine Diskussion und Neubewertung entsprechender Studien wäre daher dringend nötig.

Ein weiteres großes Problem, nicht nur der im Beitrag thematisierten Regionen, aber hier insbesondere, stellt das Faktum dar, dass Ausgrabungsdokumentationen wie auch archäologische Funde bisweilen als Besitzstände ihrer Ausgräber begriffen werden, wie dies etwa die Ausgrabungen von Gobustan betrifft ${ }^{140}$. Forschungen werden so behindert oder gar verhindert.

Ebenso - wenn nicht noch gravierender - sind die sich seit Ende der 1980er Jahre verschärfenden Konflikte

138 Anati 2001.

139 Ateshi 2011, 16-18.

140 Die Originalfundstücke der Untersuchungen werden auch 30 Jahre nach den Ausgrabungen von der Grabungsleitung noch privat verwahrt, ein Zugang nicht gewährt, weitere Untersuchungen sind dementsprechend blockiert. Die nicht sachgemäße Lagerung der Objekte dürfte sich auf die Artefakte ebenfalls nachteilig auswirken. 

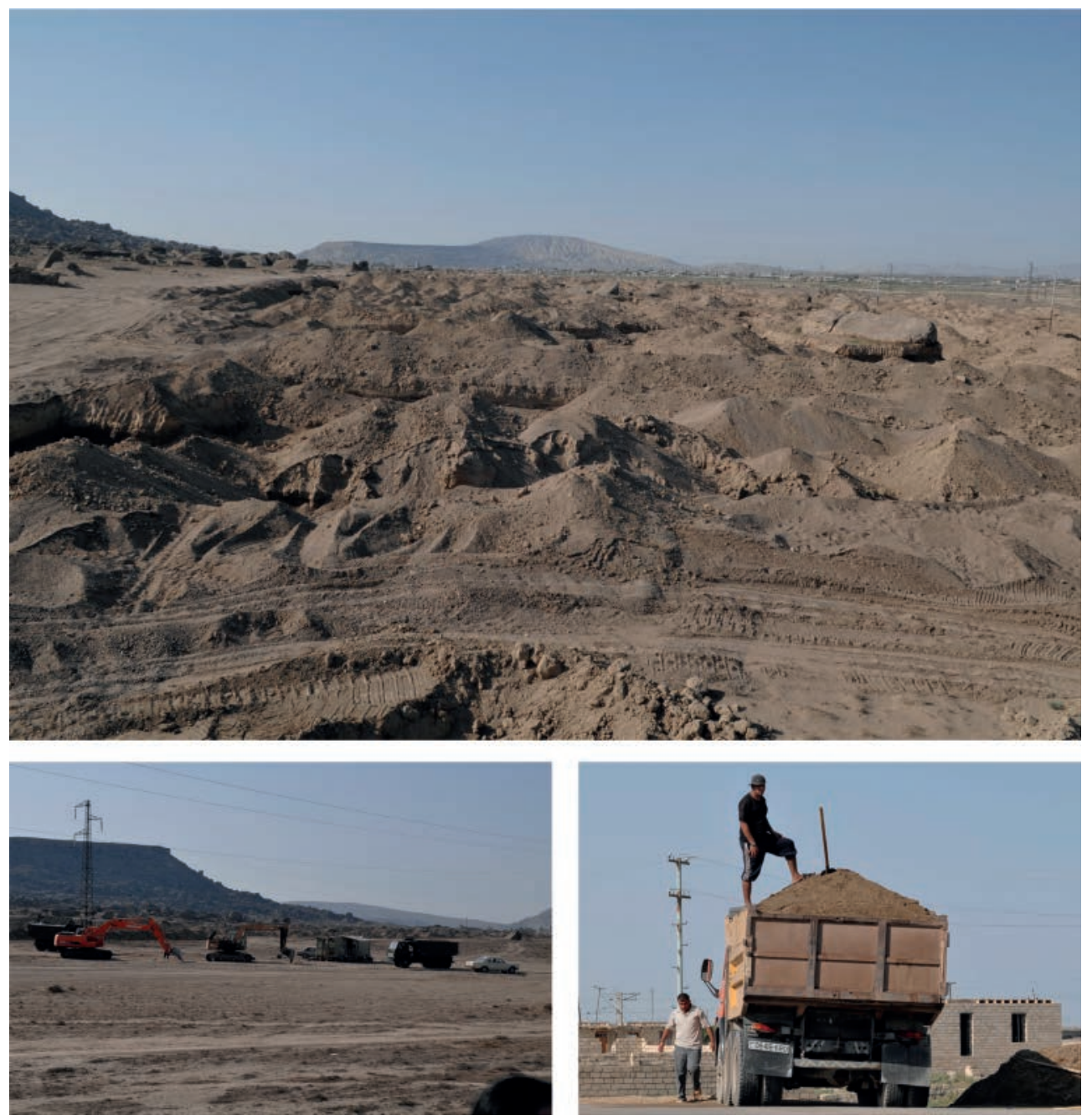

Abb. 14: Sandabbau auf dem als UNESCO Kulturerbe geschützten Gebiet von Kičik Daš (Kleiner Stein) in Gobustan (Foto: N. Ateshi-Gadirova)

um Berg-Karabach, eine Region des Kleinen Kaukasus, um deren territoriale Zugehörigkeit zwischen Armenien und Aserbaidschan Kriege geführt wurden.

Symptomatisch ist wohl auch, dass mit der zunehmenden Bedeutung des Konfliktes um Berg-Karabach die Geschichtsschreibung begann, sich von den bisherigen sowjetisch bestimmten Vorstellungen zu lösen und kleinstaatliche nationale Ideologien präferierte.

So wurden in kaukasischen Ländern wie Aserbaidschan durch Türkisierung dominierte Werke veröffentlicht, wohingegen in Armenien insbesondere von nationalen Sichtweisen beeinflusste Publikationen Verbreitung fanden, die als historischen Ansatz bereits für die Vor- und Frühgeschichte ein Großarmenien „Vom kaspischen Meer bis zum Schwarzen Meer“ postulieren. Auffällig ist in diesem Kontext, dass nach dem Zerfall der Sowjetunion sowohl Forschungen zum Südkaukasus wie auch der ge- genseitige wissenschaftliche Austausch zurückgegangen sind.

Veränderte wirtschaftliche Prioritäten führten wiederum zu eingeschränkten finanziellen Möglichkeiten für Ausgrabungen, was die Erforschung der späten Bronzeund frühen Eisenzeit des Südkaukasus noch zusätzlich behindert.

Die in jüngerer Zeit im Südkaukasus erfolgenden internationalen archäologischen Untersuchungen konnten dieser Problematik nicht ausrechend Rechnung tragen, so dass sich Fehlentwicklungen weiter fortsetzten und zahlreiche Forschungsfragen unbeantwortet blieben, ferner Museumsarchivalien nicht weiter angegangen wurden und generell chronologische und typologische Fragen hinsichtlich der in die späte Bronze- und frühe Eisenzeit des Südkaukasus datierenden Chodžali-Gedebey-Kultur offen blieben. 


\section{Die Neubelebung deutscher Forschungen im Kaukasus}

Nicht allzu lang nach der historischen Wende 1989/1990 und der darauf folgenden Auflösung der Sowjetunion wurde es auch der deutschen Archäologie wieder möglich, jenseits des ehemals „Eisernen Vorhanges“ zu forschen, etwa im Südkaukasus. So begann das Deutsche Archäologische Institut (DAI) bereits 1991 einen wissenschaftlichen Austausch mit dem Zentrum für Archäologische Forschungen in Tbilisi, Georgien. Das DAI gründete ferner 1995 die Eurasien-Abteilung mit einem Forschungsschwerpunkt im Kaukasus; tatsächlich dauerte es jedoch etwas länger, bis aktive Ausgrabungen stattfanden, die 2004 in Georgien begannen.

Aktive Feldforschungen zum Siedlungswesen der Bronze- und Eisenzeit fanden bereits seit den frühen 1990er Jahren in Kachetien (Ostgeorgien) statt und wurden von den Universitäten Saarbrücken (W. Orthmann, Grabung in Ananauri), Halle (A. Furtwängler, Grabung in Gumbati) und Tübingen (G. Mansfeld, Grabung in Tqisbolo Gora; M. Korfmann, Grabung in Didi Gora) durchgeführt, wobei es z. T. bereits ab 1996 eine Unterstützung durch das DAI gab (A. Furtwängler und I. Motzenbäcker, Grabungen in Ciskaraant-Gora und Noname Gora) bzw. diese ab 2004 fortgesetzt wurden (I. Motzenbäcker, Grabung in Tachtiperda).

$\mathrm{Ab} 2005$ sind einige ständige multinationale archäologische Expeditionen im südlichen Georgien zu verzeichnen, ab 2009 auch für die südkaukasische Milsteppe in Aserbaidschan. Diese Expeditionen widmen sich den früheren Perioden, etwa dem Neolithikum (B. Lyonnet [DAI], Grabung in Kamiltepe, Aserbaidschan), oder thematisch der Zeit des frühen Ackerbaus (S. Hansen/G. Mircxulava, Grabung in Tell Aruchlo) sowie dem prähistorischen Bergbau (Ruhruniversität Bochum/Deutsches Bergbaumuseum Bochum, Grabung in Sakdrisi).

Auch in Armenien haben sich deutsche Wissenschaftler in der Feldforschung verdient gemacht, so in den 1990er Jahren die Universität München (S. Kroll) in der eisenzeitlichen, vorurartäischen Siedlung Horom. Seit 2010 erforscht eine multinationale und interdisziplinäre Forschergruppe das Gebiet um den Sevansee. Aus Deutschland nehmen an dieser Expedition das Curt-Engelhorn-Zentrum Archäometrie gGmbH (CEZ) in Mannheim mit E. Pernicka und das Landesmuseum sowie die Universität Halle mit H. Meller und A. Furtwängler teil.

Untersuchungsschwerpunkte sind der prähistorische Goldbergbau, Gräberfelder und Siedlungen im Umfeld der Bergwerke, ferner prähistorische Felsbilder sowie achämenidische Siedlungen. Nachdem bereits 2011 ein erster kleinerer Survey vorgenommen wurde, konnte im Sommer 2012 dank der großzügigen Unterstützung des Auswärtigen Amtes in einem breit angelegten Projekt damit begonnen werden, den außerordentlich reichen Bestand an Felsbildern umfassend und interdisziplinär wissenschaftlich zu dokumentieren ${ }^{141}$.

Zu kritisieren ist jedoch an dieser Stelle, dass die Untersuchungen und Forschungen sich zu sehr örtlich und regional auf die Dokumentation der Felszeichnungen in Armenien beschränken. Wichtiger wäre es, den gesamten Südkaukasus in den Blick zu nehmen und ihn als zusammenhängenden Kulturraum zu betrachten, in dem Funde aus derselben Periode miteinander verglichen und gemeinsam bewertet werden sollten. So kann sich nur in der Zusammenschau und im Vergleich der Felszeichnungen aus Ughtasar mit jenen aus Gemigaya, aus Gobustan oder mit den sich in der Nähe befindlichen Petroglyphen in Berg-Karabach ein überzeugendes und schlüssiges Gesamtbild ergeben, das auch für die zukünftige Forschung Perspektiven bereit hält.

Letztere Petroglyphen in Berg-Karabach datieren identisch wie jene gegenwärtig untersuchten, der Kulturraum, in denen sie entstanden, ist identisch, entsprechend wäre gerade ihr Einbezug von großer Wichtigkeit. Auf Basis dieses so ersichtlich werdenden einheitlichen Kulturraumes stellt sich auch die Frage nach einer gemeinsamen kulturellen Identität jener Menschen, die diese damals auf die Felsen zeichneten, dies lange vor der Entstehung der heutigen südkaukasischen Staaten mit ihren künstlichen Grenzen und den heutigen religiösen und ethnischen Gegensätzen.

Die Bedeutung der Fundplätze zeigt sich bereits darin, dass die Petroglyphen von Gobustan bereits seit 2007 mit zum UNESCO-Weltkulturerbe gehören, für Gemigaya sollte dies ebenso angestrebt werden.

Die gegenwärtigen Untersuchungen erinnern dabei in ihrer regional fokussierten Ausrichtung - nicht von ihrer Methodik und Herangehensweise - an die Forschungen etwa eines Rudolf Virchows oder auch anderer Wissenschaftler, die einzelne Fundplätze mehr oder minder systematisch untersuchten und von hier aus weitreichende Schlüsse zogen. Wichtig wäre es jedoch, wie bereits mehrfach betont wurde, den gesamten kaukasischen Raum in den Blick zu nehmen und beispielsweise mittels der gemeinsamen Erforschung nachhaltig prägender prähistorischer Kulturen eine neue Sicht auf die Region zu bekommen.

141 http://www.lda-lsa.de/de/forschung/kooperationen/archaeologische_kooperation_mit_armenien/ 
Abgesehen von dem genannten Projekt in der Milsteppe, das aber aufgrund seines chronologischen Rahmens zu weit von unserer Thematik entfernt ist, und einer den hier behandelten Schwerpunkt nur ansatzweise berührenden Grabung durch die Universität München im achämenidischen Saritepe, fehlt es an Untersuchungen zur späten Bronze- und frühen Eisenzeit in Aserbaidschan. Gerade aufgrund der leider auch durch die Aktivitäten Rudolf Virchows komplizierten Forschungsgeschichte wäre es wünschenswert, wenn sich die deutsche Archäologie hier mit größerem Engagement beteiligen würde.

Ein weiterer bedeutender Grund, warum die Forschungsgeschichte des Kaukasus in der europäischen Forschung bislang nur ungenügend beleuchtet wurde, ist, dass es mit nur seltenen Ausnahmen an den Universitäten, Museen und Forschungsinstituten keine professionellen Kaukasologen gibt. Nur wenige Forscher beschäftigen sich eher randlich mit dem Kaukasus. Es wäre daher wünschenswert, wenn der Kaukasus und Studien zu dieser Region (insbesondere dem Süd-Kaukasus), als weiterer Schwerpunkt in die universitäre Lehre aufgenommen werden könnten.

\section{Ausstellungen und wissenschaft- liche Aufarbeitungen der Kaukasus- Sammlungen europäischer Museen}

Bewertet man die bisherigen Forschungen an den in Deutschland, Frankreich und Österreich befindlichen Kaukasus-Sammlungen, so lässt sich feststellen, dass diese nicht ausreichend sind, wobei durchaus unterschiedliche Publikationsstände vorliegen. Hinsichtlich der in den Wiener Museen lagernden stattlichen Sammlungen von Bronzen überwiegend nordkaukasischer Provenienz (Gräberfeld Koban etc.) ist zu bemerken, dass das Gros jener Funde noch der Bearbeitung und Publikation harrt, sieht man einmal von den bisweilen eigenwilligen Interpretationsansätzen- und Aufsätzen eines Franz Hančar aus den 1920er bis 1950er Jahren anhand ausgewählter Artefaktgruppen ab.

Über die Funde, die sich in den Kaukasus-Sammlungen des Museums für Vor- und Frühgeschichte Berlin befinden, sind bis jetzt einzelne Artikel, Beiträge in Katalogen und Veröffentlichungen in Museums-Publikationen entstanden.

\section{„Kaukasus und Luristan“}

1958 präsentierte das MVF im Schloss Charlottenburg, Langhansbau, einen kleinen Teil der Berliner KaukasusSammlung unter dem Titel „Kaukasus und Luristan“. Diese Ausstellung wurde im Langhansbau am 12. 09.1958 eröffnet. Die Konzeption der Ausstellung mit Objekten des MVF und Vergleichsstücken aus anderen westdeutschen Museen erfolgte in eigener Durchführung. Die Ausstellung lief über einen Zeitraum von zwei Monaten (12. 09. 195830. 11. 1958), ein Katalog wurde damals nicht vorgelegt $t^{142}$.

Ein solcher kam dann jedoch mit einer weiteren Ausstellung im Langhansbau zustande (9. 03. 1983-08. 09. $1983)^{143}$, gestaltet seitens der Gesellschaft für Anthropologie, Ethnologie und Urgeschichte unter dem Titel „Frühe Bergvölker in Armenien und im Kaukasus - Berliner Forschungen des 19. Jahrhunderts“. Kay Kohlmeyer und Geraldine Saherwala konzipierten die Ausstellung mit Objekten des MVF. Auch der Katalog hierzu wurde vom Museum gestaltet. Die Ausstellung wurde nach Berlin auch in anderen Städten gezeigt ${ }^{144}$. Präsentiert wurden kurze und allgemein gehaltene Informationen zu den Sammlungen von Belck, von Schweinitz und Korthaus, eine tief greifende Erforschung war mit dieser Ausstellung jedoch nicht verbunden.

Ein weiterer wichtiger Bestandsteil der Berliner Kaukasus-Sammlung - die Sammlung von Kossnierska wurde von Ingo Motzenbäcker (DAI) erforscht und publiziert. Sein Werk stellt eine gründliche Materialaufnahme und einen wertvollen Beitrag zur Erforschung der Kaukasus-Sammlungen dar ${ }^{145}$.

\section{„Das Silberne Pferd“}

Ein weiterer Bereich der Forschung bezieht sich auf das sog. „Silberne Pferd“, das auch als Titel für ein Begleitbuch wie eine namensgleiche Ausstellung gewählt wurde. Die Ausstellung und der Band „Das silberne Pferd: Archäolo-

142 Kohlmeyer/Saherwala 1983, 16. 143 Ausstellungskonzeption K. Kohlmeyer und G. Saherwala. 144 Nagel/Strommenger 2004/2005, 306-307. Andere Museen: und kam dabei nach Freiburg (Museum für Ur- und Frühgeschichte, 18. 04.-17. 06. 1984), Bamberg (Historisches Museum der Stadt, 01. 07.-02. 09. 1984), Göttingen (Städtisches Museum, 18. 11. 1984 -10. 02. 1985), Bonn-Bad Godesberg (Wissenschaftszentrum mit neu erstellten Ausstellungsmitteln, 24. 05.-30. 06. 1985), Schloss Carpenberg (Kreis Unna) (Schloss, 24. 07.-09. 09. 1985), Duisburg (Niederrheinisches Museum, 19. 09.-24. 11. 1985), Wiesbaden, und Ildenburg in Holstein.

145 Motzenbäcker 1996. 
gische Schätze zwischen Schwarzem Meer und Kaukasus“ widmete sich der archäologischen Forschung in Russland zum Ende des 19. bzw. dem Beginn des 20. Jahrhunderts. Einem breiten Publikum wurden hier zahlreiche Objekte der Kaukasus Sammlungen des MVF zugänglich gemacht wie auch Einblicke in die Aktivitäten der im Kaukasus agierenden Persönlichkeiten Virchow, Belck und Bayern gewährt.

Zu den Exponaten gehörten u.a. zwei mit Widderköpfen verzierte große bronzene Pfauenfedernadeln aus dem 2. bis 1. Jahrtausend v. Chr., ein bronzener Helm mit einer urartäischen Inschrift des 11. bis 8. Jahrhunderts v. Chr., ferner Grabbeigaben der Bestattung einer reichen, als „Prinzessin“ angesprochenen Frau. Präsentiert wurden außerdem goldene, in die Völkerwanderung datierende Gewandfibeln aus der sog. „Choynowski-Sammlung“. Bei dieser handelt es sich um Funde, die heute im Staatlichen Archäologischen Museum Warschau inventarisiert sind. Abgerundet wurde das Bild durch Objekte des täglichen Lebens, Waffen und Schmuck, feinste Schmiedearbeiten aus Gold und Silber. Deutlich festzustellen waren anhand dieser Ausstellung die Parallelen der deutschen und polnischen archäologischen Forschung im Kaukasus zum Ende des 19. bzw. dem Beginn des 20. Jahrhunderts ${ }^{146}$. Erkennbar wird so erneut, dass Forschungen mit Blick auf eine umfassende Einordnung und objektive Interpretation der Funde nur in der Zusammenschau verschiedener Sammlungen möglich sind.

\section{Aktuelle Forschungen zur Archäologie des Kaukasus - Gürtelbleche aus Bronze}

Zur Kaukasusforschung der jüngsten Zeit gehören Untersuchungen südkaukasischer Gürtelbleche aus Bronze, die im MVF verwahrt werden. Diese Trachtobjekte datieren in die späte Bronze- und frühe Eisenzeit und werden der Chodžali-Gedebey-Kultur (Zentralsüdkaukasische Kultur) zugerechnet ${ }^{147}$.

Rudolf Virchow hatte bereits 1895 Gürtelbleche dieser Art monografisch vorgelegt und besprochen ${ }^{148}$. Die Dokumentation zu diesen Fundstücken erwies sich bedau-

146 Das Silberne Pferd, 2011

147 Aufrichtig zu danken ist an dieser Stelle Prof. Matthias Wemhoff, der als Direktor des Museums für Vor- und Frühgeschichte diese Bleche und Kollektionen aus Aserbaidschan für die wissenschaftliche Bearbeitung zur Verfügung stellte.

148 Virchow 1895. erlicherweise als mangelhaft. Dies erklärt sich jedoch aus dem Fakt, dass Waldemar Belck gemäß der Schriftquellen wöchentlich 2-3 Kurgane öffnete, ausgräberische und dokumentarische Sorgfalt bei einem solchen Tempo kaum möglich war. Das Fehlen grundlegender Dokumentationen verhindert zahlreiche Fragestellungen, die auf heutiger Basis an das Material herangetragen werden könnten. Zum Zeitpunkt der Veröffentlichung von Virchows Monografie „Über die kulturgeschichtliche Stellung des Kaukasus" steckte die Forschung jedoch noch in ihren Kinderschuhen und war sich der Mängel entsprechender Ausgrabungsmethoden noch nicht ausreichend bewusst. Daher verwundert es nicht, dass dieses Werk in der damaligen Welt der Wissenschaften auf Anerkennung und Begeisterung stieß. C. F. L. Haupt nannte es noch 1910 „eine bedeutsame akademischen Abhandlung “149. Die Forschung der folgenden Jahrzehnte musste mit dieser mangelhaften Vorgabe dennoch arbeiten, etwa in Materialvorlagen. Eine solche veröffentlichten 1985 W. Nagel und E. Strommenger mit dem Katalog „Kalakent”, der in seiner Zusammenstellung einen weiteren Blick auf die historischen Fundstücke eröffnete (siehe Folgekapitel). Abgebildet wurden dort auch Gürtelbleche, bei denen es sich um mit großem künstlerischem Können angefertigte, dünne Bronzebleche handelt, die vermutlich ehemals auf Leder aufgezogen waren. Nur vereinzelt wurde bislang über Gürtelbleche dieser Herkunft geforscht, so dass sich in der Sammlung einige Stücke befinden dürften, die der Wissenschaftswelt bislang unbekannt waren. $\mathrm{Zu}$ solchen mag beispielsweise ein großes, spiralverziertes Gürtelbleche gehören, welches laut Beschriftung aus der „Paradiesfestung “ bzw. aus „Kalakent Grab 6“ stammt ${ }^{150}$. Zutreffen kann dies nach Ansicht der Verfasserin jedoch nicht. Zwar existiert eine zugehörige Erwerbungsakte ${ }^{151}$, doch liegen nähere Informationen zu den Fundumständen des Objektes weder in den Katalogen noch in den Akten des MVF vor. Es handelt dabei um ein Objekt aus der Sammlung von Waldemar Belck, welches mit Mitteln der RudolfVirchow-Stiftung ausgegraben und erworben wurde. Die Sammlung gelangte nach dem Tode Rudolf Virchows 1903 in das MVF und ist zu einem großen Teil dem Zweiten Weltkrieg zum Opfer gefallen, andere Objekte harren noch immer ihrer Identifikation und werden in den Akten des Museums als Kriegsverlust verzeichnet ${ }^{152}$. Ihre Identifikation scheint jedoch durchaus möglich, was der interna-

149 Lehmann- Haupt 1910, 8.

150 „IIId 2698qu Paradiesfestung“ und „IIId 2486a Kalakent Grab Nr. 6".

151 IA 16a, Bd. 1, E 94/1903.

152 Auskunft H. Junker (MVF), 2013. 
tionalen Forschung künftig ein breites Spektrum eröffnen dürfte.

Die Ursprünge bronzener Gürtelbleche werden von einigen Forschern wie B. B. Pjotrovskij und K. X. Kušnareva im urartäischen Raum gesehen, von wo aus sie dieser These nach in den Südkaukasus gelangten. Die Forscherin K. X. Kušnareva verglich die auf diesem Gürtelblechen dargestellten Ornamente mit solchen, wie sie ähnlich in Klein- und Vorderasien nachgewiesen sind. Ihrer Ansicht nach fanden sich in bronzezeitlichen Gräbern des Südkaukasus keine Gürtelbleche, sondern nur in jenen der frühen Eisenzeit, die von den Urartäern in den Südkaukasus gebracht wurden.

Die zur Chodžali-Gedebey-Kultur gehörenden Gürtelbleche datieren jedoch älter als die urartäischen Gürtelbleche, ferner zeigen sich zwischen ihnen Unterschiede in der Produktionstechnik und bei den Ornamenten. Letztere finden sich außerdem in den Felszeichnungen von Gobustan und Gemigaya sowie auf regional verbreiteten Keramiken. Dies spricht entgegen der Auffassung B. B. Pjotrovskijs und $\mathrm{K}$. X. Kušnarevas für eine Herstellung der bronzenen Gürtelbleche im Südkaukasus.

Die letzte und jüngste Ausstellung mit Exponaten aus dem Kaukasus eröffnete 2008 im Berliner Museum für Ethnologie mit dem Titel: „Aserbaidschan - Land des Feuers. Geschichte und Kultur im Kaukasus“, später wanderte diese Ausstellung auch nach Dresden. Neuere Forschungen wurden im Rahmen dieser Ausstellung jedoch nicht unternommen, auch die Präsentation der Exponate verharrte im Kontext des bisherigen wissenschaftlichen Standes. Das MVF entlieh 16 Objekte, die in ihrer Gesamtheit aus der Paradiesfestung in Kalakent, Aserbaidschan, stammen. Mit zu den bedeutenderen Artefakten des MVF gehören wie beschrieben die verzierten Gürtelbleche aus Bronze, welche jedoch nicht im ethnologischen Museum ausgestellt wurden ${ }^{153}$.

Das Museum besitzt nach dem gegenwärtigen Stand der Forschung zehn Gürtelbleche aus dem Kaukasus, von denen einige bis vor kurzem der Forschung unbekannt waren. Die Analyse der im Berliner Museum aufbewahrten Bronzegürtelbleche zeigt deutlich, dass die in dem geografisch weitläufigen Gebiet des Kaukasus der späten Bronzeund frühen Eisenzeit verbreitete Chodžali-Gedebey-Kultur bis jetzt nur lückenhaft erforscht ist und in ihrer Bedeutung erst ansatzweise erfasst wurde. Bereits anhand dieser Gürtelbleche und der Untersuchung alter Funde in Berlin, Russland, und dem Kaukasus lässt sich erkennen, dass über die Chodžali-Gedebey-Kultur verschiedene Varian-

153 Auskunft I. Schindlbeck, Ethnologisches Museum, Staatliche Museen zu Berlin, Stiftung Preußischer Kulturbesitz, 2013. ten der Geschichtsschreibung existieren und die kaukasischen Sammlungen in europäischen, kaukasischen und russischen Museen dringend international analysiert und erforscht werden müssen. Die bisherigen Publikationen über die südkaukasischen Gürtelbleche bedürfen dementsprechend einer erneuten wissenschaftlichen Überprüfung, etwa durch eine Gesamtvorlage aller bekannten Gürtelbleche ${ }^{154}$.

Insgesamt liegen also eine Reihe von Schriften - mehr oder minder kurze Artikel, Kataloge und Monografien vor, deren Bedeutung für die Erforschung der Geschichte des Kaukasus jedoch stark schwanken. Beleuchten lässt sich dies etwa am Katalogwerk „Kalakent“.

\section{Kalakent: Ein Buch, zwei Inhalte}

Wolfgang Nagel und Eva Strommenger veröffentlichten wie bereits angeführt 1985 einen Katalog unter dem Namen „Kalakent“, der sich jenen kaukasischen Denkmälern widmete ${ }^{155}$. Der vorliegende Katalog gibt dabei die Fundstücke und einen Großteil der von Belck an Virchow geschriebenen Briefe im Original wieder. Diese Zusammenstellung der sich nach den kriegsbedingten Veränderungen noch im Bestand befindlichen Funde muß als eine herausragende Leistung der Autoren angesehen werden. Gerade auch in Hinblick auf die weitere Forschung zur Chodžali-Gedebey-Kultur ist das Werk von zentraler Bedeutung.

Bedauerlicherweise erfolgte keine in diesem Kontext wünschenswerte wissenschaftliche Auswertung, die Herausgeber vermerkten vielmehr: „Eine wissenschaftliche Auswertung wird sich der Verfasser aus mancherlei Gründen versagen“156.

Probleme zeigen sich nun auf verschiedenen Ebenen, etwa darin, dass in jenen publizierten Briefquellen wie auch in den überlieferten Berichten die historischen Denkmäler in Kalakent (Gebiet Gedebey) sowie die „Dschennet Galasi“ (Paradiesfestung) fälschlicherweise Armenien zugeschrieben wurden anstelle Aserbaidschan ${ }^{157}$. In den Schriften werden auch jünger datierende albanische Kirchen als „alte armenische Kirchen“ bezeichnet, diese damit sowohl fehlerhaft chronologisch wie regional verortet. Durch die nicht weiter ergänzte Vorlage der Belck'schen Dokumente werden so dessen historischen, archäologischen und anthropologischen Fehleinschät-

154 Siehe dazu Ateshi 2013. 155 Nagel/Strommenger 1985. 156 Ebd. 10.

157 Ebd. 17; 22; 33; 37; 41; 162. 


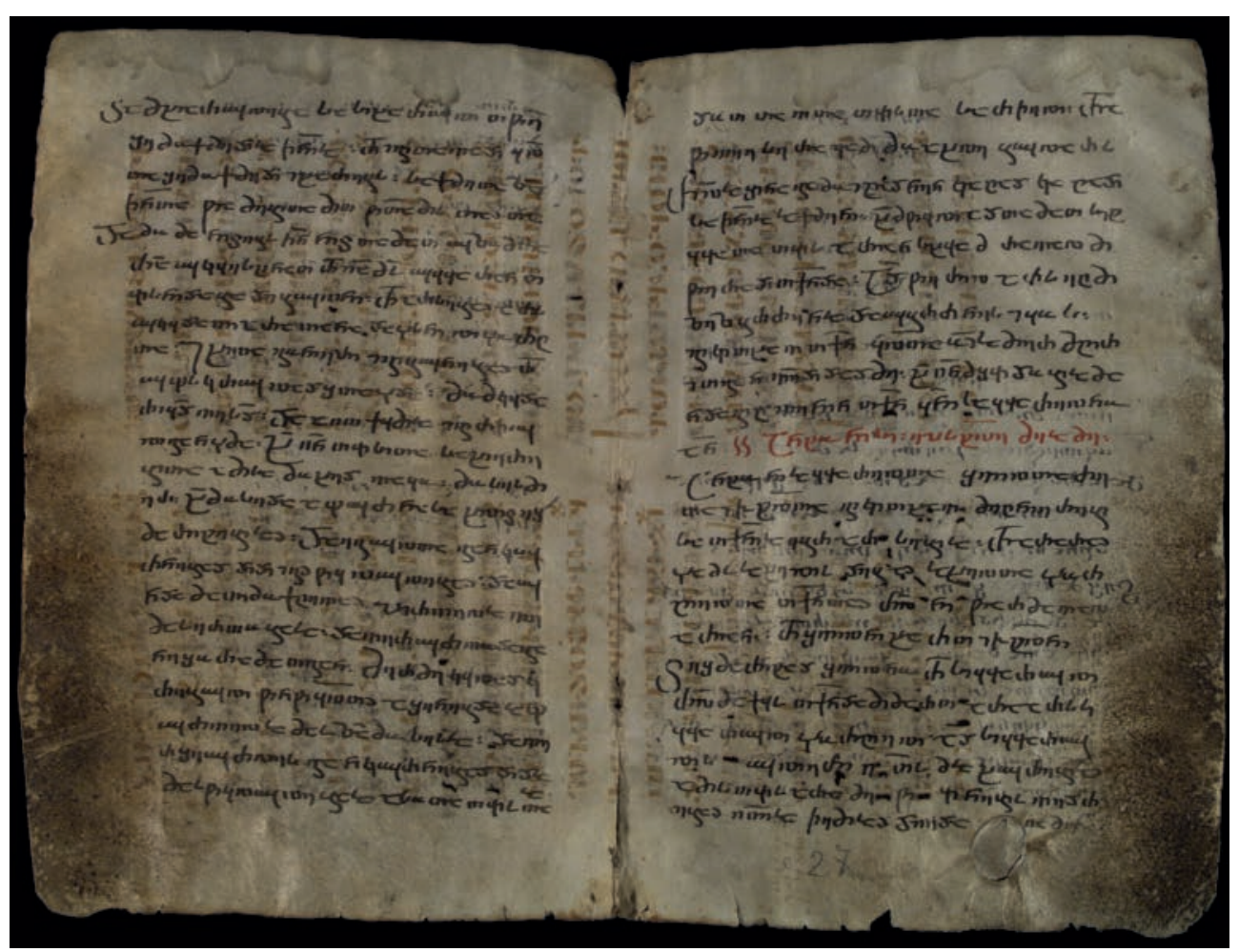

Abb. 15: Albania Palimpsest, eine von mehr als 1100 Handschriften, entdeckt am 26. 05. 1975 auf dem Berg Sinai im Keller des Klosters der heiligen Katharina (Foto: Z. Aleksidze)

zungen unkommentiert übernommen und so wissenschaftlich tradiert.

Es handelt sich dabei mitnichten um Petitessen, da diese historischen, archäologischen, geografischen, anthropologischen und politischen Fehlzuweisungen von den deutschen und aserbaidschanischen Universitäten, Museen, Forschungsinstituten wie auch seitens deutscher Historiker und Archäologen in unterschiedlichsten Werken erneut rezipiert und entsprechend als richtig und damit wahr erachtet wurden. Damit setzen sich historische wie archäologische Zuschreibungen fort, die mit Rudolf Virchow begannen und mit C. F. Lehmann-Haupt bis in die heutige Zeit reichen.

Problematisch sind etwa fehlerhafte regionale Verortungen bezüglich Gedebey, das im Werk als in Armenien gelegen benannt wird, jedoch auch zur Zeit des Zarenreiches in Aserbaidschan lag.

Auch zu Hochzeiten des Kalten Krieges im Jahre 1985 hätten die Bearbeiter des Werkes „Kalakent“ recherchieren können, dass etwa Gedebey nicht zu Armenien gehörte, sondern in jener Zeit auf aserbaidschanischem Gebiet lag, welches wiederum zum Russischen Reich gehörte. Entsprechendes betrifft bronzezeitliche Denkmäler, die ebenfalls nicht als armenisch anzusprechen sind, ferner der Feststellung, dass es im Kaukasus ab dem 4. Jahrhun- dert v. Chr. eine albanische Herrschaft gab („Albania“), und dass christliche Kirchen zum kaukasischen Albania gehört haben dürften.

Zur Erläuterung des letztgenannten Punktes: Im 4. Jahrhundert v. Chr. entstand in Kaukasien das Königreich „Albania“, das trotz Namensgleichheit in keiner Verbindung zum heutigen Staat Albanien steht. Das Gebiet von Albania erstreckte sich über das heutige Aserbaidschan und Armenien bis in den nördlichen Teil von Georgien sowie den südlichen Teil der Russischen Föderationsrepublik Dagestan. Vom 4. Jahrhundert v. Chr. bis zum 5. Jahrhundert n. Chr. war Kabala (auch Qabala) die Hauptstadt des antiken Albania. Die Ruinenstätte der einstigen Hauptstadt liegt in der Nähe der modernen Stadt Qabala/ Aserbaidschan bei dem Dorf Cuxurkend ${ }^{158}$. Obertägig noch heute sichtbar sind die Reste eines Turmes. Erschließen lässt sich die Existenz eines Königreiches Albania außerdem mittels zwischen 1990 und 2000 im Katharinenkloster am Berg Sinai (Israel) entdeckten Handschriften, bei denen es sich es sich um albanische Palimpseste handelt $(\text { Abb. } 15)^{159}$.

158 Janovskij 1846.

159 Aleksidze 2003, 20. 
Diese verweisen auf ein zum Ende des 4. Jahrhunderts v. Chr. mächtiges, kaukasisch-albanisches Reich. Mit Beginn des 3. Jahrhunderts v. Chr. entstand eine zentralisierte albanische Herrschaftsstruktur, die mit Unterbrechungen bis in das 8. Jahrhundert $n$. Chr. fortbestand. Die Bevölkerung von Albania wurde im 4. Jahrhundert n. Chr. zum Christentum bekehrt.

Nur scheinbar ein Allgemeinplatz ist es, das die Ansprache bronzezeitlicher Gräber im Kalakent-Werk als „armenisch“ falsch ist, da ein Armenien in der Bronzezeit nicht existierte. Die bereits angesprochene Zuweisung der historischen Denkmäler in Kalakent sowie Dschennet Qalasi (Paradiesfestung) an Armenien, die Benennung „alter armenischer" Gräber und Kirchen fällt in die gleiche Kategorie.

Beträfen diese Punkte „nur“ die deutschsprachige Version des Werkes „Kalakent“, so mag einem dies noch als verschmerzbar erscheinen. Da das Werk jedoch 1999 ins Aserbaidschanische übersetzt wurde, potenzieren sich die Fehler ${ }^{160}$. Die aserbaidschanische Variante weist dabei nicht nur inhaltliche Fehler auf, es ist auch zu groben grammatikalischen Transkriptionsfehlern gekommen ${ }^{161}$, andere Stellen wurden nicht korrekt übersetzt, vieles verändert, verfälscht, verdreht und nachgedichtet. Bei den Angaben von Belck lässt sich eine Neuinterpretation im nun aserbaidschanisch-nationalen Sinne erkennen, was nicht den ursprünglichen Quellen entspricht.

Redakteur der Übersetzung war der kaukasische Archäologe R. B. Göyüšov. Zusammen mit A. I. Martinov hat er das bedeutende Werk „Archäologie der UdSSR“ verfasst. Die Übersetzung ist dementsprechend nicht eine schlichte Transkription der Quelle, sondern eine Neuinterpretation, mittels der ein großer Teil der Geschichte der zentralsüdkaukasischen Kultur während der Spätbronze- und der Früheisenzeit umgeschrieben wurde. Auf Grundlage dieses damit kritisch zu betrachtenden Werkes und der in ihm verfälscht wiedergegebenen Quellen entstanden in den Folgejahren Artikel, Monografien und Dissertationen, in denen jene Publikation als bedeutende vertrauenswürdige Quelle angesehen wurde.

Im Ergebnis wird damit ein großer Teil der Geschichte der späten Bronze- und frühen Eisenzeit von Gedebey und der Chodžali-Gedebey-Kultur und darüber hinaus wissentlich oder unwissentlich falsch beschrieben. Die Artikel Virchows und Röslers finden in aserbaidschanischen und auch russischen Publikationen ebenso eine Wiedergabe,

160 Nagel/Strommenger 1999.

161 Nur ein Beispiel von vielen: „Schüsse“ im deutschen Text wurden zu „Schlüssel“ in der aserbaidschanischen Übersetzung. Nagel/ Strommenger 1999, 89. nun in Kombination mit weiteren darauf aufbauenden, zwangsläufig fehlerhaften Thesen. Es ist also wichtig zu erkennen, das bereits die immer wieder herangezogenen und von Belck und Virchow verfassten Primärquellen fehlerhaft sind, so dass die Forderung nicht zu weitgreifend erscheint, die in den letzten 185 Jahren verfasste deutsche archäologische Literatur und Geschichtsschreibung des Kaukasus zu hinterfragen und sie damit auf eine neue Basis zu stellen.

\section{Die Bedeutung der russischen Museen im Kontext der Kaukasus-Sammlungen}

Der größte Teil der in die späte Bronze- und frühe Eisenzeit datierenden und den Chodžali-Gedebey-Kultur zuweisbaren Funde des MVF wurde in Museen in der RSFSR (Russische Sozialistische Föderative Sowjetrepublik) verbracht. Dies betraf einen Großteil der ehemaligen Berliner Kaukasus-Sammlung. Jene Objekte lagern dort noch heute. Obwohl sich etwa in der Eremitage Tausende wertvolle und unersetzliche Exponate der Kaukasus-Sammlung befinden, ist der Wissenschaft der Zugang zu ihnen bisher nur sehr eingeschränkt möglich ${ }^{162}$.

Es bleibt zu hoffen, dass es bald zu einer Lösung der Problematik kommen wird, zumal die Beziehungen auf den Gebieten der Kultur und Wissenschaft von den gegenwärtigen politischen Schwierigkeiten zwischen Russland und der EU nicht betroffen sind. Der Zugang einzelner Wissenschaftler zu den Artefakten sollte wünschenswerterweise in Kooperation mit russischen Partnern erfolgen und wäre dabei ein wichtiger erster Schritt, die KaukasusSammlungen in ihren Einzelheiten und ihrer Gesamtheit $\mathrm{zu}$ erforschen, dies auch im Angesicht einer langen gemeinsamen Geschichte.

162 Anfragen individueller Forscher werden oftmals nicht beantwortet. Dabei ist es längst kein Geheimnis mehr, welche Artefakte und Dokumente über den Südkaukasus seit mehr als 100 Jahren in den jeweiligen Archiven und Magazinen ruhen. In den verschiedenen Museen von Berlin, Baku, Moskau und St. Petersburg finden sich immer wieder Hinweise zu den von Rösler und Belck gesammelten Materialien. Dies sind kleinere Veröffentlichungen, aber auch handschriftliche Bemerkungen und Notizen inklusive aufgelisteter Inventarnummern, aus denen hervorgeht, dass sich die Funde aus den Grabungen im Südkaukasus im Staatlichen Historischen Museum Moskau, im Staatlichen Museum für Bildende Künste A. S. Puschkin in Moskau sowie in der Eremitage in St. Petersburg befinden. 


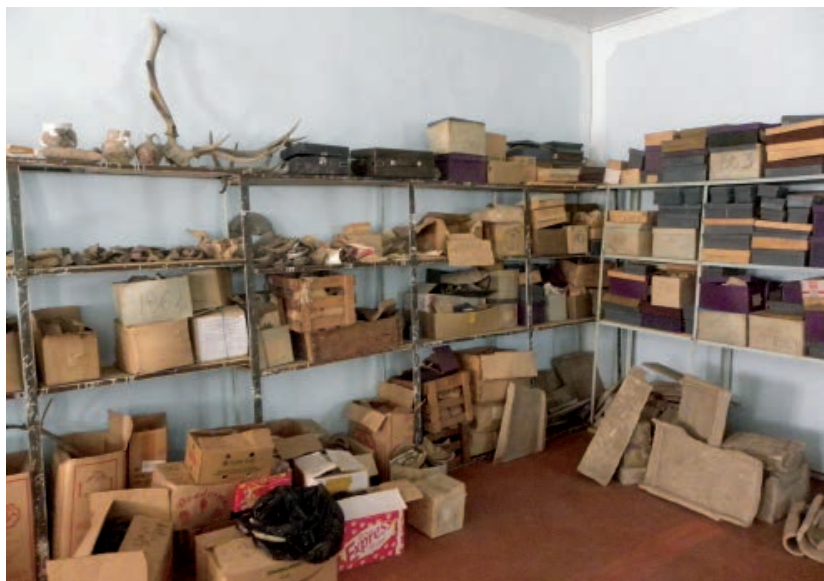

Abb. 16: Magazin des Museum Gabala. Sammlung u. a. eines der Begründer der aserbaidschanischen Archäologie (S. Gaziyev. Foto: N. Ateshi-Gadirova)

\section{Ausblick, künftige Vorhaben und Ziele}

Das primäre Ziel bei der Aufarbeitung der in den europäischen Archiven lagernden kaukasischen Funde ist die vollständige und objektive Erforschung der späten Bronzeund frühen Eisenzeit des Südkaukasus, so dass unter Einbeziehung der verschiedenen kulturellen Beziehungen, Hintergründe und Geschichtsabläufe die ChodžaliGedebey-Kultur auch anhand der über die verschiedenen Museen verteilten Funde umfangreich wissenschaftlich untersucht werden kann. Die Geschichtsschreibung des Kaukasus ist bislang in einem hohen Maße zersplittert. Erkennen lässt sich dies, betrachtet man etwa jene bislang vorliegenden Studien zur Spätbronze- und Früheisenzeit und besonders der Chodžali-Gedebey Kultur. Dabei unterscheiden sich die deutsche, russische und aserbaidschanische wie auch die armenische Historiografie bisweilen erheblich voneinander, so dass nebeneinander völlig divergente Versionen der Geschichte des Kaukasus und seiner materiellen Kulturen bestehen.

Dies ist eine Folge einer mittlerweile 185-jährigen Forschung auf Basis unterschiedlicher Herangehensweisen und Forschungstraditionen, aber auch dem Einfluss unterschiedlichster Ideologien und zeitgeschichtlicher Ereignisse wie dem Zerfall der Sowjetunion, der Entstehung einzelner Staaten und der Herausbildung nationaler Mythen über jenen langen Zeitraum hinweg geschuldet.

Daher ist für die Forschung am und im Kaukasus ein Paradigmenwechsel dringend anzumahnen, der all diese Faktoren berücksichtigt. Für eine wissenschaftlich fundierte Bewertung der Kaukasus-Sammlungen ist es nötig, die bisherigen Veröffentlichungen in den verschiedenen Sprachen miteinander zu vergleichen und die an verschiedenen Orten verbliebenen Originaldokumente und Ausgrabungsberichte deutscher, russischer und kaukasischer Forscher kritisch zu bewerten.

Zum Teil ist dies bereits erfolgt, wie aus dem vorliegenden Beitrag klar geworden sein sollte. Dies können jedoch nur die Anfänge einer umfassenden Forschungsstrategie sein. Folgende Schritte sind daher nötig:

1. Die bislang während der 185-jährigen Kaukasus-Forschung entstandenen Publikationen deutscher und anderer europäischer Forscher sollten auf breiter internationaler Ebene zur Diskussion gestellt und neu bewertet werden. Dies betrifft insbesondere die Fundvorlagen und Berichte zur Archäologie in Kaukasien in den genannten Bänden der „Zeitschrift für Ethnologie“.

2. Die damalige Rolle der Berliner Gesellschaft für Anthropologie, Ethnologie und Urgeschichte (BGAEU) und deren Aktivitäten bei der Erforschung des Kaukasus ist im Lichte der heutigen Erkenntnisse neu zu untersuchen und zu bewerten.

3. Die derzeit in den russischen Museen gelagerten, aus den Kaukasus-Sammlungen stammenden spätbronzeund früheisenzeitlichen Fundstücke sollten der Wissenschaft zugänglich gemacht und in internationalen Projekten untersucht, katalogisiert und publiziert werden. Dazu zählt auch die künftige Aufarbeitung der Originalfunde nach funktionalen und technologischen Kriterien, etwa mit Hilfe der Archäometrie, sind hier doch wissenschaftlich relevante Daten zu erwar$\operatorname{ten}^{163}$.

4. Die sich in deutschen, österreichischen, französischen und anderen mitteleuropäischen Museen befindlichen Kaukasus-Sammlungen und Archivalien sollten erneut erforscht, katalogisiert und publiziert werden. Dies betrifft insbesondere jene im MVF befindlichen, für die Forschung hervorragend zugänglichen Objekte; bei der Forschungen im Kaukasus selbst sollte ferner den dortigen, sich vielfach in keinem guten Zustand befindlichen kaukasischen Museen geholfen werden (Abb. 16), organisatorisch, technisch und museal zum internationalen Standard aufzuschließen. Diese Probleme wie auch die Ausblicke,

163 Beispielsweise beschreibt Born (1984, 31-37; 41) einen Dolch aus der Paradiesfestung, der aus einer Zinn-Blei-Bronze besteht und der Einlegearbeiten aus Eibenholz aufweist, sowie ebenfalls aus der „Paradiesfestung“ ferner einen Zierknopf, dessen großer Cabochon mit verschiedenen Einlagen aus Aragonit, Glas, Bitumen, Ton und wohl einer Knochenmasse versehen ist 
künftige Vorhaben und sowie Ziele und Vorschläge, wurden seit 2013 in mehreren internationalen Konferenzen der Wissenschaftswelt dargelegt und Apelle betreffs einer Zusammenarbeit und Mitwirkung an sie gerichtet ${ }^{164}$.

5. Forschungslücken sind $\mathrm{zu}$ identifizieren und im Rahmen internationaler Projekte zu schließen. Dies betrifft besonders die Chodžali-Gedebey Kultur.

6. Die von deutscher wie auch sonstiger europäischer Seite ergrabenen Fundstätten in Südkaukasien sollten erneut aufgesucht und mit modernen Verfahren nachuntersucht werden. Das Potenzial solcher Nachgrabungen zeigen im letzten Jahrzehnt von der Deutschen Forschungsgemeinschaft (DFG) unterstützte Projekte wie die erneuten Ausgrabungen im Neandertal bei Düsseldorf ${ }^{165}$, im kaiserzeitlichen Lübsow/ Lubieszewo (Polen) ${ }^{166}$ oder im eiszeitlichen Oberkassel im Rheinland ${ }^{167}$.

Ziel dieser Initiativen ist die Etablierung eines KaukasusForschungszentrums, in dem deutsche, russische und kaukasische Wissenschaftler gemeinsam einen neuen, multinationalen Blick auf die Geschichte des Kaukasus erarbeiten können.

Die bisherige Forschung, die insbesondere heutzutage von regionaler Diversifikation geprägt ist, erlaubt es nicht, die Zuschreibungen im Stile Virchows zu überwinden. Die historisch überkommenen, mitteleuropäisch geprägten Vermutungen über die Ursprünge und Zusammenhänge der gefundenen Artefakte bestärken die gegenwärtigen kleinstaatlich-nationalen Deutungen und Darstellungen.

Ein Kaukasus-Forschungszentrum kann und muss entschieden die großräumige Perspektive suchen, den Kaukasus als Kulturraum in der Forschung etablieren, um damit dessen Bedeutung als einer für die Menschheitsgeschichte eminent wichtigen Region gerecht zu werden.

164 Internationale Konferenzen: „Aserbaidschanische Archäologie und Ethnografie in den unabhängigen Jahren“, 11.-13. November 2013, Baku; „Aktuelle Probleme Kaukasischer Geschichte”, 15. -18. Oktober 2015, Gence; "Spaces and Territories along the Caspian Sea during the Bronze and Iron Ages", Internationale Conference, December $4^{\text {th }}-5^{\text {th }}$ 2015, Paris; "International Congresses on the Archaeology of the Ancient Near East" (ICAANE) April $25^{\text {th }}-29^{\text {th }}$ 2016, Vienna.

165 Grabungen durch R. W. Schmitz und J. Thissen im Jahr 2000.

166 Grabungen durch J. Schuster ab 2006.

167 Grabungen durch R. W. Schmitz und J. Thissen im Jahr 1994.

\section{Literatur}

Aleksidze 2003: Z. Aleksidze, Gafgaz albanlari dillendiler (Tbilisi 2003).

Aliyev 2013: V. Aliyev, Azerbaycan archäologiya və etnografiya elmleri müstegillik illerinde, Beynelchalq elmi konfransin materiallari (Baku 2013).

Anadolu uyqarligi 1982: Görsel Anadolu tarihi Ansiklopedisi: 6 ciltte, 1.cilt (İstanbul 1982) 216.

Anati 2001: E. Anati, Gobustan, Azerbaijan, Centro Camuno (Capo di Ponte 2001).

Andree 1976: Chr. Andree, Rudolf Virchow als Prähistoriker, 1 (Köln, Wien 1976).

- 2008: -, Sämtliche Werke. Bd. 54, Abt. III, Anthropologie, Ethnologie, Urgeschichte. Das Gräberfeld von Koban im Lande der Osseten, Kaukasus. Eine vergleichend-archäologische Studie. Mit zusätzlichen Texten Virchows über das Gräberfeld und den Kaukasus (Hildesheim, Zürich, New York 2008).

Arešjan 1974: G. E. Arešjan, O rannem ètape osvoenija železa v Armenii in a Južnom Kavkaze. Ist.-fil. žurn. (Eriwan) 2/74, 1974, 192-212.

Ateshi 2011: N. Ateshi, Kaukasische Amazonen (Berlin 2011).

- 2013a: -, Raskryvayutsya sledy materialnokulturnych obraztsov tsentralnogo Kavkaza: 10 originalnykh bronzovykh poyasov $\mathrm{v}$ Berlinskom Muzee (MVF). Azerbaijan Arch. 2 (Baku 2013).

- 2013b: -, Materielle und kulturelle Beispiele der ChodžaliGedebey-Kultur in Deutschland/Ein kritischer Überblick über die Ausgrabungen von Waldemar Belck und neue Forschungen/ Archäologie und Ethnologie in den Jahren der Unabhängigkeit. Materialien der Internationalen Konferenz AMEA (Baku 2013).

- 2015: -, 185 Jahre deutsche Archäologie im Kaukasus, Eine Epoche und drei verschiedene Geschichtsschreibungen. Antike Welt (Darmstadt 2015).

Avšarova/Pirquliyeva 2010: G. Avscharov/Pirquliyeva, Gafgaz archäologiyasi (Baku 2019).

Bayern 1885: F. Bayern, Friedrich Bayern`s Untersuchungen über die ältesten Gräber- und Schatzfunde in Kaukasien, hrsg. und mit einem Vorwort versehen von R. Virchow. Zeitschr. f. Ethnol. 17, 1885, Suppl., 1-60.

Belck 1893: W. Belck, 23. Hr. Waldemar Belck berichtet über archäologische Forschungen in Armenien. Zeitschr. f. Ethnol. 25, 1893, Verhandlungen, 61-82.

Born 1984: H. Born, Meisterwerke kaukasischer Bronzeschmiede. Bilderh. Staatl. Mus. preuß. Kulturbes. (Berlin 1984).

Brather 2004: S. Brather, Ethnische Interpretationen in der frühgeschichtlichen Archäologie. Geschichte, Grundlagen und Alternativen. RGA 42 (Berlin, New York 2004).

Bringschulte 2002: E. Bringschulte „Geld und Raum braucht es, um etwas Großes zu schaffen“"Virchow und Berliner Krankenhäuser“. In: G. Saherwala/Th. Schnalke/K. Vanja/ H.-J. Veigel (Hrsg.), Zwischen Charité und Reichstag, Rudolf Virchow - Mediziner, Sammler, Politiker. Berliner Medizinhist. Mus. 2002, 82-83.

Bünyadov 1960: T. Bünyadov, Azerbaycan archeologiyasi otscherkleri, Baku Azerbaycan Dövlet neşriyyati (Baku 1960).

Chalilli 2006: F. S. Chalilli, Tbilisi Muzeyinden Azerbaycan Tarixi Muzeyinə daxil olmuş archäoloji materiallar. Azerbaycan Milli Elmlər Akademiyas ıaspirantlarının elmi konfransın ınmaterialları. Iyun 2006-cı il (Baku 2006) 
Chantré 1886: E. Chantré, Récherches anthropologiques dans le Caucase 2, Text. Période protohistorique (Paris, Lyon 1886).

Das Silberne Pferd: Archäologische Schätze zwischen Schwarzem Meer und Kaukasus. In: M. Wernhoff/A. Kokowski (Hrsg.), Das Silberne Pferd, Archäologische Schätze zwischen Schwarzem Meer und Kaukasus 2011. Begleitbuch zur Ausstellung des Museums für Vor- und Frühgeschichte - Staatliche Museen zu Berlin und dem Archäologischen Institut der Universität Marie Curie-Sklodowskiej, Lublin (Bevern 2011).

Džafarov 2000: H. Džafarov, Azerbaycan e.e. IV minilliyin achıri - I minilliyin evvellərinde (Garabagın Qarqartschay ve Tertertschay hövzesinin materialları esasında) (Baku 2000).

Ferzeli 2008: E. Ferzeli, Gemigaya, Gobustan medeniyyeti (Baku 2008).

Goldmann/Reich 1996: K. Goldmann/Chr. Reich, Museum für Vorund Frühgeschichte. Verzeichnis der seit 1945 vermissten Bestände des Museum für Vor- und Frühgeschichte. In: Generaldirektion der Staatlichen Museen zu Berlin - Stiftung Preußischer Kulturbesitz (Hrsg.), Dokumentation der Verluste IV (Berlin 1996).

Goschler 2002: C. Goschler: „R. Virchow und die deutsche Politik: Vom gescheiterten Revolutionär zum überforderten Honoratior“. In: G. Saherwala/Th. Schnalke/K. Vanja/H.-J. Veigel (Hrsg.), Zwischen Charité und Reichstag, Rudolf Virchow - Mediziner, Sammler, Politiker. Berliner Medizinhist. Mus. 2002, 53-61.

Göyüšov/Martınov 1991: R. B. Göyüşov/A. İ. Martınov, SSRi Archäologiyasi (Baku, Maarif 1991).

Hasanov 2005: Z. Hasanov, Tschar skifler, Abilov (Baku 2005).

Ivanovskij 1911: A. A. Ivanovskij, Materialy po archäologii Kavkaza. Ausg. VI, 1911, 159 (Moskau 1911).

Jaraliev/Osmanov 2003: J. A. Jaraliev/H. O. Osmanov, Istoriya Lezgin (Moskau 2003).

Kohlmeyer/Saherwala 1983: K. Kohlmeyer/G. Saherwala (Red.), Frühe Bergvölker in Armenien und im Kaukasus. Berliner Forschungen des 19. Jahrhunderts. In: Vorstand der Gesellschaft für Anthropologie, Ethnologie und Urgeschichte (Hrsg.), Ausstellung des Museums für Vor- u. Frühgeschichte Berlin, Staatliche Museen Preußischer Kulturbesitz und der Berliner Gesellschaft für Anthropologie, Ethnologie und Urgeschichte (Berlin 1983).

Kušnareva 1951: K. Ch. Kušnareva, Kultura Nagornogo Karabakha po arkheologicheskim istochnikam (Ende 3. bis Mitte 1. Jahrt. v. Chr.) (Diss. Leningrad 1951).

Lehmann-Haupt 1910: C. F. Lehmann-Haupt, Armenien, einst und jetzt (Berlin 1910).

Machmudov 2008: F. R. Machmudov, Kultura yugo-vostochnogo Azerbaidzhana v epokhu bronzy i rannego zheleza (Nauka, Baku 1910).

Menghin 2004/2005: W. Menghin (Hrsg.), 1829-2004. Das Berliner Museum für Vor- und Frühgeschichte. Festschrift zum 175-jährigen Bestehen. Acta Praehist. et Arch. 36/37 (Berlin 2004/2005).

Michel 2002: K. Michel, Der Anti-Bode: Rudolf Virchow als Museumsgründer: In: G. Saherwala/Th. Schnalke/K. Vanja/H.-J. Veigel (Hrsg.), Zwischen Charité und Reichstag, Rudolf Virchow - Mediziner, Sammler, Politiker. Berliner Medizinhist. Mus. 2002, 107-112.

de Morgan 1889: J. de Morgan, Mission scientifique au Caucase. Études archéologiques et historiques (Paris 1889).
-/Scheil 1893: -/J.-V. Scheil, La stele de Kel-i-chin. Rec. travaux d'égyptologie, d'assyriologie et d'archéologie orientale 14, 1893, 153-160.

Motzenbäcker 1996: I. Motzenbäcker, Sammlung Kossnierska - der digorische Formenkreis der kaukasischen Bronzezeit. Staatl. Mus. Berlin, Bestandskat. 3 (Berlin 1996).

Nagel/Strommenger 2004/2005: W. Nagel/E. Strommenger, Die Vorderasiatische Sammlung im Museum für Vor- und Frühgeschichte Berlin bis 1992. In: W. Menghin (Hrsg.), 1829-2004. Das Berliner Museum für Vor- und Frühgeschichte. Festschrift zum 175-jährigen Bestehen. Acta Praehist. et Arch. 36/37 (Berlin 2004/2005) 296-319.

Nagel/Strommenger 1985: W. Nagel/E. Strommenger (Hrsg.), Kalakent. Früheisenzeitliche Grabfunde aus dem transkaukasischen Gebiet von Kirovabad/Jelisavetopol. Berl. Beitr. z. Vor- u. Frühgesch. NF. 4 (Berlin 1985).

-/- 1999: -/- (Hrsg.), Galakend. Cenubi Qafqazin Kirovabad/Jelisavetopol erazisinde erken demir dövrünün archäoloji tapintilari (Baku 1999).

Nawroth 2011: M. Nawroth, Die Bronze- und Eisenzeit im Kaukasus. In: M. Wernhoff/A. Kokowski (Hrsg.), Das Silberne Pferd, Archäologische Schätze zwischen Schwarzem Meer und Kaukasus 2011. Begleitbuch zur Ausstellung des Museums für Vor- und Frühgeschichte - Staatliche Museen zu Berlin und dem Archäologischen Institut der Universität Marie Curie-Sklodowskiej, Lublin (Bevern 2011) 75-80.

- 2011: -, Reisen in das Paradies: Berliner Forschungen des 19. Jahrhunderts im Kaukasusgebiet. In: M. Wernhoff/A. Kokowski (Hrsg.), Das Silberne Pferd, Archäologische Schätze zwischen Schwarzem Meer und Kaukasus 2011. Begleitbuch zur Ausstellung des Museums für Vor- und Frühgeschichte Staatliche Museen zu Berlin und dem Archäologischen Institut der Universität Marie Curie-Sklodowskiej, Lublin (Bevern 2011) 81-107.

Pjotrovskij 1944: B. B. Pjotrovskij, Istoriya i kultura Urartu (Erevan 1944).

- 1949: -, Arheologija Zakavkaz ja (s drevnejših vremen do I tysjačeletija do n. è. (Leningrad 1949).

Rösler 1892a: E. Rösler, 27. Hr. Gynasiallehrer Emil Rösler in Šuša. Zeitschr. f. Ethnol. 24, 1892, Verhandlungen, 565-566.

- 1892b: -, 27. Zwei Gräber von Šuša (Transkaukasien) Zeitschr. f. Ethnol. 24, 1892, Verhandlungen, 566-569.

- 1894: -, 28. Hr. Waldemar Belck überreicht im Namen des Hrn. Emil Rösler in Šuša den nachfolgenden Berichtes Letzteren über seine archäologische Thätigkeit im Jahre 1893 in Transkaukasien. Zeitschr. f. Ethnol. 26, 1894, Verhandlungen, 213-241.

- 1895a: -, 11. E. Rösler berichtet in einem Briefe an Hrn. Rud. Virchow aus Šuša, Transkaukasien, 25. September (7. October) über neue Grabfunde von Chodžali. Zeitschr. f. Ethnol. 27 1895, Verhandlungen, 549-551.

- 1895b: -, 24. Hr. E. Rösler berichtet in einem Briefe an den Vorsitzenden aus Baku, 16. Dezember 1894, über transkaukasische Forschungen. Zeitschr. f. Ethnol. 27, 1895, Verhandlungen, 147-148.

- 1896a: -, 10. Das auswärtige Mitglied Hr. E. Rösler, hat Hrn. Rud. Virchow mit Schreiben aus Šuša vom 13. Januar einen umfassenden Bericht übersendet, betreffend archäologische Untersuchungen in Transkaukasien. Zeitschr. f. Ethnol. 28, 1896, Verhandlungen, 77-108. 
- 1896b: -, 12. Hr. E. Rösler übersendet d. d. Šuša, 25. Mai, durch Vermittelung des des Hrn. R. Virchow folgenden Bericht über neue Ausgrabungen bei Gülaplu, Transkaukasiens. Zeitschr. f. Ethnol. 28, 1896, Verhandlungen, 398-402.

- 1897: -, 12. Hr. E. Rösler übersendet aus Šuša, 19./31. März, folgende Mittheilungen:Mitteilungen über archäologische Funde in Transkaukasien. Zeitschr. f. Ethnol. 29, 1897, Verhandlungen, 209-213.

- 1898: -, 13. Hr. E. Rösler sendet aus Šuša unter dem 10. Juni einen archäologisch-ethnologischen Bericht über seine für die kaiserl. russ. Archäologische Commission unternommenen Untersuchungen im Gouv. Elisabethpol im Februar und April 1897. Ausgrabungen südlich von Šuša an der Eriwanschen Poststraße. Darin die Beiträge Untersuchung eines von Dorfbewohnern zerstörten vorhistorischen Grabhügels mit Bestattungsgrab aus der Eisenzeit bei dem Dorfe Mechtikend, Kreis Šuša sowie Ausgrabungen bei dem Dorfe Daschalti, Kreis Šuša. Zeitschr. f. Ethnol. 30, 1898, Verhandlungen, 290-329.

- 1899: -, 10. E. Rösler übersendet aus Šuša, 26. December, den Schluss seiner im Auftrage der Kaiserlich Russischen Archäologischen Commission unternommene archäologischen Forschungen in Transkaukasien im Jahre 1897. Neue Ausgrabungen am Flusse Chatschenaget und Forschungsreisen daselbst (Kreis Dshewanschir). Zeitschr. f. Ethnol. 31, 1899, Verhandlungen, 243-291.

- 1901: -, 10. Hr. Emil Rösler in Elisabethpol übersendet unter dem 31. December 1900 folgenden Bericht über die für die kaiserl. Russische Archäologische Commission im Jahre 1899 unternommenen archäologischen Forschungen in Transkaukasien. Archäologische Untersuchungen und Ausgrabungen im Elisabethpolischen Gouvernement, Kreis Elisabethpol. Zeitschr. f. Ethnol. 33, 1901, Verhandlungen, 78-150.

- 1902: -, 19. Von Hrn. Staatsrath Rösler (Elisabethpol, Transkaukasien) ist ein ausführlicher Bericht eingegangen über archäologische Forschungen und Ausgrabungen in Transkaukasien, unternommen für die kaiserlich russische Archäologische Commission im Jahre 1900. A. Fortsetzung der archäologischen Ausgrabungen bei der Colonie Helenendorf, Kreis und Gouvernement Elisabethpol, im Jahre 1900. Zeitschr. f. Ethnol. 34, 1902, Verhandlungen, 137-191.

- 1902: -, 13. Hr. Emil Rösler sendet aus Elisabethpol den Schluss (vgl. Verhandlungen 1902, 187, seines Berichtes über archäologische Forschungen und Ausgrabungen in Transkaukasien, unternommen für die kaiserlich Russische Archäologische Commission im Jahre 1900, B. Reisen in die Gouvernements Kars und Eriwan. Zeitschr. f. Ethnol. 34, 1902, Verhandlungen, 221-245.
- 1903: -, 10. Hr. E. Rösler aus Tbilisi übersendet wieder einen sehr fleissigen Bericht über archäologische Ausgrabungen im Transkaukasus im Jahre 1901, welche er unternommen im Jahre 1901 im Auftrage der kaiserlich russischen Archäologischen Regierung durchgeführt hat. Zeitschr. f. Ethnol. 35, 1903, 926.

- 1905: -, Bericht über archäologische Ausgrabungen in Transkaukasien. Von Emil Rössler-Tbilisi. Unternommen im Jahre im Auftrage der kaiserlich russischen Archäologischen Kommission. Zweimaliger Ausflug nach dem Dorfe Bayan Kreis und Gouvernement, Elisabethpol und Ausgrabungen daselbst. Zeitschr. f. Ethnol. 37, 1905, 114-151. Rosendorf 1903: G. O. Rosendorf, Raskopki OAK za 1903 goda (St. Petersburg 1903).

Safarov 1989: Y. Safarov, Qedim Azerbaycan: ne bilirik (Baku 1989). Saherwala et al. 2002: G. Saherwala/Th. Schnalke/K. Vanja/H.-J. Veigel (Hrsg.), Zwischen Charité und Reichstag, Rudolf Virchow - Mediziner, Sammler, Politiker. Berliner Medizinhist. Mus. 2002.

Schmidt 1929: A. V. Schmidt, Die Kurgane der Stanica Konstantinovskaja. Eurasia Septentr. Ant. V, 1929, 9-21.

Skinder 1906: V. A. Skinder, Opit archäologiceskoj razvedki (Pjatigorsk 1906).

Uvarova 1900: P. S. Uvarova, Okrajni xrebet vysokoj Armenii. Verxnjaja dolina reki Akstafy. Redkin lager’. (Arheologija. Kollekcii Kavkazskogo Museja. Tom M. Sostavila grafinja P. S. Uvarova, 1900) 48-62.

Veit 2006: U. Veit, Gründerjahre: Die mitteleuropäische Ur- und Frühgeschichtsforschung um 1900. In: J. Callmer/M. Meyer/ R. Struwe/C. Theune (Hrsg.), Die Anfänge der ur- und frühgeschichtlichen Archäologie als akademisches Fach (1890-1930) im europäischen Vergleich. Berliner Arch. Forsch. 2 (Rahden/ Westf. 2006) 43-61.

Virchow 1881: R. Virchow, Hr. Virchow hält einen Vortrag über Kaukasische Prähistorie. Zeitschr. f. Ethnol. 13, 1881, Suppl. 411-427.

- 1883: -, Das Gräberfeld von Koban im Lande der Osseten, Kaukasus. Eine vergleichend-archäologische Studie (Berlin 1883).

- 1888: -, Gräberfunde von Radewege in Butzow bei Brandenburg a. H. Zeitschr. f. Ethnol. 20, 1888, 581-586.

- 1895: -, Über die Kulturgeschichtliche Stellung des Kaukasus (Berlin 1895).

-/Dolbežev 1882:-/W. Dolbežev, Der archäologische Congress in Tbilisi (1881). Zeitschr. f. Ethnol. 14, 1882, 78-111.

Janovskij 1846: A. O. Janovskij, O drevney Kavkazskoy Albani. Journal Minist. Narodn. Prosveschenija, c. LII, 1846.

lessen 1935: A. A. lessen, K voprosu o drevneyshey metallurgii medi na Kavkaze, Izv. GAIMK (Leningrad 1935). 